\title{
DRY-DOCKING TIME AND LABOUR
}

\author{
(DOI No: 10.3940/rina.ijme.2018.a4.499)
}

A K Dev, Newcastle University in Singapore and M Saha, M K Marine Pte Ltd, Singapore

\section{SUMMARY}

The duration of stay of a ship in a drydock depends on the scope of routine underwater (submerged portion of the ship's hull) repairing works (dry-docking works only) to be carried out. More specifically, the repairing works that are affected by outside water. These are, mainly, hull cleaning, coating (blasting and painting), rudder, propeller, stern tube aft seal, hull anodes, ICCP, sea valves, sea chests, tunnel thruster(s), bottom plugs, underwater structural steel (bottom and shipside) and so on. These dry-docking works dictate ships'dry-docking time (days) and labour (man-days). Then what about the deadweight, age and type? Do these have any impact on dry-docking time and labour? An attempt has been made in this article to examine if there exist any possible relationship between a ships' dry-docking time and its labour, and deadweight, age and type. Dry-docking time and related information for 586 cargo ships and dry-docking labour and related information for 50 cargo ships of various deadweights, ages and types were collected from a single shipyard. These were analyzed and presented in both tabular and graphical forms to demonstrate the possible relationship between dry-docking time and labour, and deadweight, age and type of ships. Ships' dry-docking time and labour are very vital for both the ship owner and the shipyard because various charges in drydock are many folds higher than that at quayside. As such, the reduction in ships' dry-docking time and labour contributes in saving for the ship owner and increases the earning for the shipyard. A proper estimation of ships' dry-docking time and labour can achieve this. In order to do so, the past information/data about ships' dry-docking time and labour may serve a practical guide to prepare an achievable time and labour planning for dry-docking works. In this article, the authors have attempted to identify the independent variables that influence ships' dry-docking time and labour (dependent variables) and suggested their possible inter-relationships. The inter-relationships between the independent variables (deadweight, age and type) and dependent variables (time and labour) appear to be linear.

\section{INTRODUCTION}

Ships' dry-docking time (from now on dry-docking time) and ships' dry-docking labour (from now on dry-docking labour) refer to the number of days of stay in a graving dock/floating dock/slipway, i.e. days between dock-in and dock-out and corresponding workforce (labour) utilized during a dry-docking period. It is always an issue for ship owners (from now on owners) as well as shipyard (from now on yards) management. Both parties expect the shorter duration of dry-docking time and so, the labour. Normally, owners always expect shorter drydocking time to save cost because various dry-docking charges for dock are much higher compared to quay-side charges. Whereas yards, too, expect a shorter duration of dry-docking time to maximize the number of ships in drydock in a particular period (say yearly) which also helps to increase the revenue.

Dry-docking of a ship is a routine activity which occurs at a regular intervals required by the classification society's (from now on CS) rules. The purpose of drydocking is to carry out different surveys, in particular, the underwater items. Figure 1 demonstrates the sequence of various surveys that require a ship to go in a drydock. It appears from the Fig.1 that for two types of surveys, namely, docking survey and special survey, a ship is required to go to a drydock. Other surveys, such as, an annual survey and intermediate survey are carried out afloat.

Dry-docking time and labour independently, definitely, is a function of only dry-docking works. Various dry- docking works for various types of ships are listed in the Table 1. Dry-docking works are categorized into two types, 1) routine maintenance and 2) occasional maintenance. Routine maintenance refers to works that are carried out on a regular basis and as per CS requirements, such as hull coating, various clearance measurements, sea valves overhauling, anchor chain calibration, chain locker cleaning and so on. Occasional maintenance refers to works that required by CS rules (as per survey status) or recommended by the surveyor, such as propeller removal, tail shaft withdrawal, tunnel thruster(s) and so on.

In real life, on many occasions, the scope of repairing works were identical for two identical ships, even for the same ship but the prevailing situation in the shipyard was completely different, such as, one ship was alongside quay, but another ship was alongside another ship (restricted material handling) or one ship was at quay prior to go into a drydock but another ship was put into a drydock directly on arrival (no time for accessory works for propeller removal/shaft withdrawal) and so on. Such situation easily results in a longer dry-docking time and higher labour. A guideline for dry-docking time and labour for ships of various deadweight (tonnes), age (years) and type can provide a useful source of reference.

In order to have a guideline for dry-docking time and labour for ships of various deadweight, age and type, the historical information/data regarding dry-docking time and labour can provide a useful source of reference. These data can be used to predict the dry-docking time and labour. 
Table 1 List of dry-docking activities

\begin{tabular}{|c|c|c|c|c|c|c|c|c|c|}
\hline SL & Type of Ships $\rightarrow$ & $\begin{array}{l}\text { Crude } \\
\text { Oil } \\
\end{array}$ & Container & Bulk & Chemical & L.P.G & L.N.G & General & Car \\
\hline NO & Activities $\downarrow$ & Tanker & Carrier & Carrier & Tanker & Carrier & Carrier & Cargo & Carrier \\
\hline & \multicolumn{9}{|l|}{ Routine maintenance } \\
\hline 1 & Hull coating & $\sqrt{ }$ & $\sqrt{ }$ & $\sqrt{ }$ & $\sqrt{ }$ & $\sqrt{ }$ & $\sqrt{ }$ & $\sqrt{ }$ & $\sqrt{ }$ \\
\hline 2 & $\begin{array}{l}\text { Rudder pintle and } \\
\text { bush }\end{array}$ & $\sqrt{ }$ & $\sqrt{ }$ & $\sqrt{ }$ & $\sqrt{ }$ & $\sqrt{ }$ & $\sqrt{ }$ & $\sqrt{ }$ & $\sqrt{ }$ \\
\hline 3 & $\begin{array}{ll}\begin{array}{l}\text { Rudder } \\
\text { edge }\end{array} & \text { leading } \\
\end{array}$ & $\sqrt{ }$ & $\sqrt{ }$ & $\sqrt{ }$ & $\sqrt{ }$ & $\sqrt{ }$ & $\sqrt{ }$ & $\sqrt{ }$ & $\sqrt{ }$ \\
\hline 4 & Propeller polishing & $\sqrt{ }$ & $\sqrt{ }$ & $\sqrt{ }$ & $\sqrt{ }$ & $\sqrt{ }$ & $\sqrt{ }$ & $\sqrt{ }$ & $\sqrt{ }$ \\
\hline 5 & $\begin{array}{l}\text { Propeller repairing } \\
\text { in place }\end{array}$ & $\sqrt{ }$ & $\sqrt{ }$ & $\sqrt{ }$ & $\sqrt{ }$ & $\sqrt{ }$ & $\sqrt{ }$ & $\sqrt{ }$ & $\sqrt{ }$ \\
\hline 6 & Stern tube seal & $\sqrt{ }$ & $\sqrt{ }$ & $\sqrt{ }$ & $\sqrt{ }$ & $\sqrt{ }$ & $\sqrt{ }$ & $\sqrt{ }$ & $\sqrt{ }$ \\
\hline 7 & Rope guard & $\sqrt{ }$ & $\sqrt{ }$ & $\sqrt{ }$ & $\sqrt{ }$ & $\sqrt{ }$ & $\sqrt{ }$ & $\sqrt{ }$ & $\sqrt{ }$ \\
\hline 8 & Sea valve & $\sqrt{ }$ & $\sqrt{ }$ & $\sqrt{ }$ & $\sqrt{ }$ & $\sqrt{ }$ & $\sqrt{ }$ & $\sqrt{ }$ & $\sqrt{ }$ \\
\hline 9 & Sea chest & $\sqrt{ }$ & $\sqrt{ }$ & $\sqrt{ }$ & $\sqrt{ }$ & $\sqrt{ }$ & $\sqrt{ }$ & $\sqrt{ }$ & $\sqrt{ }$ \\
\hline 10 & MGPS & $\sqrt{ }$ & $\sqrt{ }$ & $\sqrt{ }$ & $\sqrt{ }$ & $\sqrt{ }$ & $\sqrt{ }$ & $\sqrt{ }$ & $\sqrt{ }$ \\
\hline 11 & Hull anodes & $\sqrt{ }$ & $\sqrt{ }$ & $\sqrt{ }$ & $\sqrt{ }$ & $\sqrt{ }$ & $\sqrt{ }$ & $\sqrt{ }$ & $\sqrt{ }$ \\
\hline 12 & Anchor \& chain & $\sqrt{ }$ & $\sqrt{ }$ & $\sqrt{ }$ & $\sqrt{ }$ & $\sqrt{ }$ & $\sqrt{ }$ & $\sqrt{ }$ & $\sqrt{ }$ \\
\hline 13 & Chain locker & $\sqrt{ }$ & $\sqrt{ }$ & $\sqrt{ }$ & $\sqrt{ }$ & $\sqrt{ }$ & $\sqrt{ }$ & $\sqrt{ }$ & $\sqrt{ }$ \\
\hline 14 & Bottom plugs & $\sqrt{ }$ & $\sqrt{ }$ & $\sqrt{ }$ & $\sqrt{ }$ & $\sqrt{ }$ & $\sqrt{ }$ & $\sqrt{ }$ & $\sqrt{ }$ \\
\hline \multirow[t]{2}{*}{15} & Ram door & $\mathrm{X}$ & $\mathrm{X}$ & $\mathrm{X}$ & $\mathrm{X}$ & $\mathrm{X}$ & $\mathrm{X}$ & $X$ & $\sqrt{ }$ \\
\hline & \multicolumn{9}{|c|}{ Occasional maintenance } \\
\hline 1 & Rudder unship & $\sqrt{ }$ & $\sqrt{ }$ & $\sqrt{ }$ & $\sqrt{ }$ & $\sqrt{ }$ & $\sqrt{ }$ & $\sqrt{ }$ & $\sqrt{ }$ \\
\hline 2 & $\begin{array}{l}\text { Propeller } \\
\text { withdrawal }\end{array}$ & $\sqrt{ }$ & $\sqrt{ }$ & $\sqrt{ }$ & $\sqrt{ }$ & $\sqrt{ }$ & $\sqrt{ }$ & $\sqrt{ }$ & $\sqrt{ }$ \\
\hline 3 & $\begin{array}{l}\text { Tailshaft } \\
\text { withdrawal }\end{array}$ & $\sqrt{ }$ & $\sqrt{ }$ & $\sqrt{ }$ & $\sqrt{ }$ & $\sqrt{ }$ & $\sqrt{ }$ & $\sqrt{ }$ & $\sqrt{ }$ \\
\hline 4 & Under water steel & $\sqrt{ }$ & $\sqrt{ }$ & $\sqrt{ }$ & $\sqrt{ }$ & $\sqrt{ }$ & $\sqrt{ }$ & $\sqrt{ }$ & $\sqrt{ }$ \\
\hline 5 & ICCP anodes & $\sqrt{ }$ & $\sqrt{ }$ & $\sqrt{ }$ & $\sqrt{ }$ & $\sqrt{ }$ & $\sqrt{ }$ & $\sqrt{ }$ & $\sqrt{ }$ \\
\hline 6 & Stern thruster & $\sqrt{ }$ & $\sqrt{ }$ & $\sqrt{ }$ & $\sqrt{ }$ & $\sqrt{ }$ & $\sqrt{ }$ & $\sqrt{ }$ & $\sqrt{ }$ \\
\hline 7 & Bow thruster & $\sqrt{ }$ & $\sqrt{ }$ & $\sqrt{ }$ & $\sqrt{ }$ & $\sqrt{ }$ & $\sqrt{ }$ & $\sqrt{ }$ & $\sqrt{ }$ \\
\hline 8 & Active fin stabilizer & $\sqrt{ }$ & $\sqrt{ }$ & $\sqrt{ }$ & $\sqrt{ }$ & $\sqrt{ }$ & $\sqrt{ }$ & $\sqrt{ }$ & $\sqrt{ }$ \\
\hline 9 & Draught gauge & $\sqrt{ }$ & $\sqrt{ }$ & $\sqrt{ }$ & $\sqrt{ }$ & $\sqrt{ }$ & $\sqrt{ }$ & $\sqrt{ }$ & $\sqrt{ }$ \\
\hline 10 & Echo sounder & $\sqrt{ }$ & $\sqrt{ }$ & $\sqrt{ }$ & $\sqrt{ }$ & $\sqrt{ }$ & $\sqrt{ }$ & $\sqrt{ }$ & $\sqrt{ }$ \\
\hline 11 & Speed log & $\sqrt{ }$ & $\sqrt{ }$ & $\sqrt{ }$ & $\sqrt{ }$ & $\sqrt{ }$ & $\sqrt{ }$ & $\sqrt{ }$ & $\sqrt{ }$ \\
\hline 12 & Bottom pitts & $\sqrt{ }$ & $\sqrt{ }$ & $\sqrt{ }$ & $\sqrt{ }$ & $\sqrt{ }$ & $\sqrt{ }$ & $\sqrt{ }$ & $\sqrt{ }$ \\
\hline 13 & Thickness gauging & $\sqrt{ }$ & $\sqrt{ }$ & $\sqrt{ }$ & $\sqrt{ }$ & $\sqrt{ }$ & $\sqrt{ }$ & $\sqrt{ }$ & $\sqrt{ }$ \\
\hline
\end{tabular}

$\sqrt{ }=$ Applicable, $X=$ Not Applicable 


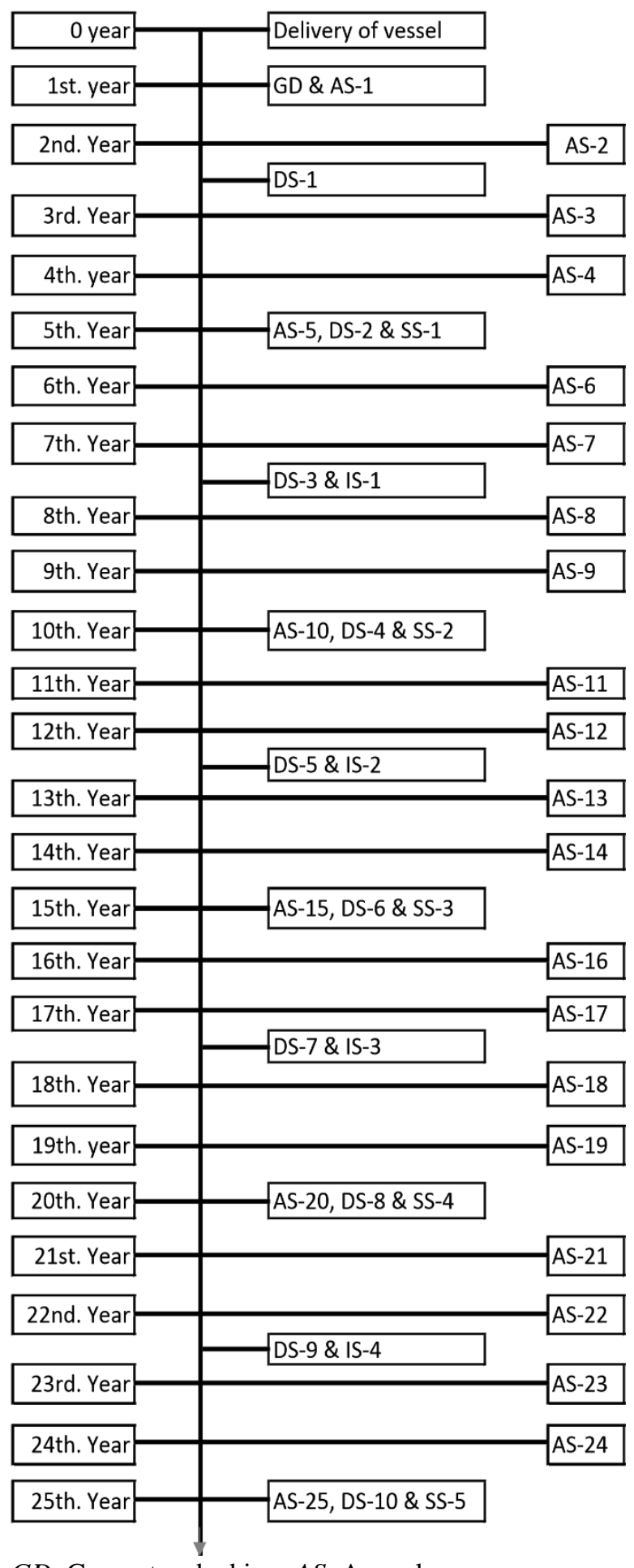

GD: Guarantee docking; AS: Annual survey;

$D S$ : Docking survey in dock; SS: Special survey in dock; IS: Intermediate survey

Figure. 1 Dry-docking cycle of a ship

This article is limited to the research of dry-docking time (days) and dry-docking labour (man-days) only for ships of different deadweight, age and type.

The aims of this article are to investigate and establish the inter-relationship among the dependent and independent variables for dry-docking time and labour.
Data collection and analyses are carried out both analytically and graphically for dealing with the task.

A review of the related literature is highlighted in Section 2. Problem formulation and related assumptions are discussed in Section 3. Data collection and methodology are presented in Section 4. Analysis of dry-docking time and labour are presented in graphical forms in Section 5 and 6 respectively. In Section 7, results of analyses and application of findings are discussed. Finally, Section 8 concludes the article and proposes suggestions for future research works.

\section{LITERATURE REVIEW}

There is no documented information available about drydocking time and labour of ships regarding their deadweight, age and type. Such information could be useful for owners, ship managers and ship management to estimate dry-docking time and labour of a ship in terms of her deadweight, age and type. However, some works, not exactly with a similar approach but close to the issue, were done from different viewpoints and using different variables.

Dev, A.K. and Saha, M. (2015), studied ship repairing time (total days counting from the arrival at the yard to the departure from the yard). It shows that the ship repairing time (day) is linearly related to ships' age, deadweight and repairing works, namely, external hull coating, structural steel, tank coating and piping. A mathematical model was developed and proposed a multiple linear regression equation to estimate expected ship repairing time for crude oil tankers using age, deadweight and quantity of repairing works.

Dev, A.K. and Saha, M. (2016), studied ship repairing labour (total man-days counting from the arrival at the yard to the departure from the yard). It shows that the ship repairing labour (man-day) is linearly related to ships' age, deadweight and repairing works, namely, external hull coating, structural steel and piping. A mathematical model was developed and proposed a multiple linear regression equation to estimate expected ship repairing labour using age, deadweight, type and quantity of repairing works.

Jose, R.B.C. (2009), investigated and studied drydocking time and cost and used multi-criteria decisionmaking methods called goal programming model to minimize dry-docking time and cost. The article demonstrates the technique of goal programming model to balance the time and cost of dry-docking of a ship.

Surjandari, I. and Novita, R. (2013) examined and emphasized on dry-docking duration using data mining technique. It explores and identifies the relationship between dry-docking time and other variables responsible for drydocking works. The authors then propose a mathematical model for estimation of dry docking time using CART 
(Classification and Regression Tree) method of estimation. This dry-docking time referred to the duration that a ship stays in the dock for routine maintenance works.

Naffisah, M. S., Surjandari, I., Rachman, A. and Palupi, R (2014), examined and analysed the real-life dry-docking maintenance time (days) using Artificial Neural Network technique with back propagation algorithm. They used 29 types of works in drydock maintenance activities as input and developed and proposed a mathematical model of drydocking maintenance time estimation.

\section{PROBLEM FORMULATION AND RELATED ASSUMPTIONS}

\subsection{PROBLEM FORMULATION}

It is true beyond doubt that the scope of dry-docking works is the main deciding variable for the dry-docking time and labour. However, the question remains unanswered is "Do deadweight, age and type have any impact on dry-docking works and hence time and labour"? The answer is not straightforward and easy. Past data of dry-docking time and labour, can provide the valuable information to get an appropriate answer of this question. In view of the above question, this article focuses on the inter-relationship between dry-docking time and labour and various variables like deadweight, age and type of a ship. Using this relationship, the necessary dry-docking time and labour could be estimated, which may then be used to solve the above problem, if not completely, partially.

\subsection{RELATED ASSUMPTIONS}

\subsubsection{Ships' deadweight}

Deadweight of a ship is considered as the size which also comprises the cargo carrying capacity (load). A big size ship means bigger dimensions with larger machinery and equipment. Logically, the bigger ships need longer drydocking time, and higher labour for dry-docking works. Therefore, ceteris paribus, the first assumption is that deadweight of a ship has a positive impact on drydocking works and hence dry-docking time and labour and the relation are assumed to be linearly associated. Mathematically, dry-docking time and labour are independently a function of the deadweight of a ship and is considered to be linearly associated.

\subsubsection{Ships' age}

The age of a ship at the time of dry-docking is the number of years for which the ship is in operation. It is thus expected that older ships having older machinery and equipment will experience higher wear and tear depending on the maintenance policy of owner. Also, the flag state rules and the CS rules demand higher standards/criteria of testing, inspection or survey for older ships. In the end, older ships need more extensive repair and maintenance than the newer ones, in particular, for dry-docking works. Therefore, ceteris paribus, the second assumption is that the age of a ship has a positive impact on dry-docking works and hence dry-docking time and labour and the relation are assumed to be linearly associated. Mathematically, dry-docking time and labour are independently a function of the age of a ship and is considered to be linearly associated.

\subsubsection{Ships' type}

Due to the type of cargo and nature of the cargo, the configuration of ship varies widely including hull form, machinery and outfitting. Also, there are inherent differences between types of ships concerning piping arrangement, tank arrangement, cargo handling facilities, etc. As such, it is also logical that different types of ships may, thus, require different dry-docking time and labour. Therefore, ceteris paribus, the third assumption is that the type of ship has a positive impact on dry-docking time and labour and the relation are assumed to be linearly associated. Mathematically, dry-docking time and labour are independently a function of the type of a ship and is considered to be linearly associated.

\subsubsection{Dry-docking works}

Generally speaking, dry-docking works refer to activities which cannot be carried out under afloat condition. It is also true that during dry-docking, other activities (non-drydocking activities) are also carried out with equal importance. Someone cannot consider to carry out only drydocking works during dry-docking. It will not reduce the dry-docking time in anyway but substantially increase the total ship repairing time (dry-docking time + quay-side time). Therefore, practically, labour utilized during drydocking is inclusive of non-dry-docking activities too. Since, the information related to dry-docking time and labour are collected after a ship left the yard, it is hardly possible to isolate the man-power utilized for dry-docking activities only. Moreover, logically, all allowable and possible activities are carried out simultaneously to reduce the total working days. However, it is more important to know dry-docking time and labour rather than quantity and type of works carried out during dry docking. As such, dry docking activities are not considered as an independent variable to relate dependent variables, dry-docking time and labour. Instead, dry-docking time is considered as an independent variable to relate dependent variable, drydocking labour. Therefore, ceteris paribus, the fourth assumption is that dry-docking time (days) has a positive impact on dry-docking labour and the relation is assumed to be linearly associated. Mathematically, dry-docking labour is a function of dry-docking time and considered to be linearly associated.

So far, it has been highlighted theoretically that deadweight, age and type of a ship are directly, positively and linearly associated with the corresponding dry-docking time (days) and labour (man-days) independently. In other words, drydocking time and labour (dependent variable) is a linear 
function of deadweight, age and type (independent variables). Additionally, dry-docking labour is a linear function of dry-docking time. Mathematically, the above assumptions can be expressed in the form of equations 1-7 as follows,

$$
\begin{aligned}
& D D_{\mathrm{TIME}}=\mathrm{f}\left(S_{\mathrm{D}}\right)=a+b * S_{\mathrm{D}} \\
& D D_{\mathrm{TIME}}=\mathrm{f}\left(S_{\mathrm{A}}\right)=a+b * S_{\mathrm{A}} \\
& D D_{\mathrm{TIME}}=\mathrm{f}\left(S_{\mathrm{T}}\right)=a+b * S_{\mathrm{T}} \\
& D D_{\mathrm{LABOUR}}=\mathrm{f}\left(S_{\mathrm{D}}\right)=a+b * S_{\mathrm{D}} \\
& D D_{\mathrm{LABOUR}}=\mathrm{f}\left(S_{\mathrm{A}}\right)=a+b * S_{\mathrm{A}} \\
& D D_{\mathrm{LABOUR}}=\mathrm{f}\left(S_{\mathrm{T}}\right)=a+b * S_{\mathrm{T}} \\
& D D_{\mathrm{LABOUR}}=\mathrm{f}\left(D D_{\mathrm{TIME}}\right)=a+b * D D_{\mathrm{TIME}}
\end{aligned}
$$

Where $D D_{\text {TIME }}$ : Dry-docking time (days)

$D D_{\text {LABour }}$ : Dry-docking labour (man-days)

$S_{\mathrm{A}}$ : Age of a ship (years)

$S_{\mathrm{D}}$ : Deadweight of a ship (tonnes)

$S_{\mathrm{T}}$ : Type of a ship

$a, b$ : Regression coefficients

\section{DATA COLLECTION AND METHODOLOGY}

In order to study the trend/pattern of dry-docking time and labour against various variables, the past data of relevant items/variables must be known. For this purpose, drydocking time and labour utilization records and related information on repaired ships were collected. The deadweight, age and type were recorded for each ship.

\subsection{DRY-DOCKING TIME}

A total of 586 ships were selected for the present research. These ships were repaired in the same shipyard between May 1999 and March 2012. Their dry-docking time, deadweight, age and type were collected in a tabular form. This tabulated information is the main input for this analysis.

A general picture of sample ships is presented in both tabular and graphical forms in Table 2 and in Figures.2-5 respectively. Table 2 shows the sample size, average ships' deadweight (from now on deadweight), ships' age (from now on age), ship repairing time and dry-docking time for different types of ships.

Figure 2 shows the distribution of deadweight of sample ships with a mean and standard deviation of 75,717 tonnes and 78,190 tonnes respectively. It also suggests that $88 \%$ of sample ships fall within 180,000 tonnes of deadweight range.

Figure 3 shows the distribution of age of sample ships with a mean and standard deviation of 9.83 years and 6.67 years respectively. It also suggests that 93\% of sample ships fall within 20 years of age range.

Figure 4 shows the distribution of type of ships of sample ships. The highest number of ships are from container carriers (178) followed by crude oil tankers (146), chemical tankers (88), bulk carriers (88), L.P.G. carriers (40) and so on. Those jointly cover about $92 \%$ of total population. Due to small sample size, dredgers, L.N.G. carriers, ore carriers, live-stock carriers and wood carriers were not included in the data analysis.

Figure 5 shows the distribution of dry-docking time of sample ships with a mean and standard deviation of 7.33 days and 3.66 days respectively. It also suggests that $95 \%$ of sample ships fall within 14 days of the drydocking time range.

Table 2 Sample ships at a glance for dry-docking time

\begin{tabular}{|l|l|l|l|l|l|}
\hline \multirow{2}{*}{ Type of ships } & \multirow{2}{*}{ No. of ships } & \multicolumn{4}{|c|}{ Average } \\
\cline { 3 - 6 } & & $S_{\mathrm{D}}$ & $S_{\mathrm{A}}$ & $S_{\mathrm{TIME}}$ & $D_{\mathrm{TIME}}$ \\
\hline Container carrier & 178 & 37,081 & 10.45 & 12.44 & 7.28 \\
\hline Crude oil tanker & 146 & 170,793 & 9.55 & 20.49 & 7.54 \\
\hline Chemical tanker & 88 & 38,691 & 7.41 & 14.19 & 6.58 \\
\hline Bulk carrier & 88 & 76,601 & 9.00 & 14.19 & 6.55 \\
\hline LPG carrier & 40 & 47,196 & 12.93 & 21.10 & 6.63 \\
\hline General cargo & 18 & 12,343 & 8.67 & 12.44 & 6.67 \\
\hline Car carrier & 15 & 15,501 & 13.80 & 12.47 & 7.07 \\
\hline Dredger & 5 & 8642 & 13.40 & 19.40 & 11.40 \\
\hline LNG carrier & 4 & 72,776 & 6.50 & 23.25 & 8.00 \\
\hline Ore carrier & 2 & 123,233 & 18.50 & 15.50 & 7.00 \\
\hline Live stock & 1 & 39,266 & 38.00 & 79.00 & 19.00 \\
\hline Wood carrier & 1 & 53,679 & 17.00 & 12.00 & 6.00 \\
\hline Total & 586 & 76,277 & 9.83 & 15.82 & 7.12 \\
\hline
\end{tabular}




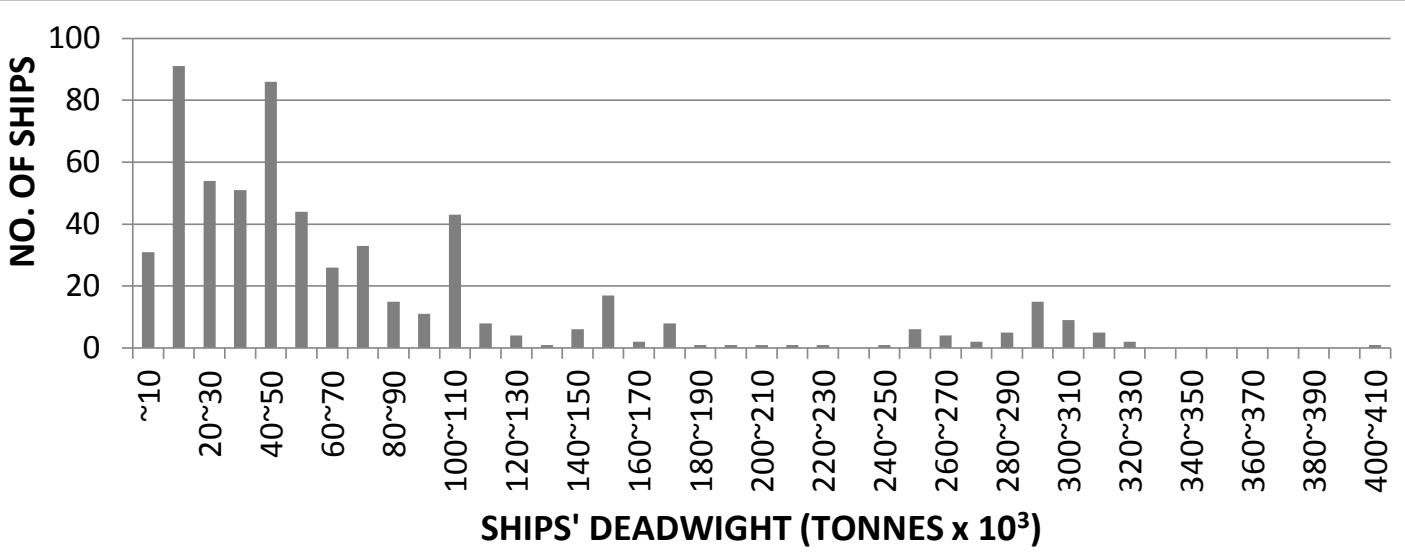

Figure. 2 Distribution of ships' deadweight of sample ships (dry-docking time)

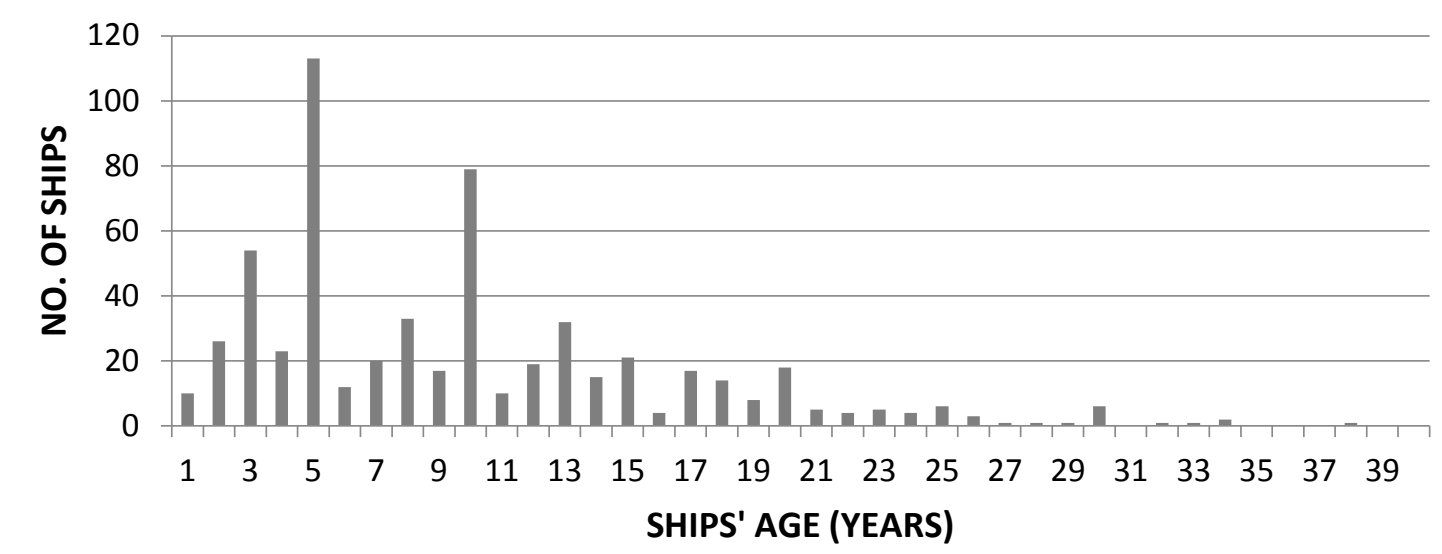

Figure. 3 Distribution of ships' age of sample ships (dry-docking time)

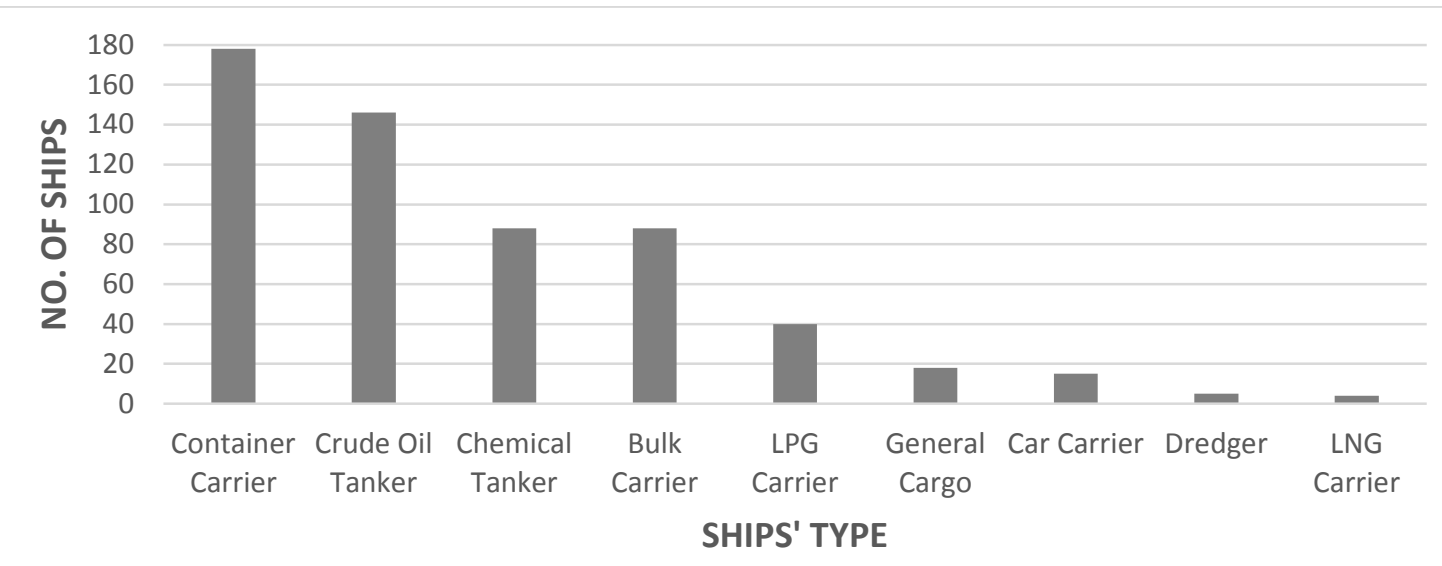

Figure. 4 Distribution of ships' type of sample ships (dry-docking time) 


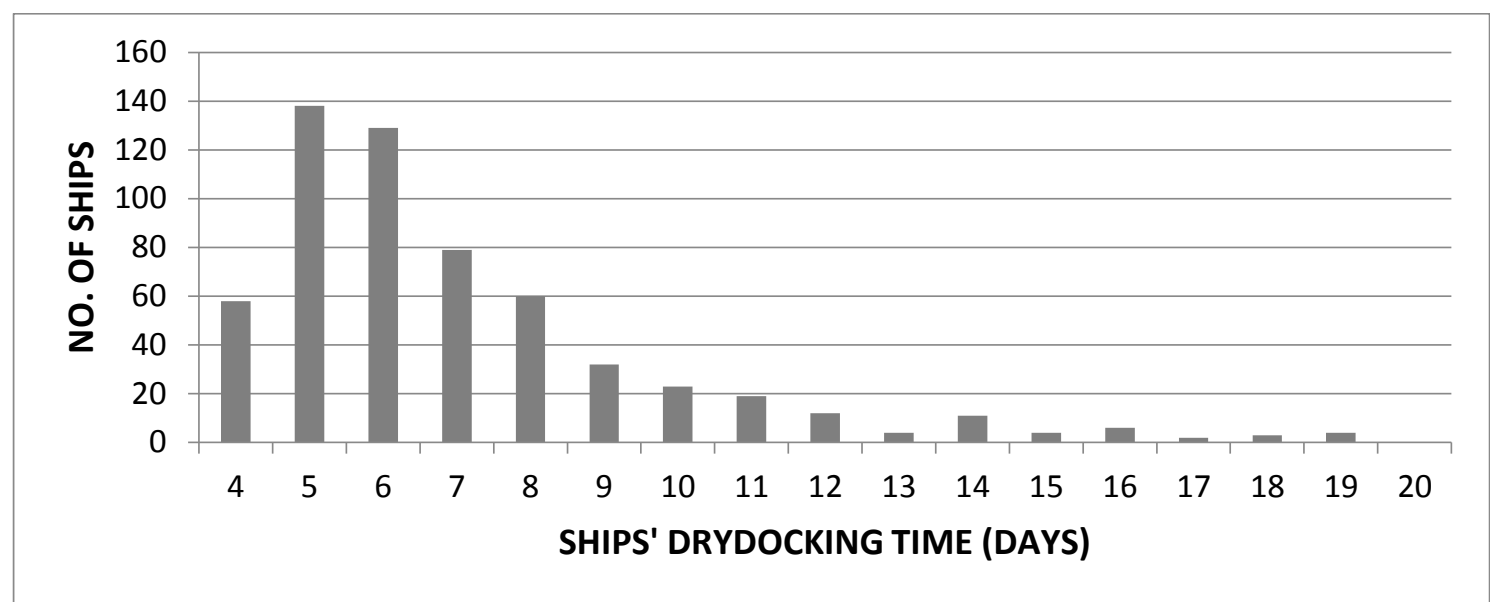

Figure. 5 Distribution of ships' dry-docking time of sample ships

Table 3 Sample ships at a glance for dry-docking labour

\begin{tabular}{|l|l|l|l|l|l|}
\hline \multirow{2}{*}{$\begin{array}{l}\text { Type of } \\
\text { Ships }\end{array}$} & \multirow{2}{*}{ No. of ships } & \multicolumn{4}{|c|}{ Average } \\
\cline { 3 - 6 } & & $S_{\mathrm{A}}$ & $S_{\mathrm{D}}$ & $S R_{\text {LABOUR }}$ & $D D_{\text {LABOUR }}$ \\
\hline Crude oil tanker & 13 & 7.08 & 188,005 & 1,925 & 1,414 \\
\hline Container carrier & 12 & 11.33 & 34,620 & 3,065 & 2,104 \\
\hline Chemical tanker & 9 & 7.00 & 46,136 & 2,481 & 1,543 \\
\hline L.P.G. carrier & 8 & 14.00 & 41,866 & 4,773 & 2,258 \\
\hline Bulk carrier & 5 & 9.00 & 85,409 & 1,489 & 1,287 \\
\hline General cargo & 1 & 20.00 & 9,594 & 2,857 & 1,349 \\
\hline Car carrier & 1 & 2.00 & 15,154 & 1,216 & 1,104 \\
\hline L.N.G. Carrier & 1 & 5.00 & 75,248 & 3,681 & 1,889 \\
\hline Total & 50 & 9.50 & 82,733 & 2,750 & 1,727 \\
\hline
\end{tabular}

\subsection{DRY-DOCKING LABOUR}

A total of 50 ships were selected for the present research. These ships were repaired in the same shipyard between February 2006 and April 2012. Their dry-docking labour, deadweight, age and type were collected in a tabular form. This tabulated information is the main input for this analysis.

A general picture of sample ships is presented in both tabular and graphical forms in Table 3 and Figures.6-9 respectively. Table 3 shows the sample size, average deadweight, age, ship repairing labour and dry-docking labour for different types of ship. Figure 6 shows the distribution of deadweight of sample ships with a mean and standard deviation of 84,574 tonnes and 36,577 tonnes respectively. It also suggests that $89 \%$ of sample ships falls within 180,000 tonnes of deadweight range. Figure 7 shows distribution of age of sample ships with a mean and standard deviation of 9.53 years and 2.74 years respectively. It also suggests that $96 \%$ of sample ships falls within 20 years of the age range. Figure 8 shows the distribution of type of sample ships. The highest number of ships is from crude oil tanker (13) followed by container carrier (12), chemical tanker (9), L.P.G. carrier (8) and bulk carrier (5) and so on. Due to small sample size, general cargo ship and car carrier are not included in the analysis. Figure 9 shows the distribution of drydocking labour of sample ships with a mean and standard deviation of 1,761 man-days and 1,279 man-days respectively. It also suggests that $96 \%$ of sample ships falls within 4,500 man-days of dry-docking labour range. 


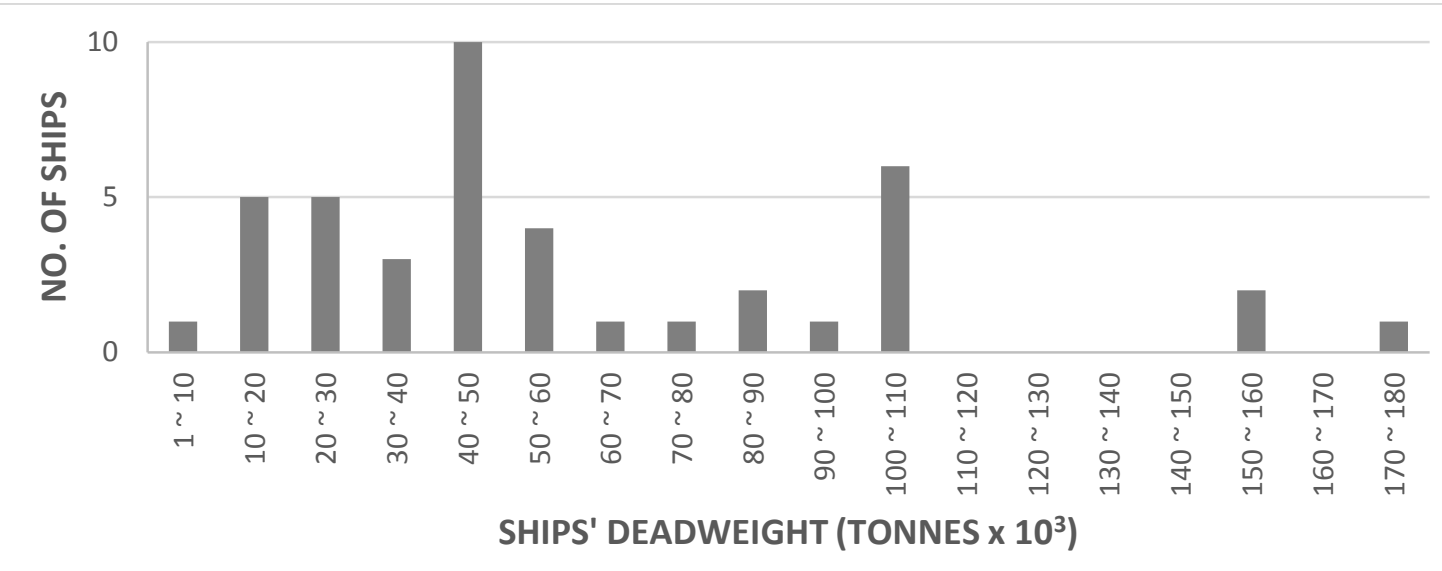

Figure. 6 Distribution of ships' deadweight of sample ships (dry-docking labour)

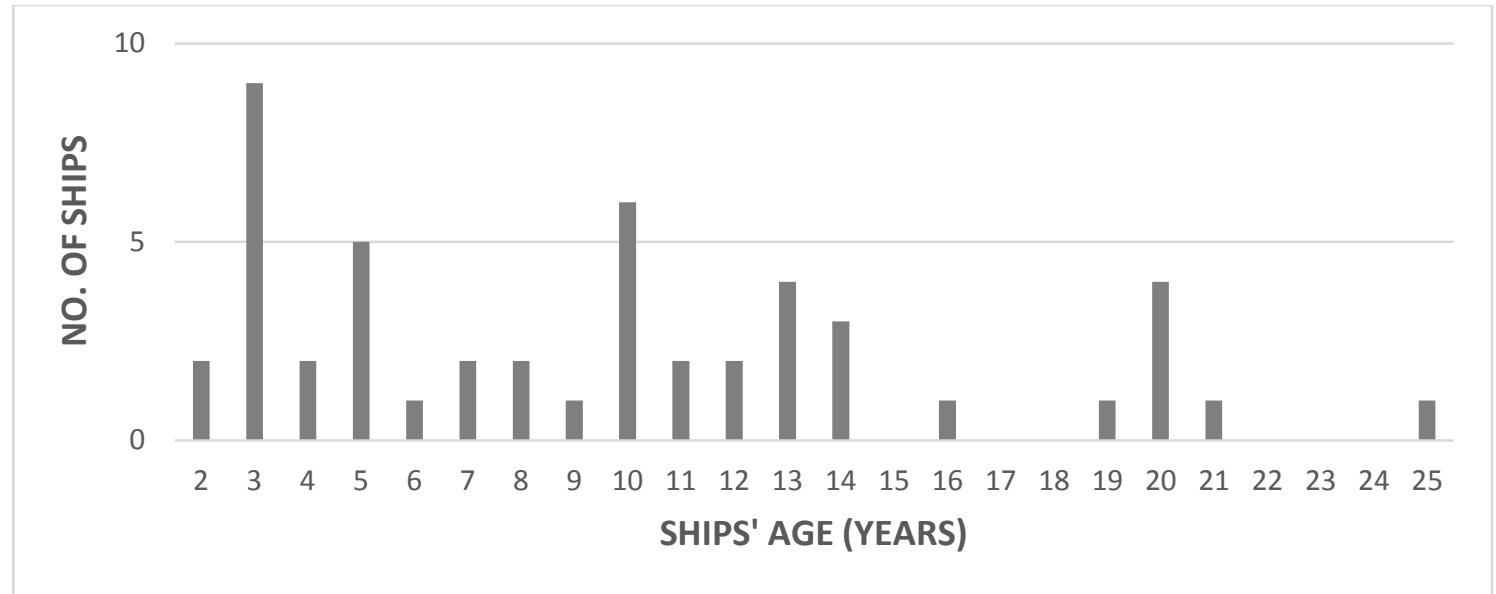

Figure. 7 Distribution of ships' age of sample ships (dry-docking labour)

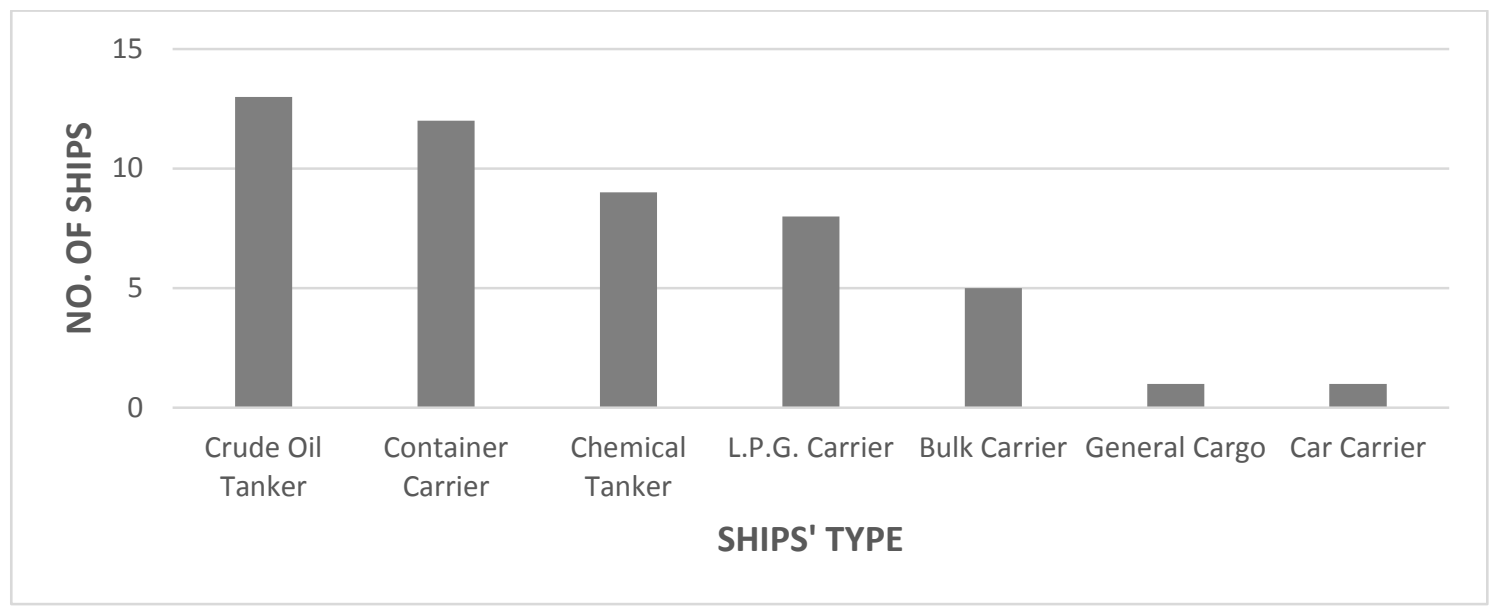

Figure. 8 Distribution of ships' type of sample ships (dry-docking labour) 


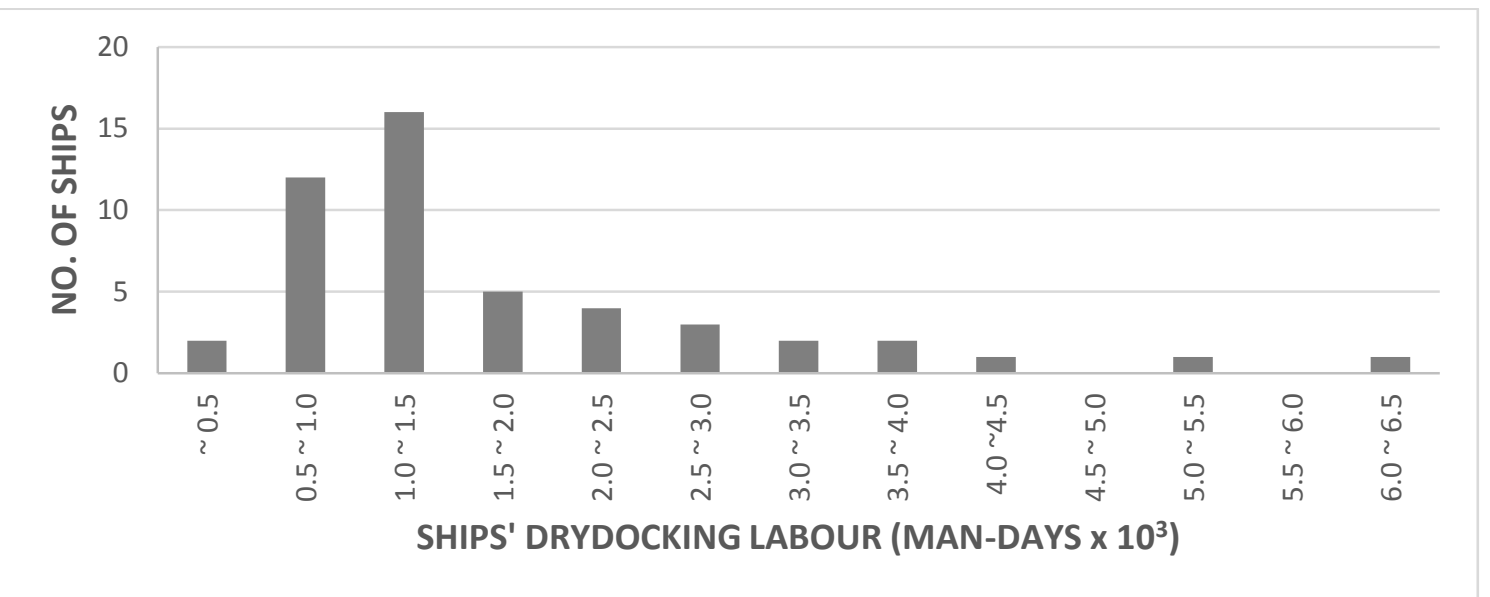

Figure. 9 Distribution of ships' dry-docking labour of sample ships

\section{DRY-DOCKING TIME ANALYSIS}

Initial investigations of pairs of variables of interests related to dry-docking time are shown in Figures.10-47 from different viewpoints. Corresponding $r^{2}$ values assuming a linear relationship and non-linear relationship (exponential) are presented in Tables 4, 5, 6 and 7.

\subsection{DEADWEIGHT}

Dry-docking time and the corresponding deadweight of ships are analysed to determine a trend or pattern between those irrespective of their age and type. The results are presented in Figures.10-13. Figures 10 and 11 show the observed dry-docking time and average drydocking time (average by deadweight group) respectively. Both figures suggest that with the change of deadweight, the dry-docking time does change but does not follow any pattern instead they are scattered, although the regression line has a positive slope. It suggests that a weak linear relationship exists between dry-docking time and deadweight.
Figures 12 and 13 show the observed dry-docking time as a fraction of ship repairing time against deadweight and average dry-docking time as a fraction of ship repairing time (average by deadweight group) against deadweight respectively. Both figures suggest the same phenomenon but with a negative slope of the regression line (Figure.12). Mathematically, a negative slope means that contribution of dry-docking time to ship repairing time decreases with the increase of deadweight. As such, it conforms that dry-docking time does change but does not follow any pattern. Therefore, deadweight does have an influence on dry-docking time but with a low degree of response. It means that bigger ships may or may not need longer dry-docking time compared to smaller ships.

In Table 4, one can easily find that for a particular relationship (Figures.10 and 12), the values of $r^{2}$ for a linear relationship and corresponding exponential relationship are very close.

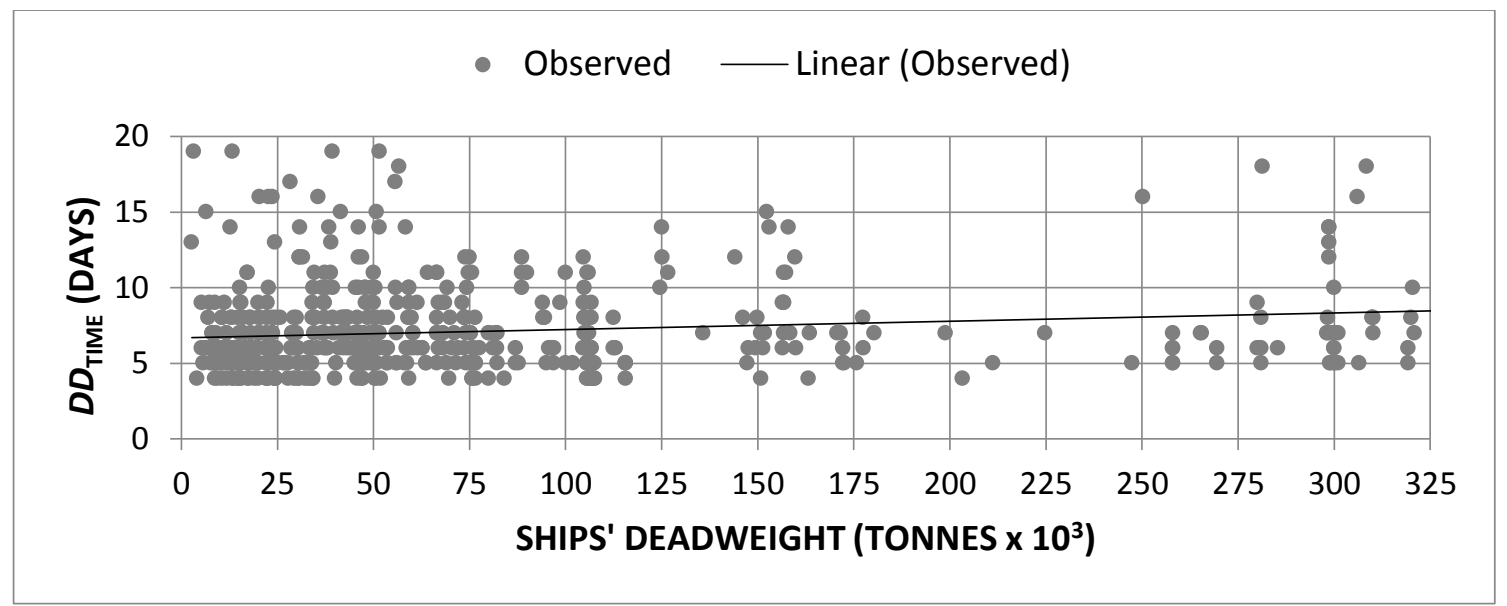

Figure. 10 Dry-docking time versus ships' deadweight of sample ships 


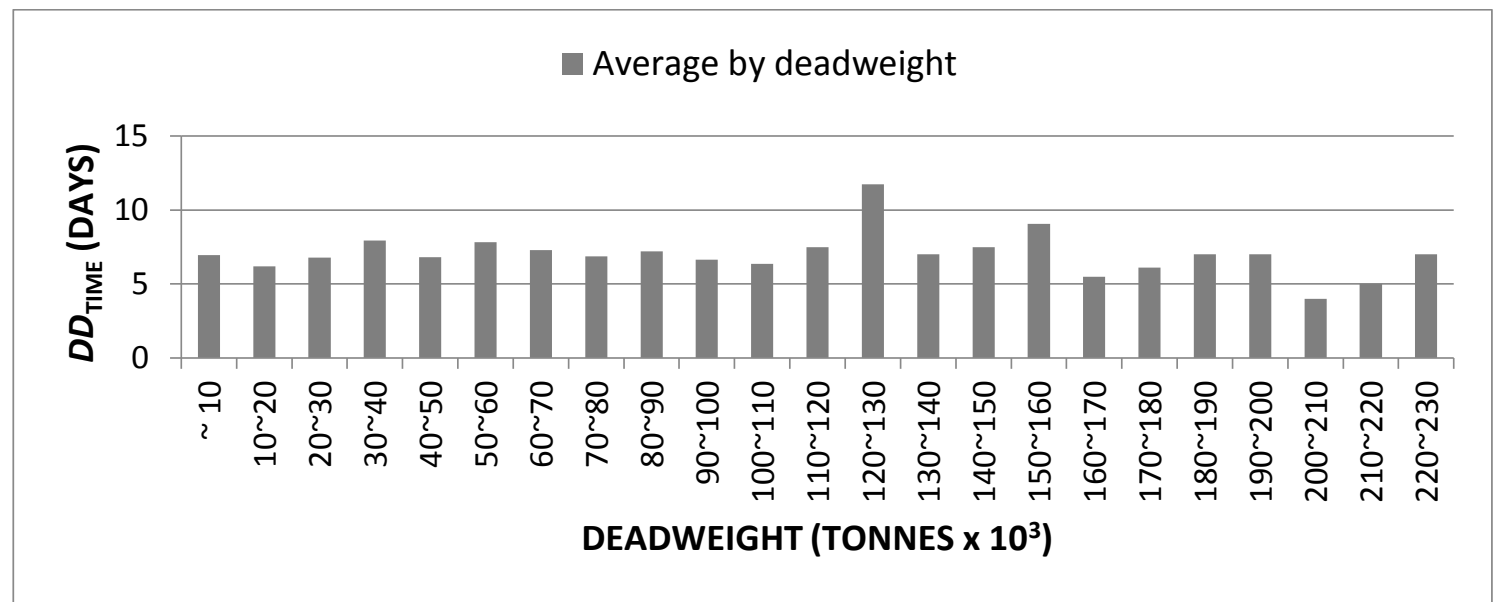

Figure. 11 Average dry-docking time versus ships' deadweight of sample ships

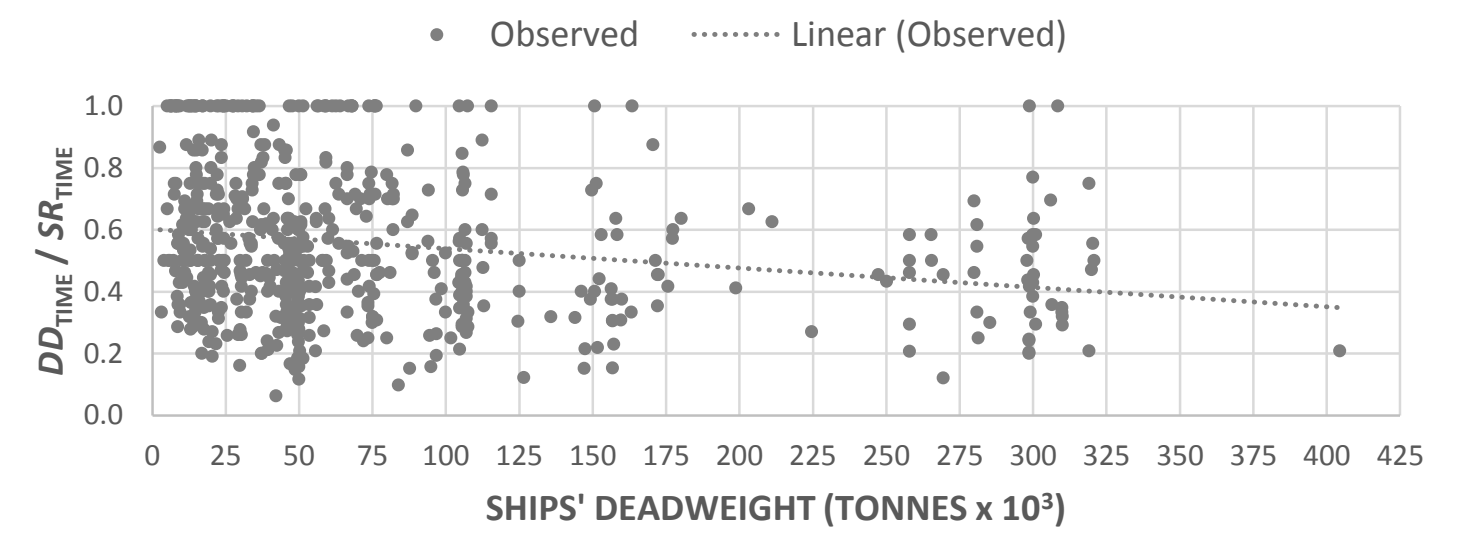

Figure. 12 Dry-docking time as fraction of $S R_{\mathrm{TIME}}$ versus ships' deadweight of sample ships

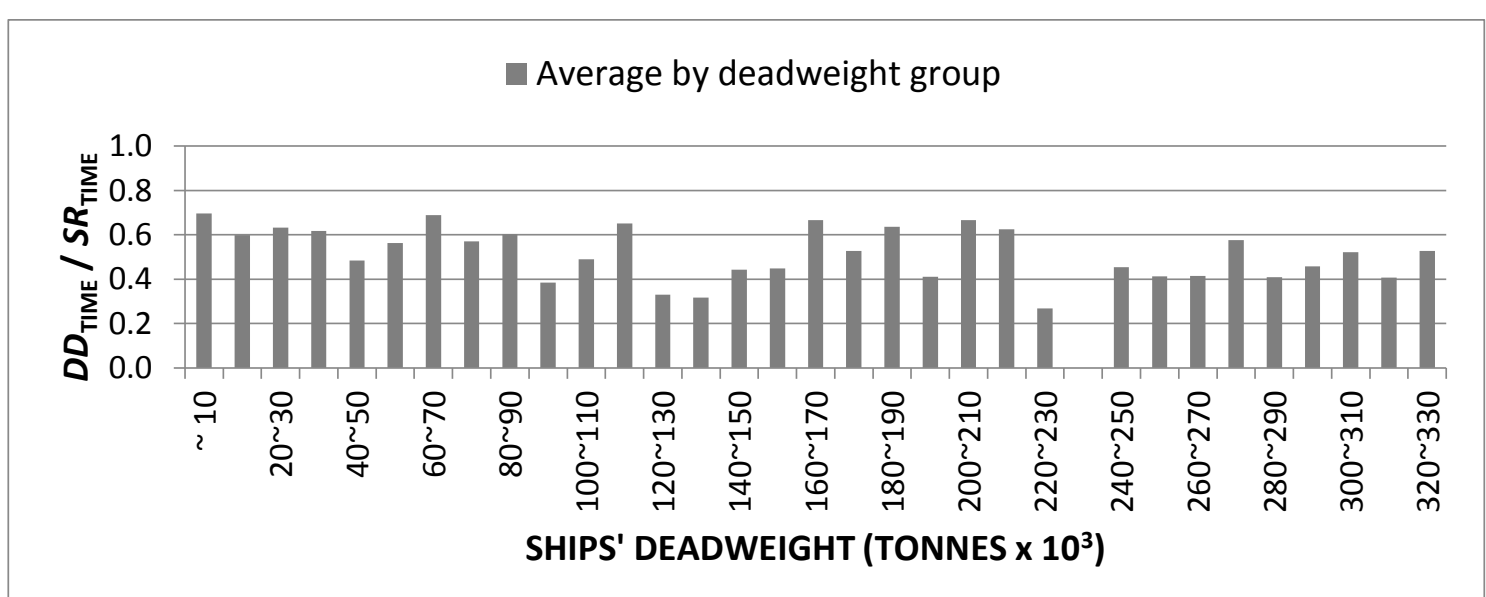

Figure. 13 Average dry-docking time as fraction of $S R_{\mathrm{TIME}}$ versus ships' deadweight of sample ships

Table 4 Summary of correlation coefficients of linear and exponential relationship

\begin{tabular}{|l|l|l|l|l|}
\hline \multirow{2}{*}{$\begin{array}{l}\text { Figure } \\
\text { No. }\end{array}$} & \multirow{2}{*}{ Variables } & \multicolumn{2}{|l|}{$r^{2}$ values } & \multirow{2}{*}{ Remarks } \\
\cline { 3 - 4 } 10 & $D D_{\mathrm{TIME}}$ Vs $S_{\mathrm{D}}$ & 0.0206 & 0.0202 & Sample ships \\
\hline 12 & $\begin{array}{l}\mathrm{D} D_{\mathrm{TIME}} / S R_{\mathrm{TIME}} \text { vs } \\
S_{\mathrm{D}}\end{array}$ & $0.0435(-)$ & $0.0413(-)$ & Sample ships \\
\hline
\end{tabular}




\section{$5.2 \quad$ AGE}

Dry-docking time and the corresponding age of ships are analyzed to determine a trend or pattern between those irrespective of their deadweight and type. The results are presented in the graphical form in Figures.14-17. Figures 14 and 15 show the observed dry-docking time and average dry-docking time (average by age group) respectively. Both figures suggest that with the change of age, dry-docking time does change but does not follow any pattern instead they are scattered, although the regression line has a positive slope. It suggests that a linear relationship exists between dry-docking time and age of a ship.

Figures 16 and 17 show the observed dry-docking time as a fraction of ship repairing time against age and average dry-docking time as a fraction of ship repairing time (average by age group) against age respectively. Both figures suggest the same phenomenon but with a negative slope of the regression line (Figure.16). Mathematically, negative slope means that contribution of dry-docking time to ship repairing time decreases with increase of age. As such, it conforms that dry-docking time does change but does not follow any pattern. Therefore, age of a ship does have an influence on dry-docking time but with a low degree of response. It means that older ships may or may not need longer dry-docking time compared to relatively newer ships.

In Table 5, one can easily find that for a particular relationship (Figures.14-17), the values of $r^{2}$ for a linear relationship and corresponding exponential relationship are very close except Figure.17.

Table 5 Summary of correlation coefficients of linear and exponential relationship

\begin{tabular}{|c|c|c|c|c|}
\hline \multirow{2}{*}{$\begin{array}{l}\text { Figure } \\
\text { No. }\end{array}$} & \multirow{2}{*}{ Variables } & \multicolumn{2}{|l|}{$r^{2}$ values } & \multirow{2}{*}{ Remarks } \\
\hline & & Linear & Exponential & \\
\hline 14 & $D D_{\text {TIME }}$ vs $S_{\mathrm{A}}$ & 0.0557 & 0.0620 & Sample ships \\
\hline 15 & $D D_{\text {TIME }}$ Vs $S_{\mathrm{A}}$ & 0.1492 & 0.1180 & Sample ships \\
\hline 16 & $\begin{array}{l}D D_{\text {TIME }} / S R_{\text {TIME }} \text { VS } \\
S_{\mathrm{A}}\end{array}$ & $0.0491(-)$ & $0.0713(-)$ & Sample ships \\
\hline 17 & $\begin{array}{l}D D_{\text {TIME }} / S R_{\text {TIME }} \text { VS } \\
S_{\mathrm{A}}\end{array}$ & $0.0846(-)$ & $0.1552(-)$ & Sample ships \\
\hline
\end{tabular}

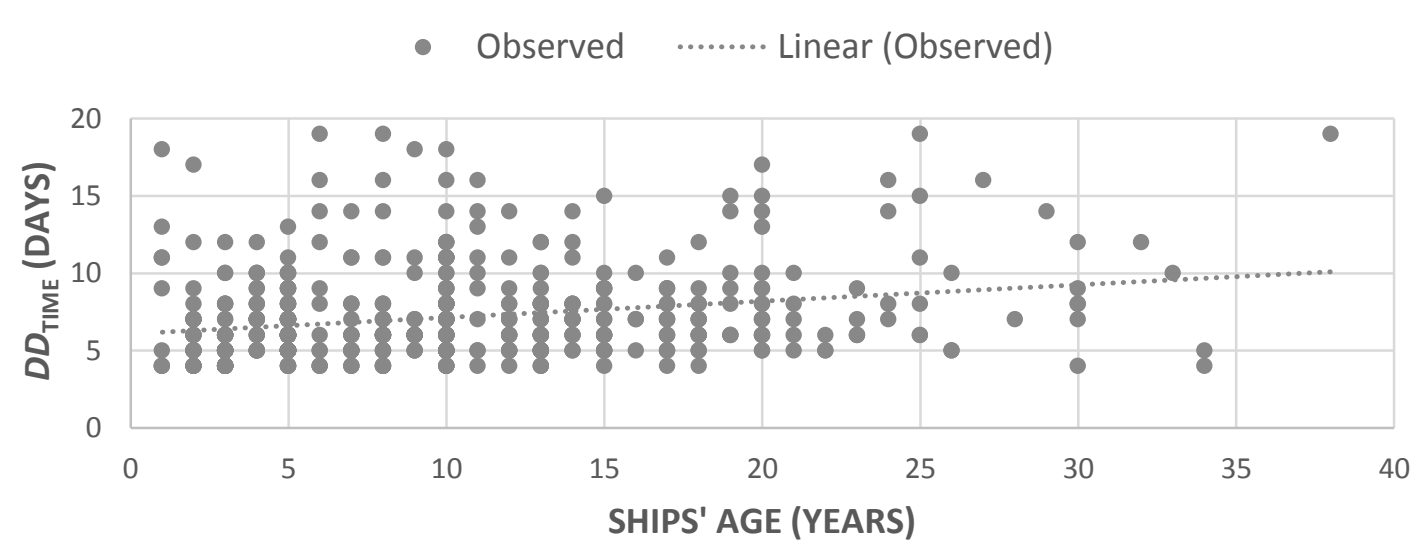

Figure. 14 Dry-docking time versus ships' age of sample ships 


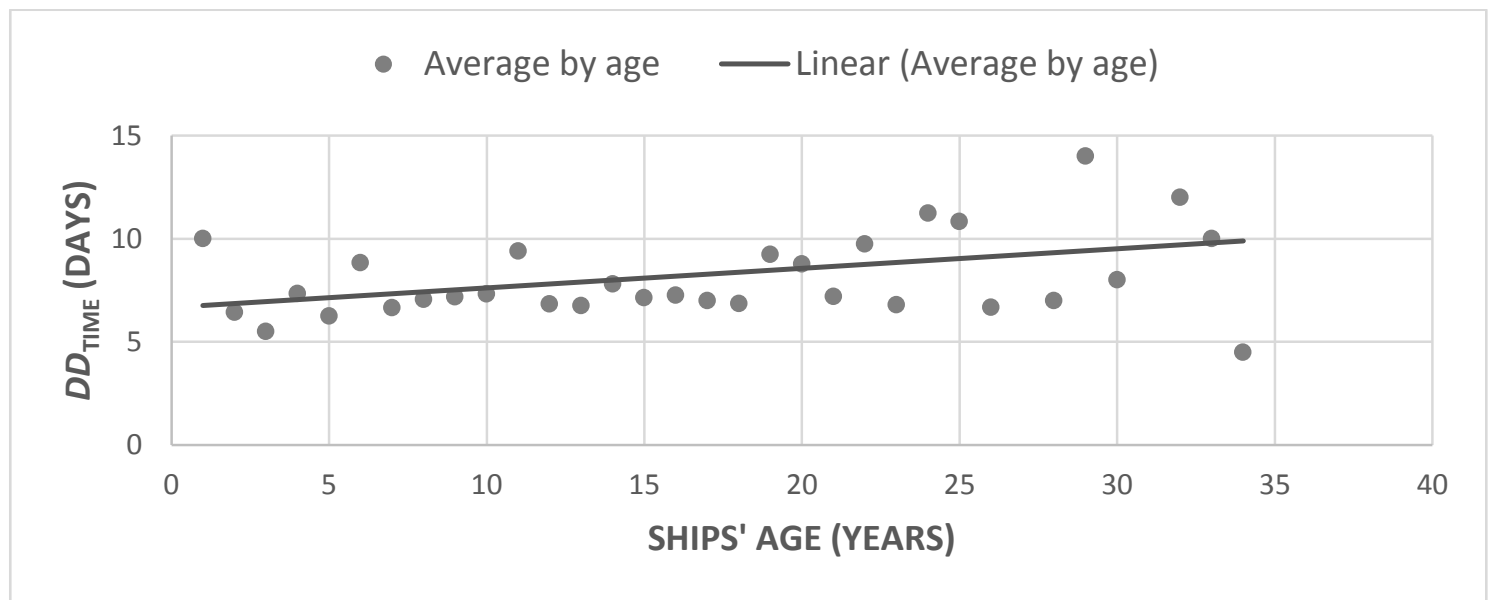

Figure. 15 Average dry-docking time versus ships’ age of sample ships

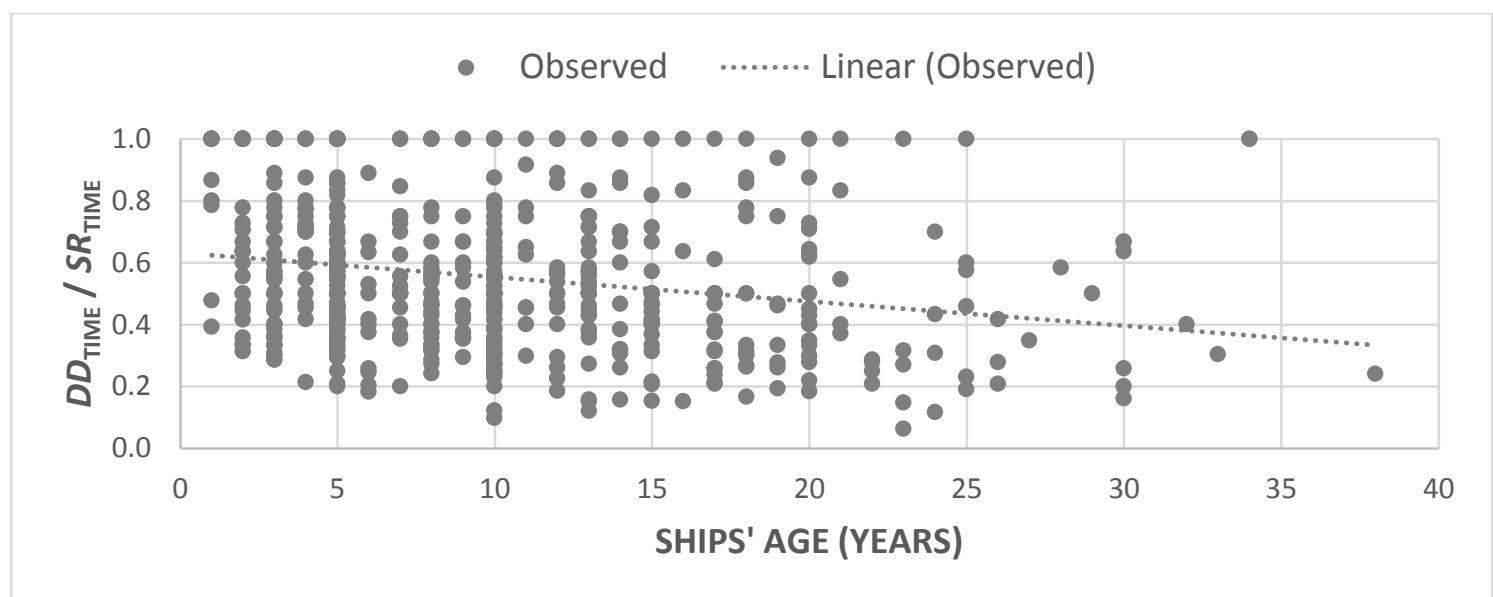

Figure. 16 Dry-docking time as fraction of $S R_{\mathrm{TIME}}$ versus ships' age of sample ships

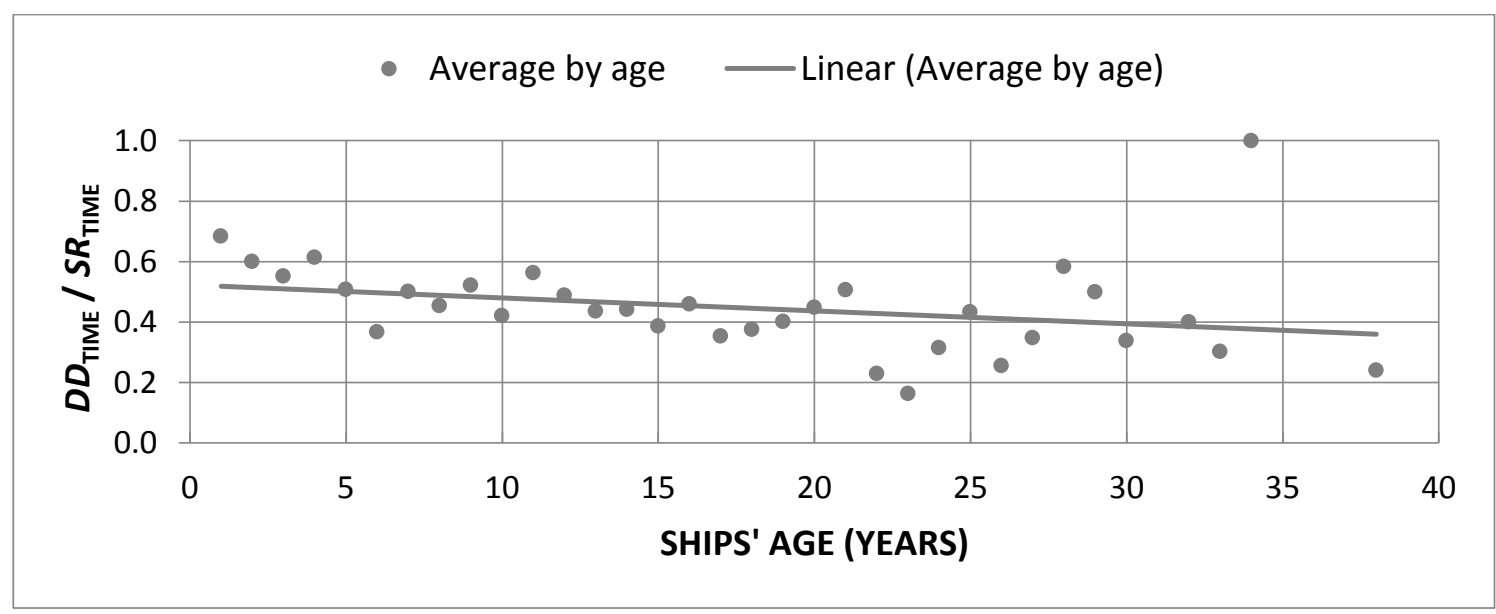

Figure. 17 Average dry-docking time as fraction of $S R_{\text {TIME }}$ versus ships' age of sample ships 


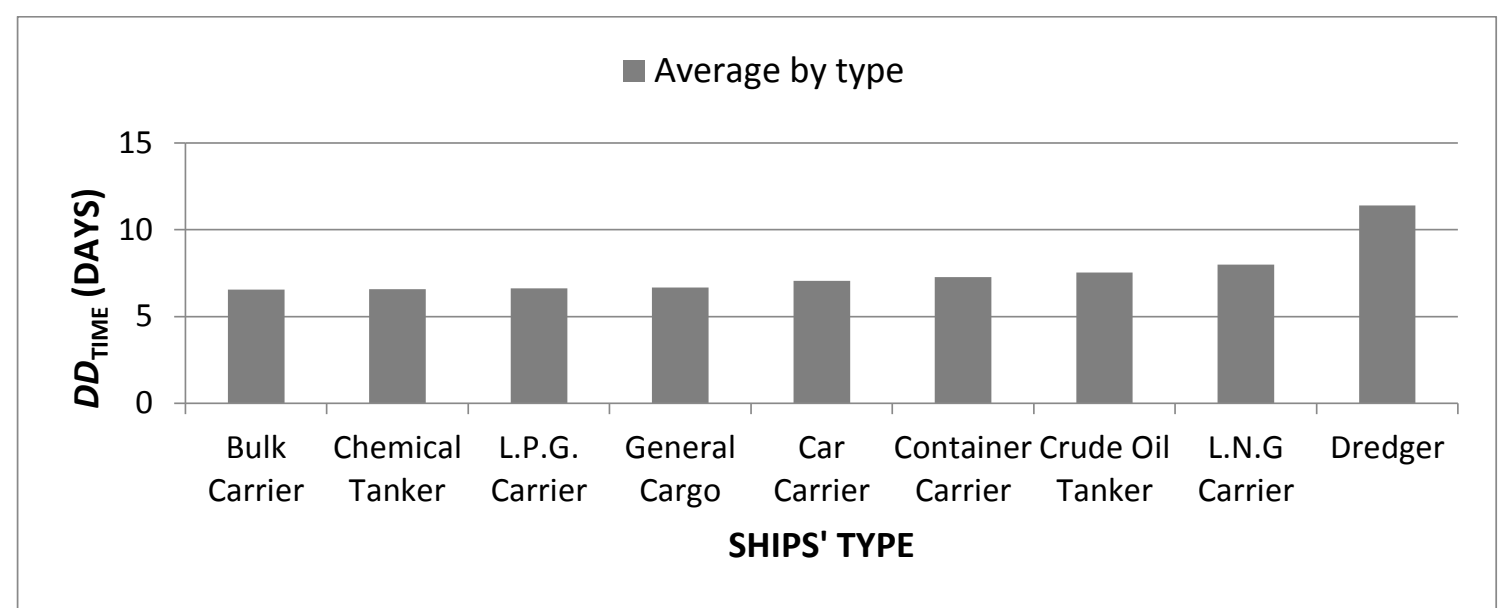

Figure. 18 Average dry-docking time versus ships' type of sample ships

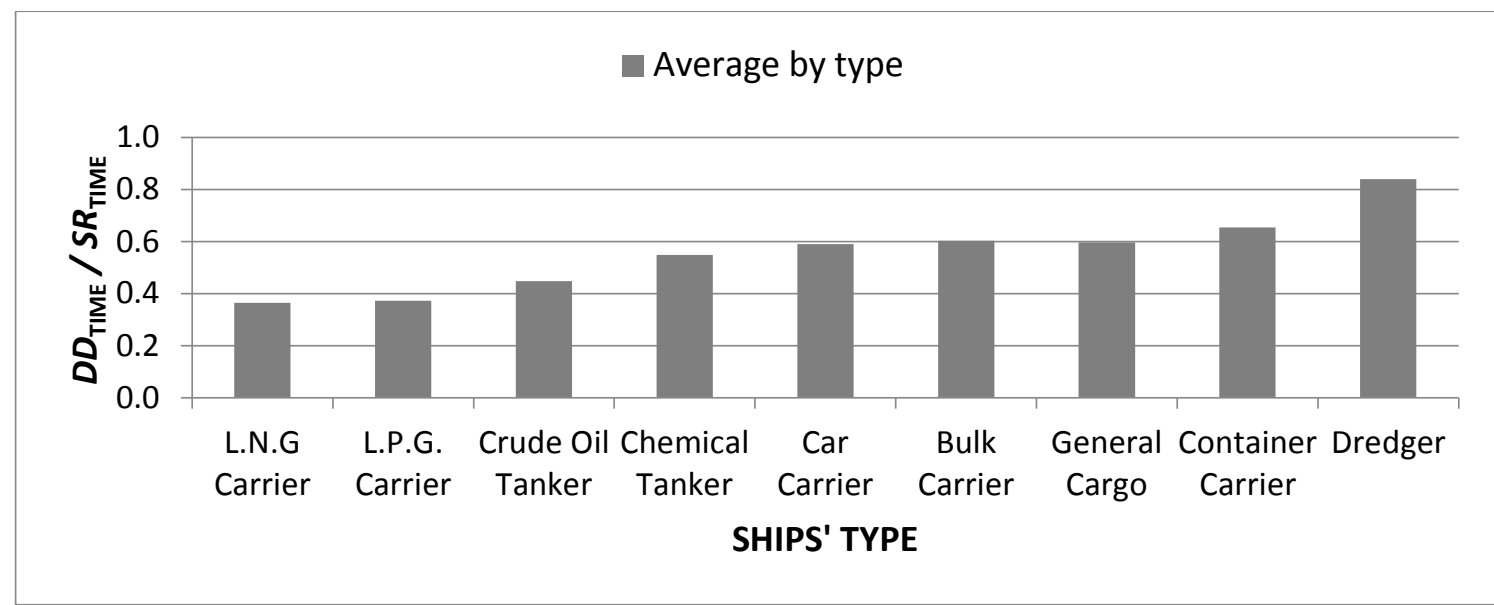

Figure. 19 Average dry-docking time as fraction of $S R_{\mathrm{TIME}}$ versus ships type of sample ships

\subsection{TYPE}

Dry-docking time and the corresponding type of ships are analysed to determine a trend or pattern between those irrespective of their deadweight and age. The results are presented in Figures.18 and 19. It demonstrates the behaviour of average dry-docking time and average dry-docking time as a fraction of average ship repairing time for ship type respectively. Both figures show that with the change of type, dry-docking time does change but very little except for dredgers. It suggests that the type of a ship does have an influence on dry-docking time but within a close range. It means that different types of ships will have different dry-docking time even though they are of same deadweight and age but within very close range of 6.55 days for bulk carriers to 8 days for L.N.G. carriers.

\subsection{DEADWEIGHT AND TYPE}

Dry-docking time and deadweight are analysed for various types of ship irrespective of their age. The results are presented in Figures 20-33 for crude oil tankers, chemical tankers, bulk carriers, container carriers, L.P.G. carriers, car carriers and general cargo carriers respectively.

Figures 20-21 show the observed dry-docking time and average dry-docking time (average by deadweight group) respectively against deadweight for crude oil tankers. Both figures suggest that with change of deadweight, dry-docking time does change but does not follow any pattern instead they are scattered, although the regression line has a slight positive slope. It suggests that a linear relationship exists between dry-docking time and deadweight of crude oil tankers. Therefore, deadweight of crude oil tankers does have influence on dry-docking time. It means that the bigger crude oil tankers may need longer dry-docking time compared to smaller ones.

Figures 22-23 show the observed dry-docking time and average dry-docking time (average by deadweight group) respectively against deadweight for chemical tankers. Both figures suggest that with change of deadweight, dry-docking time does change but does not follow any pattern instead they are scattered, although the regression line has a slight positive slope. It suggests that a linear 
relationship exists between dry-docking time and deadweight of a chemical tankers. Therefore, the deadweight of chemical tankers does have influence on dry-docking time. It means that the bigger chemical tankers may need longer dry-docking time compared to smaller ones.

Figures 24-25 show the observed dry-docking time and average dry-docking time (average by deadweight group) respectively against deadweight for bulk carriers. Both figures suggest that with change of deadweight, drydocking time does change but does not follow any pattern instead they are scattered, although the regression line has a slight negative slope. It suggests that a weak linear relationship exists between dry-docking time and deadweight of a bulk carriers. Therefore, deadweight of bulk carriers does not have significant influence on drydocking time. It means that bigger bulk carriers do not necessarily need longer dry-docking time compared to smaller ones.

Figures 26-27 show the observed dry-docking time and average dry-docking time (average by deadweight group) respectively against deadweight for container carriers. Both figures suggest that with change of deadweight, dry-docking time does change but does not follow any pattern instead they are scattered, although the regression line has a comparatively sharp positive slope. It suggests that a strong linear relationship exists between dry-docking time and deadweight of container carriers. Therefore, deadweight of container carriers does have significant influence on drydocking time. It means that bigger container carriers may need longer dry-docking time compared to smaller ones but within very close range.

Figures 28-29 show the observed dry-docking time and average dry-docking time (average by deadweight group) respectively against deadweight for L.P.G. carriers. Both figures suggest that with change of deadweight, dry- docking time does change but does not follow any pattern instead they are scattered, although the regression line has a positive slope. It suggests that a linear relationship exists between dry-docking time and deadweight of L.P.G. carriers. Therefore, deadweight of L.P.G. carriers does have influence on dry-docking time. It means that bigger L.P.G. carriers may need longer drydocking time compared to smaller ones.

Figures 30-31 show the observed dry-docking time and average dry-docking time (average by deadweight group) respectively against deadweight for car carriers. Both figures suggest that with change of deadweight, drydocking time does change and the regression line has a sharp positive slope. It suggests that a strong linear relationship exists between dry-docking time and deadweight of car carriers. Therefore, deadweight of car carriers does have significant influence on dry-docking time. It means that bigger car carriers do need longer drydocking time compared to smaller ones but within very close range.

Figures 32-33 show the observed dry-docking time and average dry-docking time (average by deadweight group) respectively against deadweight for general cargo carriers. Both figures suggest that with change of deadweight, dry-docking time does change and the regression line has a negative slope. It suggests that a linear relationship exists between dry-docking time and deadweight of general cargo carriers. Therefore, deadweight of general cargo carriers does have influence on dry-docking time. It means that bigger general cargo carriers may or may not need longer dry-docking time compared to smaller ones.

Mathematically, the negative slope of a regression line (Figures.24 and 32) means that the rate of increase in deadweight (x-axis) is comparatively higher than the rate of increase in dry-docking time (y-axis).

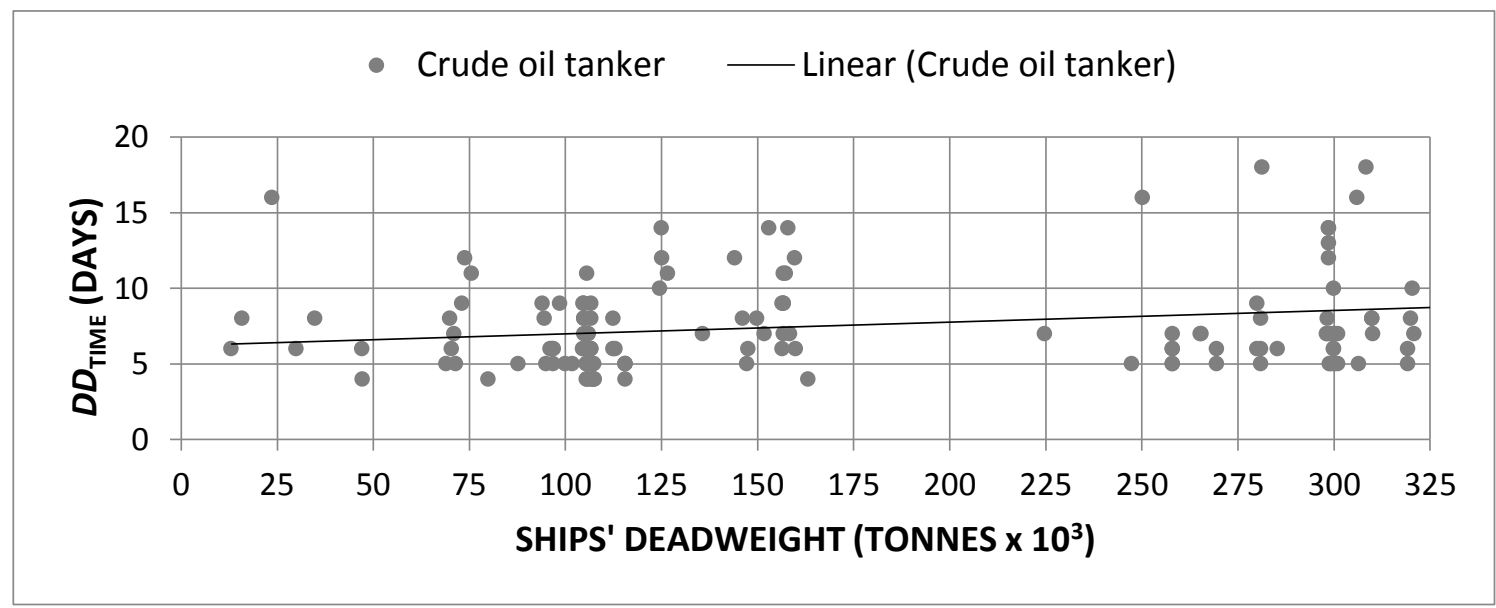

Figure. 20 Dry-docking time versus ships' deadweight for crude oil tankers 


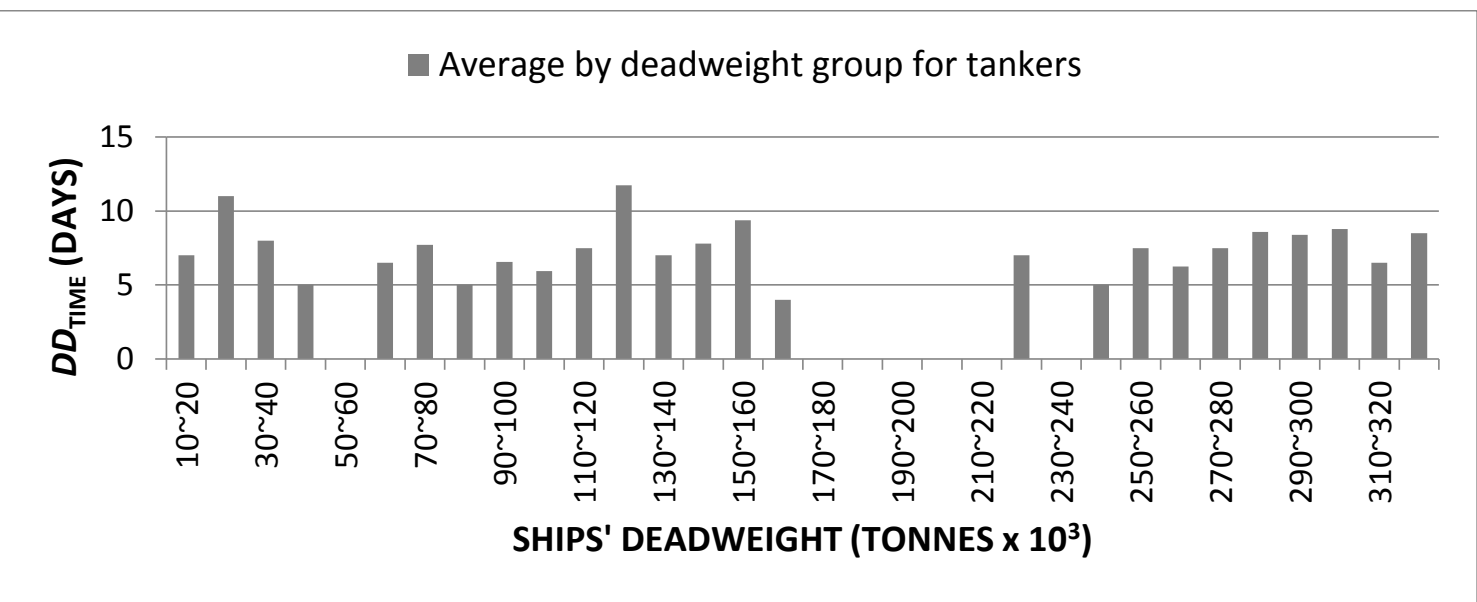

Figure.21 Average dry-docking time versus ships' deadweight for crude oil tankers

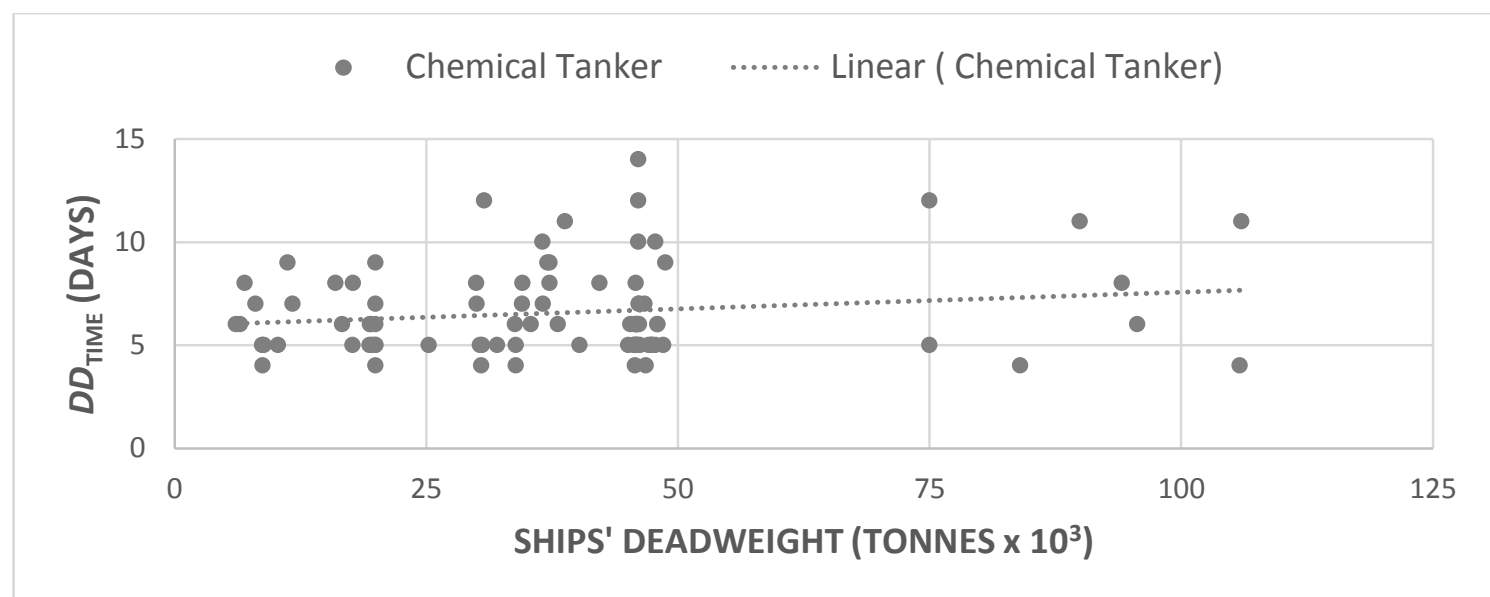

Figure.22 Dry-docking time versus ships' deadweight for chemical tankers

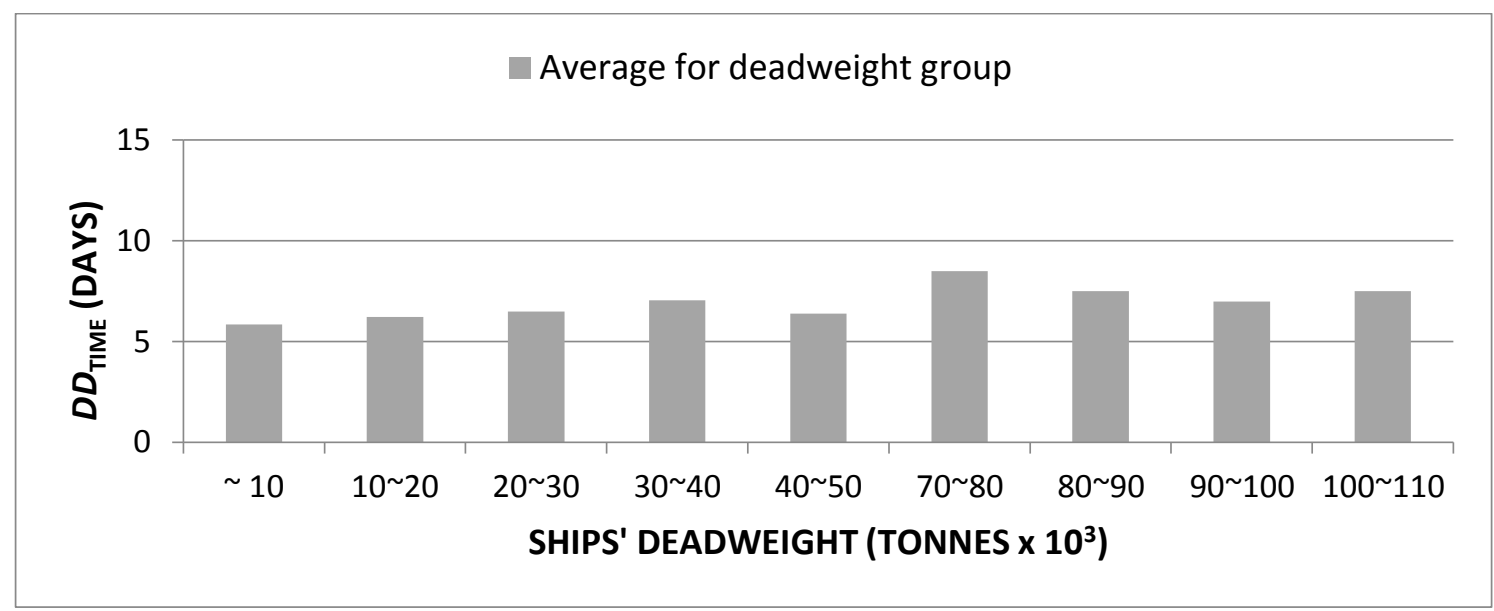

Figure.23 Average dry-docking time versus ships' deadweight for chemical tankers 


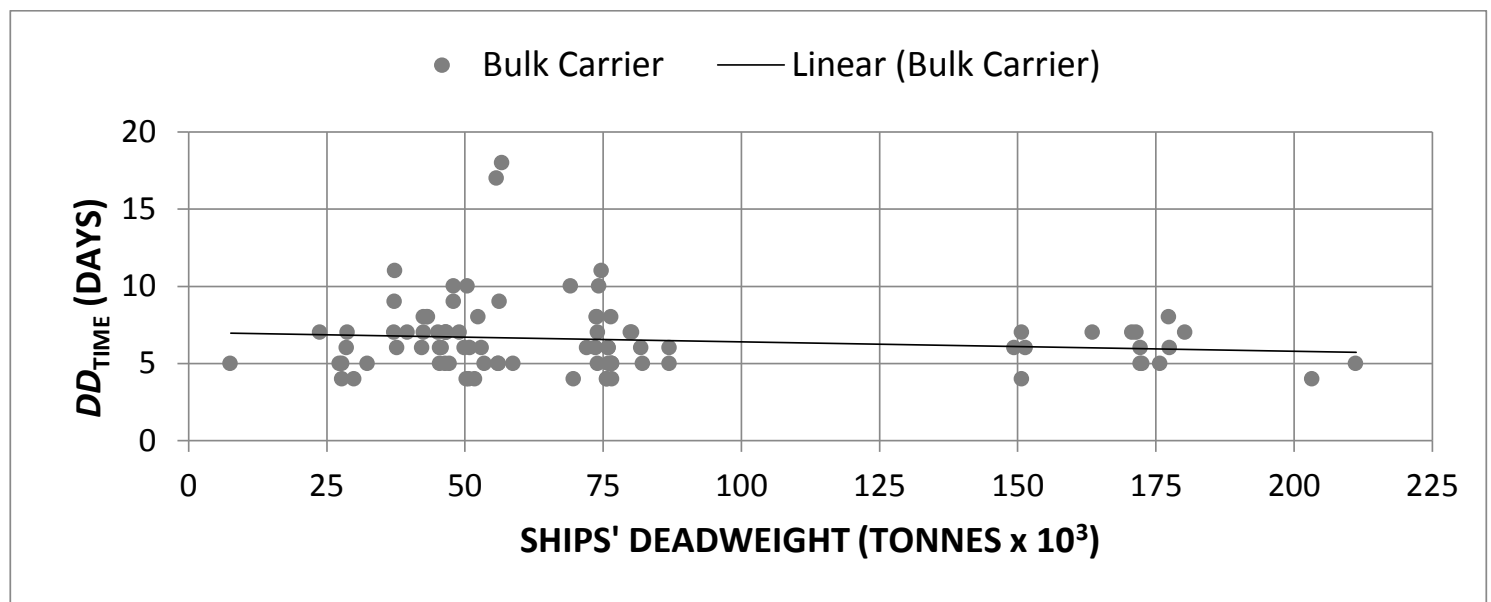

Figure.24 Dry-docking time versus ships' deadweight for bulk carriers

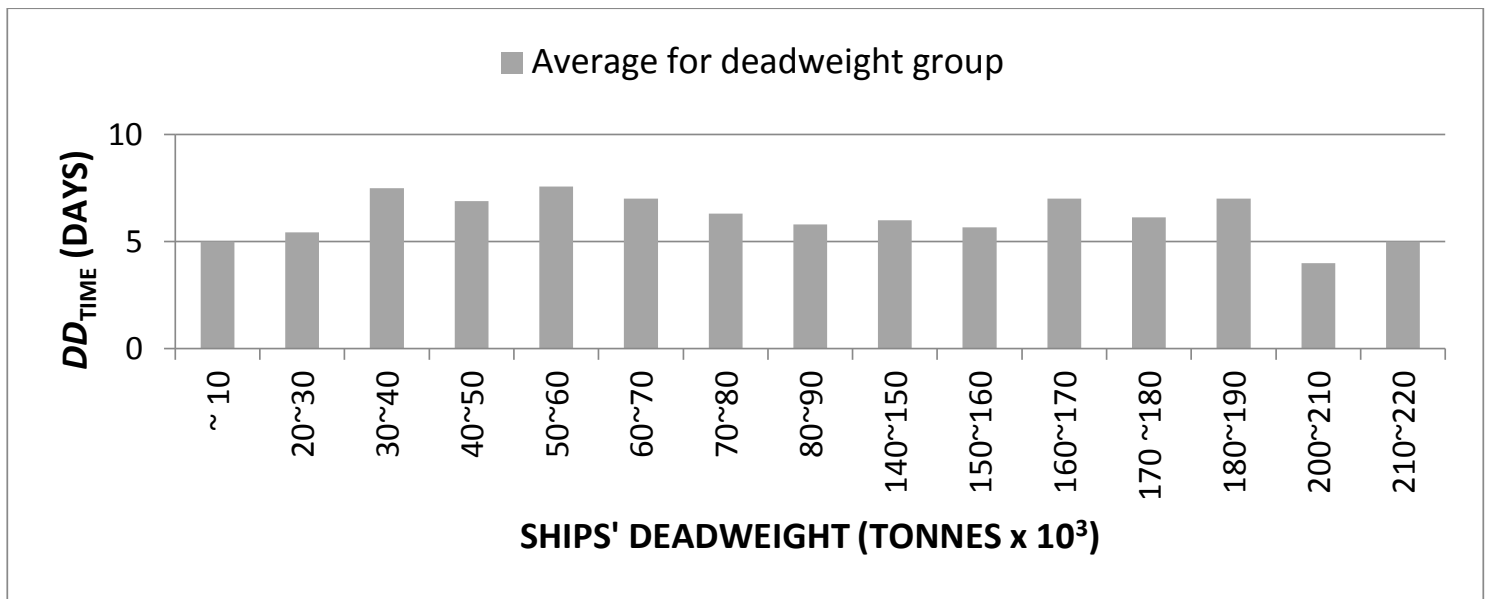

Figure.25 Average dry-docking time versus ships, deadweight for bulk carriers

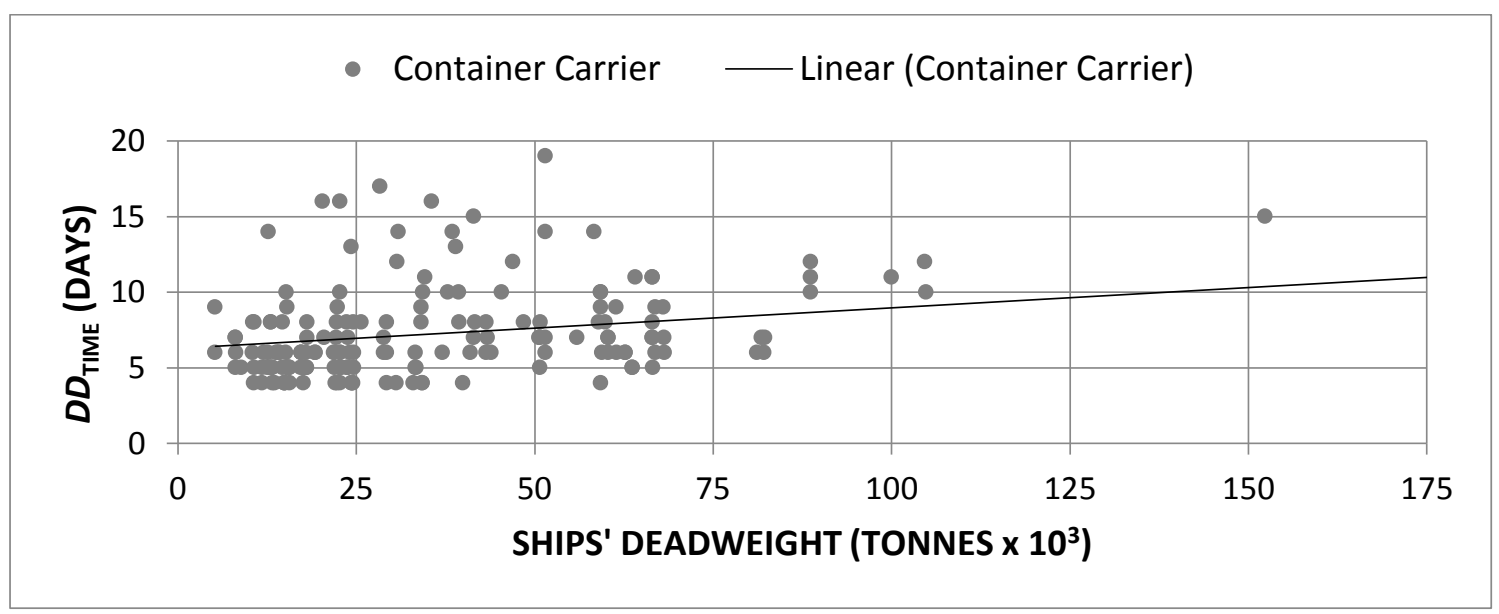

Figure.26 Dry-docking time versus ships' deadweight for container carriers 


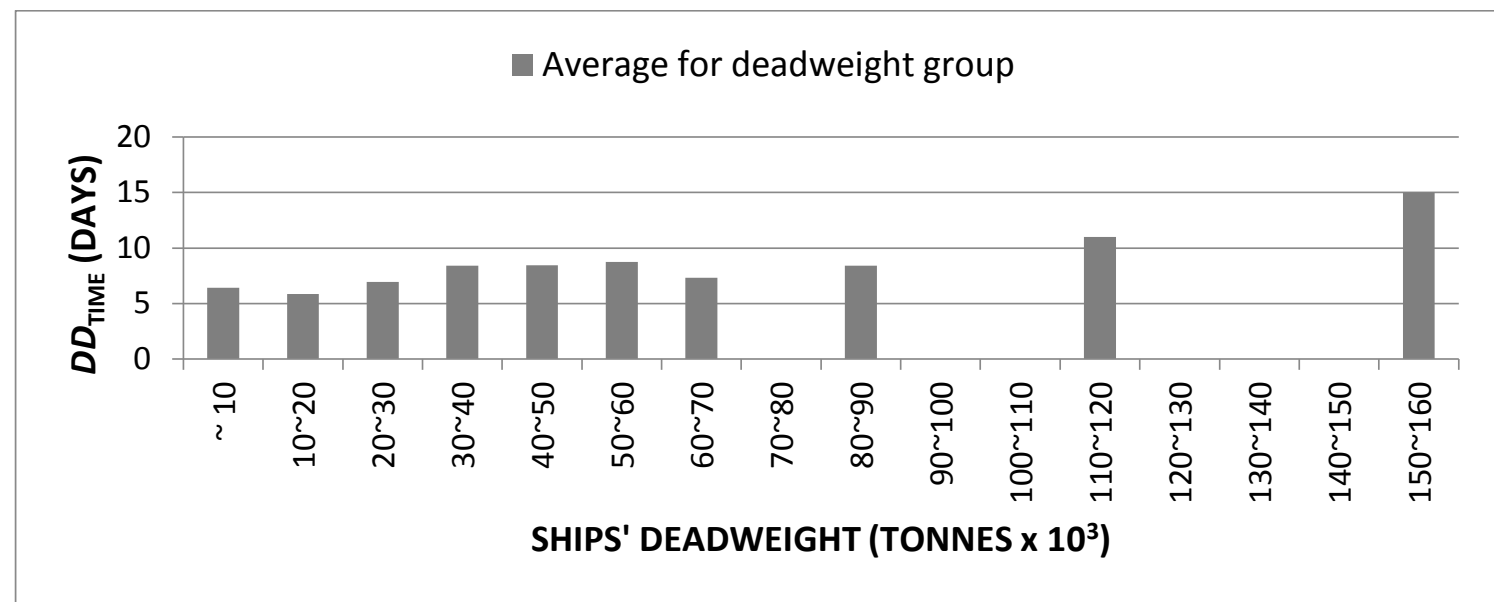

Figure.27 Average dry-docking time versus ships' deadweight for container carriers

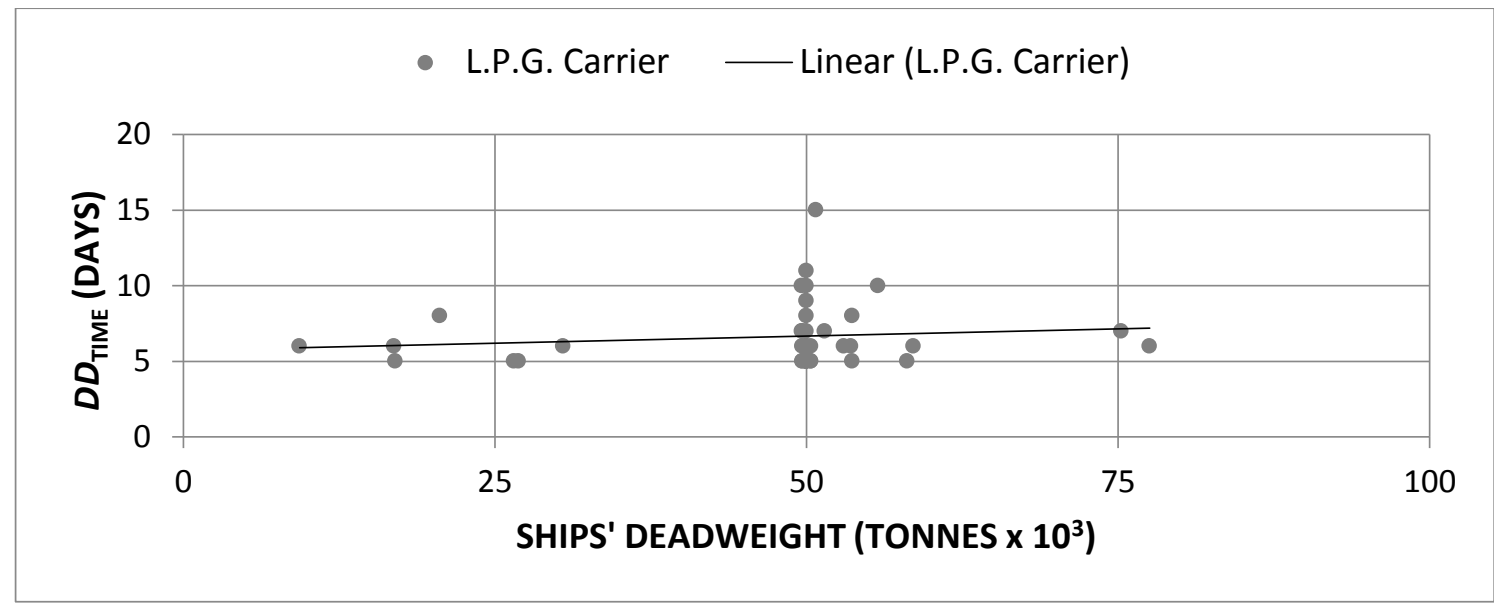

Figure.28 Dry-docking time versus ships' deadweight for L.P.G. carriers

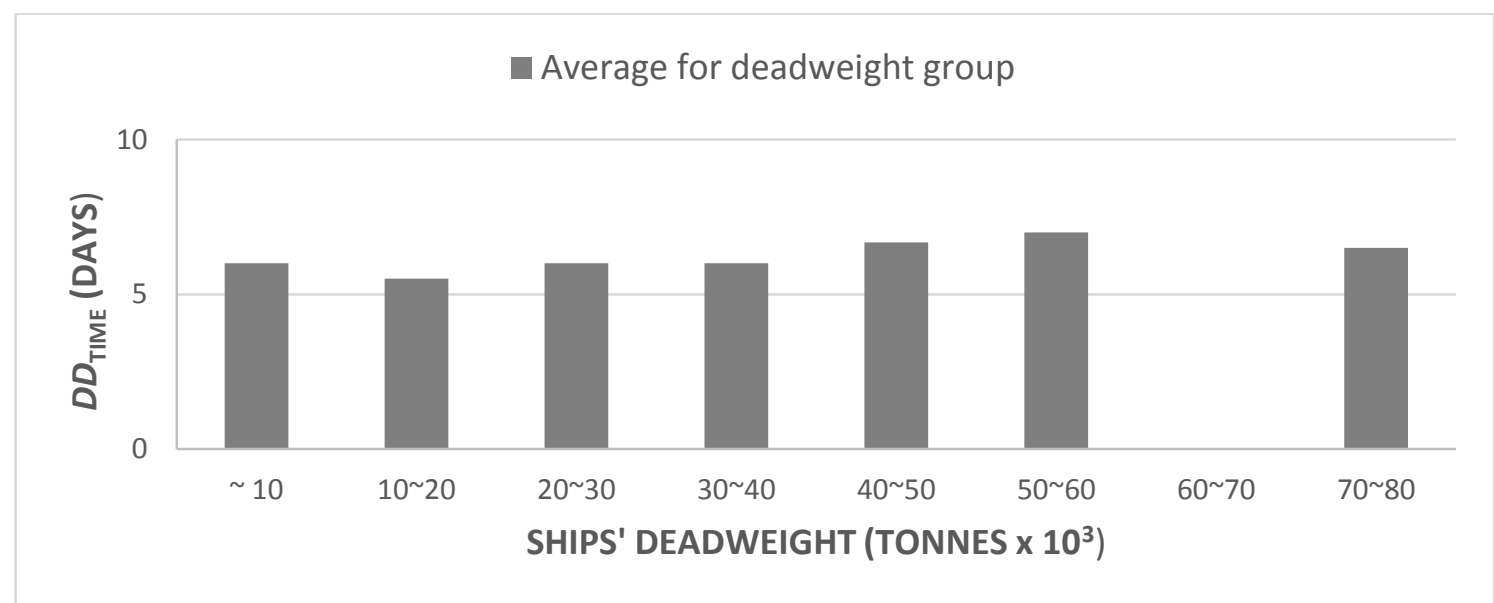

Figure.29 Average dry-docking time versus ships' deadweight for L.P.G. carriers 


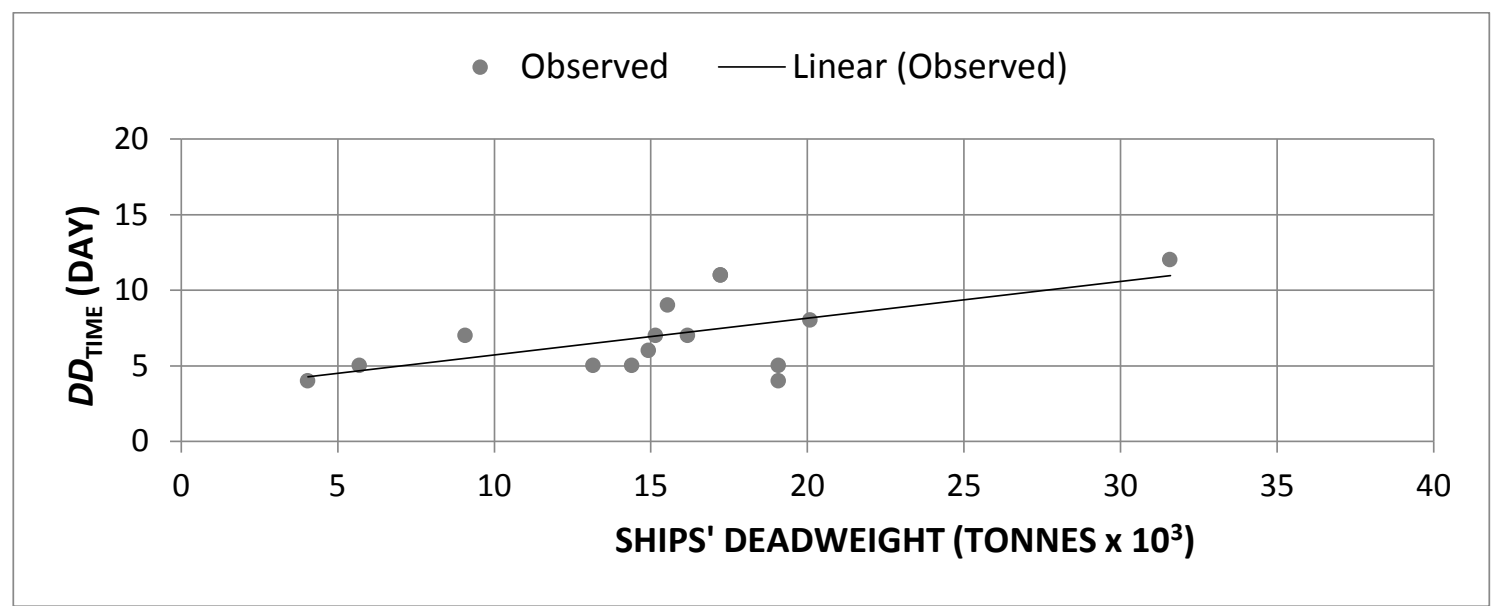

Figure.30 Dry-docking time versus ships' deadweight for car carriers

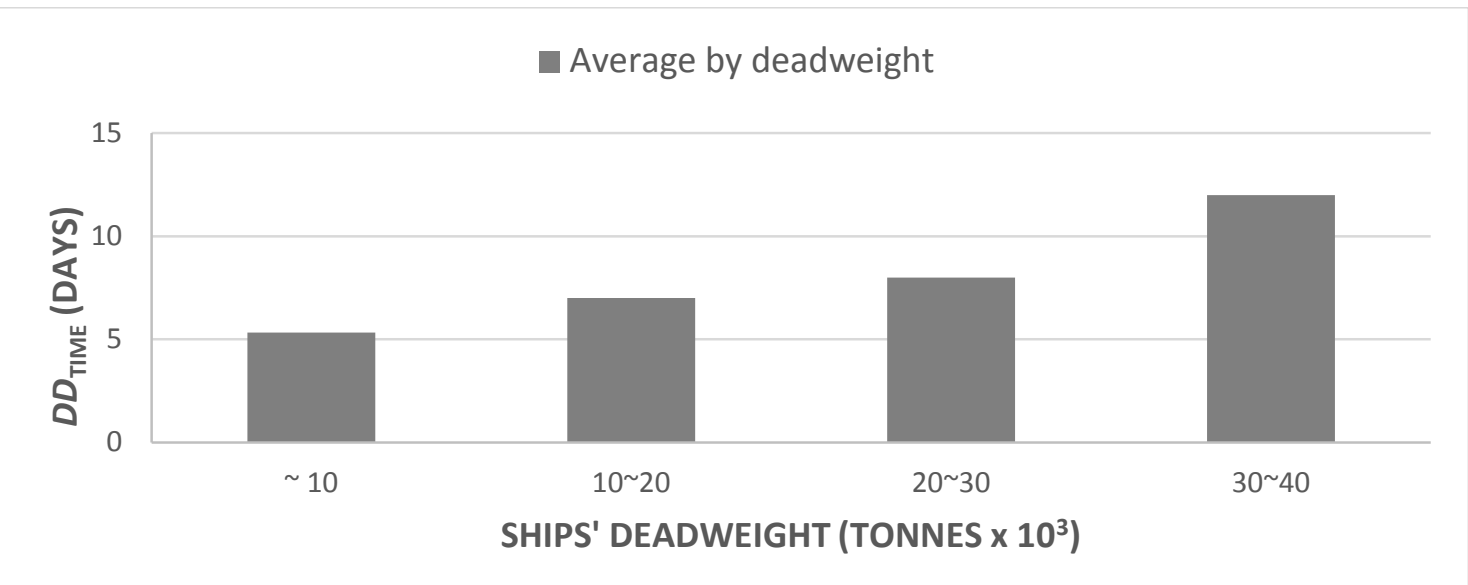

Figure.31 Average dry-docking time versus ships' deadweight for car carriers

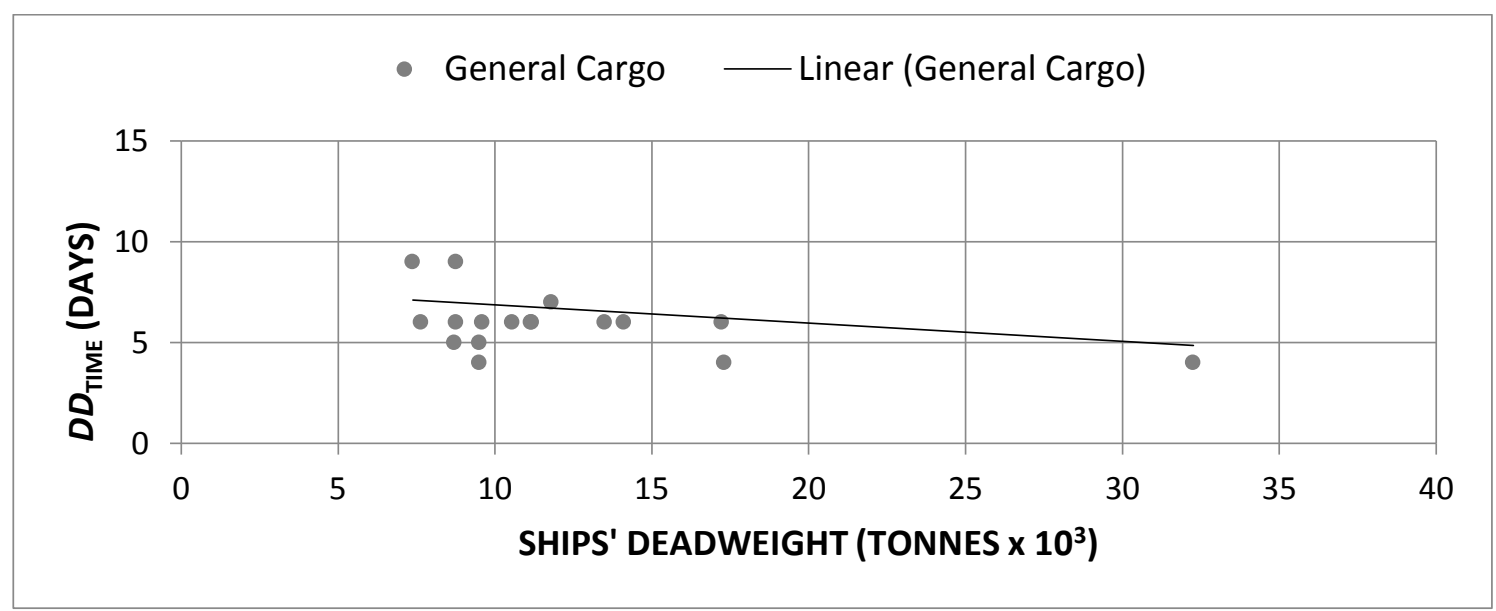

Figure.32 Dry-docking time versus ships' deadweight for general cargo carriers 


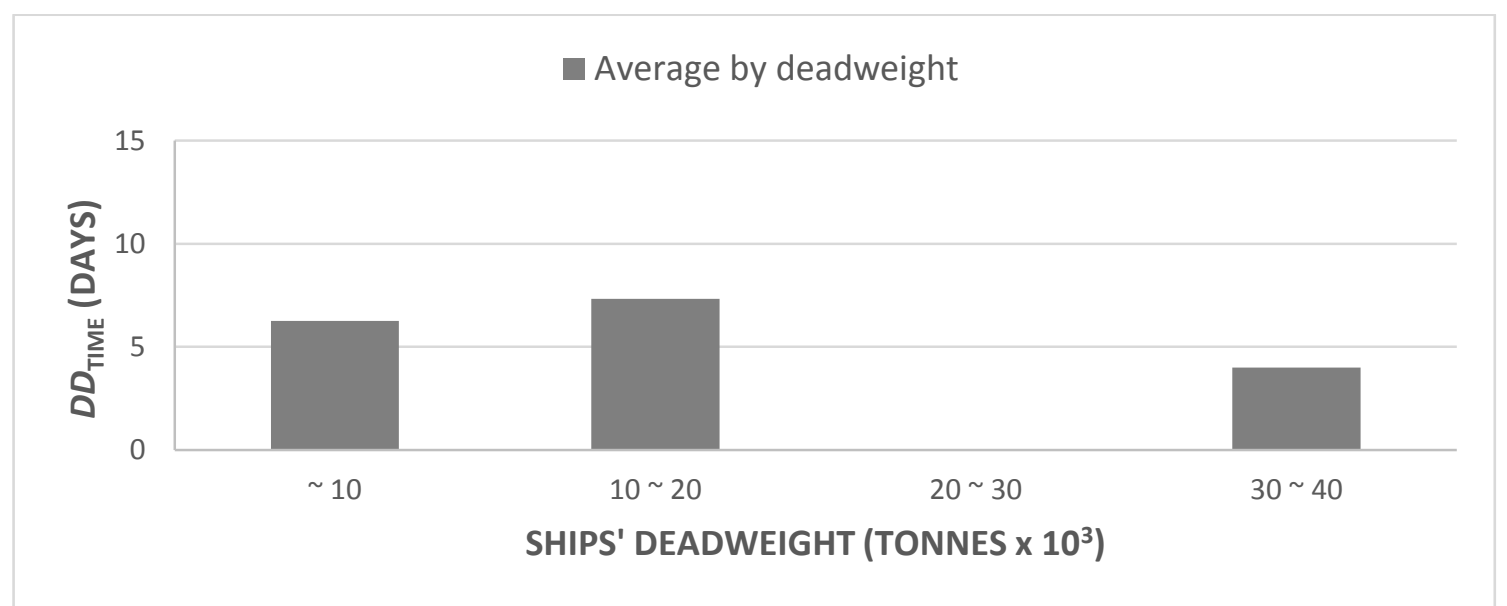

Figure.33 Average dry-docking time versus ships' deadweight for general cargo carriers

Table 6 Summary of correlation coefficients of linear and exponential relationships

\begin{tabular}{|l|l|l|l|l|}
\hline \multirow{2}{*}{$\begin{array}{l}\text { Figure } \\
\text { No. }\end{array}$} & \multirow{2}{*}{ Variables } & \multicolumn{2}{|l|}{$r^{2}$ values } & \multirow{2}{*}{ Remarks } \\
\cline { 3 - 4 } & & Linear & Exponential & \\
\hline 20 & $D D_{\text {TIME }}$ vs $S_{\mathrm{D}}$ & 0.0434 & 0.0418 & Crude oil tanker \\
\hline 22 & $D D_{\text {TIME }}$ Vs $S_{\mathrm{D}}$ & 0.0251 & 0.0138 & Chemical tanker \\
\hline 26 & $D D_{\text {TIME }}$ vs $S_{\mathrm{D}}$ & $0.0154(-)$ & $0.0133(-)$ & Bulk carrier \\
\hline 28 & $D D_{\text {TIME }}$ Vs $S_{\mathrm{D}}$ & 0.0787 & 0.0990 & Container carrier \\
\hline 30 & $D D_{\text {TIME }}$ vs $S_{\mathrm{D}}$ & 0.0147 & 0.0167 & L.P.G. carrier \\
\hline 32 & $D D_{\text {TIME }}$ Vs $S_{\mathrm{D}}$ & 0.3561 & 0.3196 & Car carrier \\
\hline
\end{tabular}

In Table 6, one can easily find that for a particular relationship (Figures.20-32), the values of $r^{2}$ for a linear relationship are very close and higher than an exponential relationship, except Figures.26 and 32.

Based on $r^{2}$ values, maximum relationships have a fair goodness of fit to a linear relationship and others are very close. Therefore, it is not biased to consider a general assumption that dry-docking time is a function of deadweight irrespective of age and type and they are linearly associated. More specifically, bigger ships are expected to have longer dry-docking time than smaller ships.

\subsection{AGE AND TYPE}

Dry-docking time and age are analysed for various types of ships irrespective of their deadweight. The results are presented in Figures.34-47 for crude oil tankers, chemical tankers, bulk carriers, container carriers, L.P.G. carriers, car carriers and general cargo carriers respectively.

Figures 34-35 show the observed dry-docking time and average dry-docking time (average by age group) respectively against age for crude oil tankers. Both figures suggest that with a change of age, dry-docking time does change and the regression line has a positive slope. It suggests that a linear relationship exists between dry-docking time and age of crude oil tankers. Therefore, the age of crude oil tankers does have an influence on dry-docking time. It means that the older crude oil tankers may need longer dry-docking time compared to newer ones.

Figures 36-37 show the observed dry-docking time and average dry-docking time (average by age group) respectively against age for chemical tankers. Both figures suggest that with a change of age, dry-docking time does change and the regression line has a positive slope. It suggests that a linear relationship exists between dry-docking time and age of chemical tankers. Therefore, 
the age of chemical tankers does have an influence on dry-docking time. It means that the older chemical tankers may need longer dry-docking time compared to newer ones.

Figures 38-39 show the observed dry-docking time and average dry-docking time (average by age group) respectively against age for bulk carriers. Both figures suggest that with a change of age, dry-docking time does change and the regression line has, almost, a zero slope. It suggests that a very weak linear relationship exists between dry-docking time and age of bulk carriers. Therefore, the age of bulk carriers does not have an influence on dry-docking time. It means that the older bulk carriers are unlikely need longer dry-docking time compared to newer ones.

Figures 40-41 show the observed dry-docking time and average dry-docking time (average by age group) respectively against age for container carriers. Both figures suggest that with a change of age, dry-docking time does change and the regression line has a positive slope. It suggests that a linear relationship exists between dry-docking time and age of container carriers. Therefore, the age of container carriers does have an influence on dry-docking time. It means that the older container carriers may need longer dry-docking time compared to newer ones.

Figures 42-43 show the observed dry-docking time and average dry-docking time (average by age group) respectively against age for L.P.G. carriers. Both figures suggest that with a change of age, dry-docking time does change and the regression line has a slight positive slope. It suggests that a linear relationship exists between dry-docking time and age of L.P.G. carriers. Therefore, the age of L.P.G. carriers does have an influence on dry-docking time. It means that the older L.P.G. carriers likely need longer drydocking time compared to newer ones.
Figures 44-45 show the observed dry-docking time and average dry-docking time (average by age group) respectively against age for car carriers. Both figures suggest that with a change of age, dry-docking time does change and the regression line has a positive slope. It suggests that a linear relationship exists between dry-docking time and age of car carriers. Therefore, the age of car carriers does have an influence on dry-docking time. It means that the older car carriers likely need longer dry-docking time compared to newer ones.

Figures 46-47 show the observed dry-docking time and average dry-docking time (average by age group) respectively against age for general cargo carriers. Both figures suggest that with a change of age, dry-docking time does change and the regression line has a slight positive slope. It suggests that a weak linear relationship exists between dry-docking time and age of general cargo carriers. Therefore, the age of general cargo carriers does have an influence on dry-docking time. It means that the older general cargo carriers likely need longer dry-docking time compared to newer ones.

Mathematically, the negative slope of a regression line (Figure.38) means that the rate of increase in age (x-axis) is comparatively higher than the rate of increase in drydocking time (y-axis).

In Table 7 , one can easily find that for a particular relationship (Figures.34-47), the values of $r^{2}$ for a linear relationship and corresponding exponential relationship, are very close.

Based on $r^{2}$ values, maximum relationships have fair goodness of fit to a linear relationship. Therefore, it is not biased to consider a general assumption that drydocking time is a function of age irrespective of size and type and they are linearly associated. More specifically, older ships are expected to have higher dry-docking time compared to newer ships.

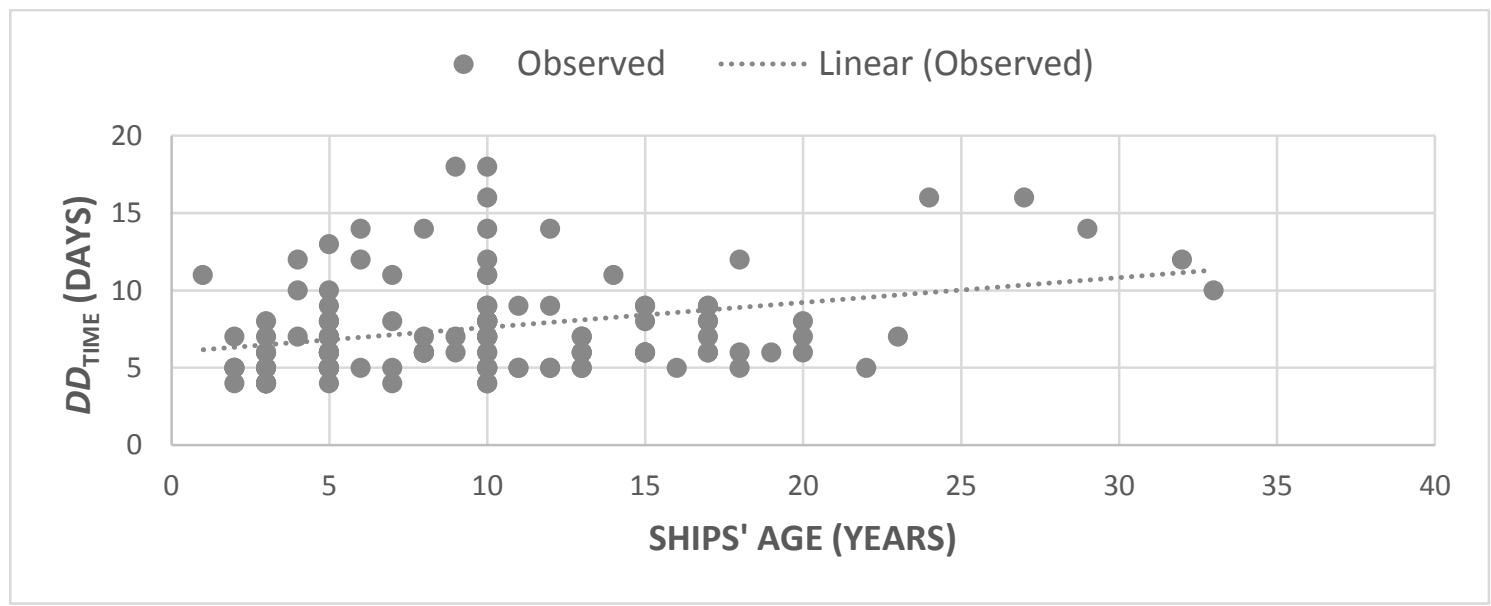

Figure.34 Dry-docking time versus ships’ age for crude oil tankers 


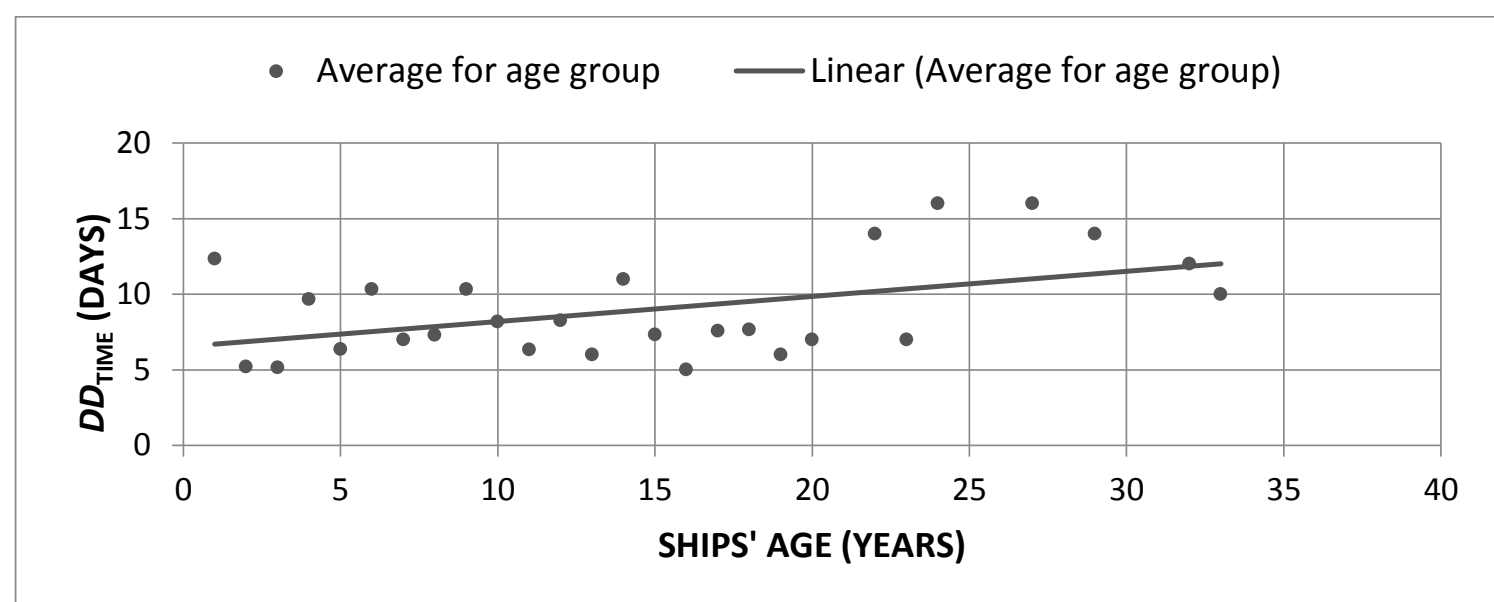

Figure.35 Average dry-docking time versus ships’ age for crude oil tankers

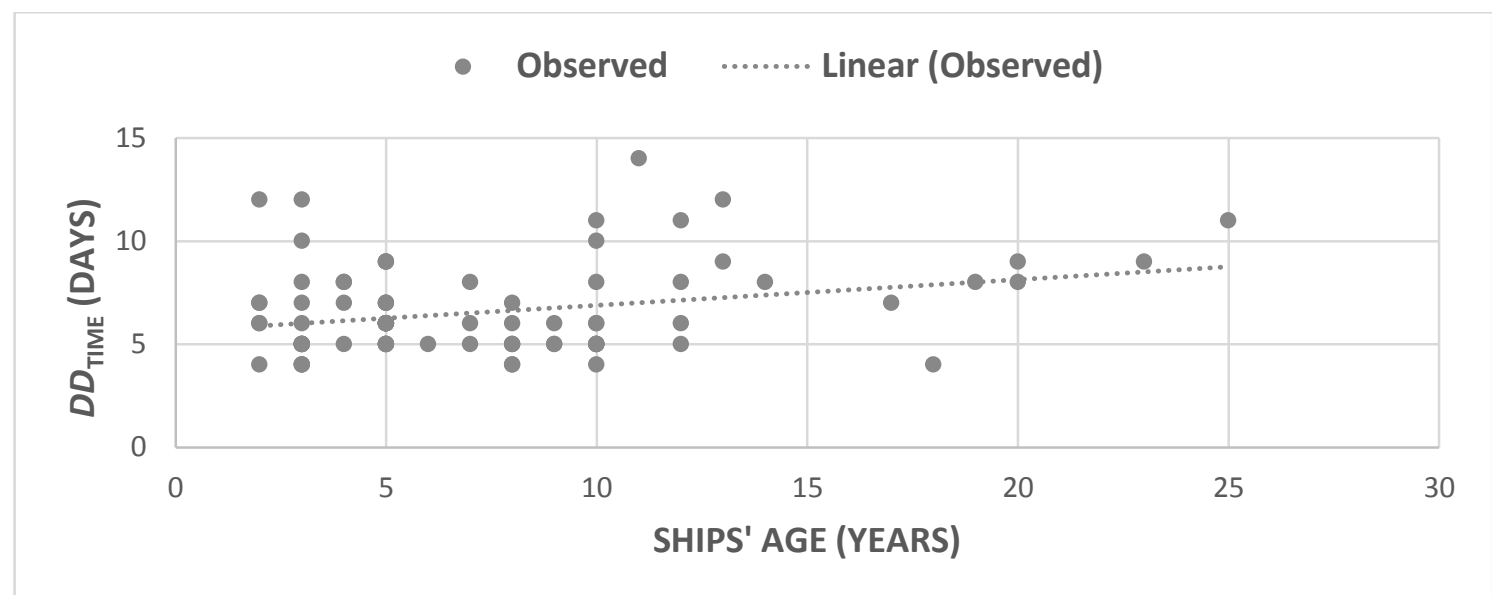

Figure.36 Dry-docking time versus ships’ age for chemical tankers

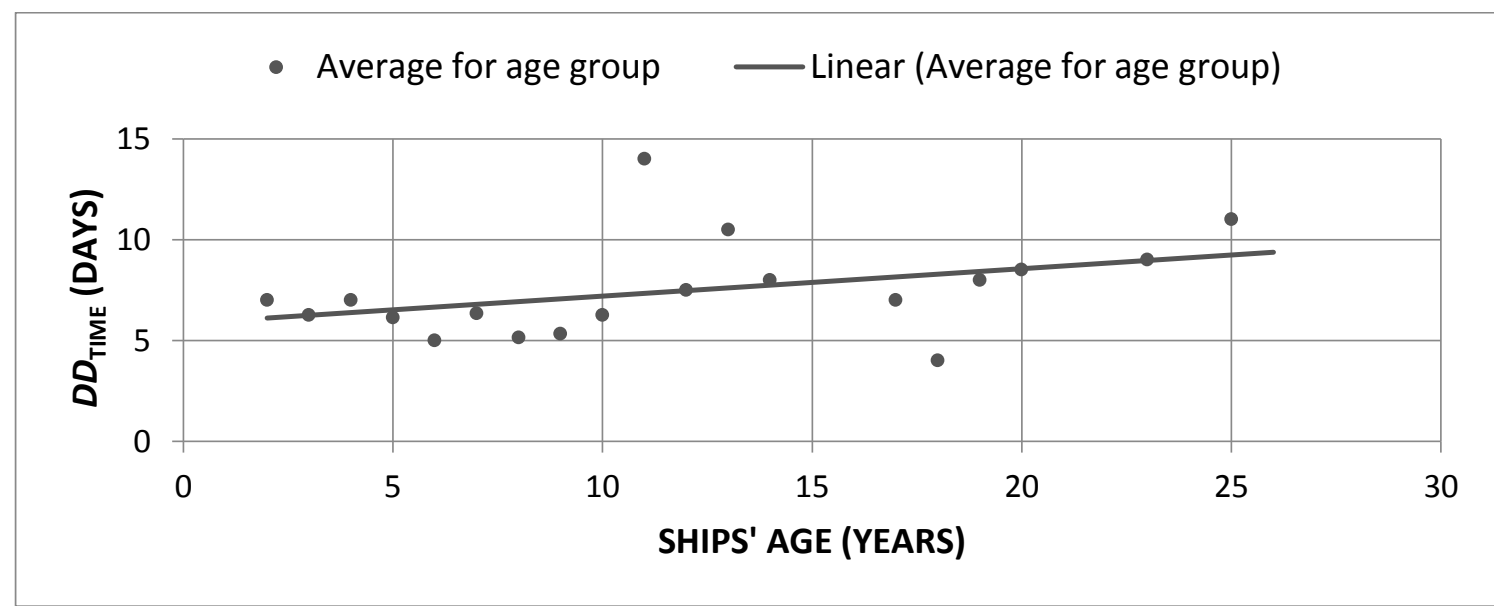

Figure.37 Average dry-docking time versus ships’ age for chemical tankers 
- Observed Linear (Observed)

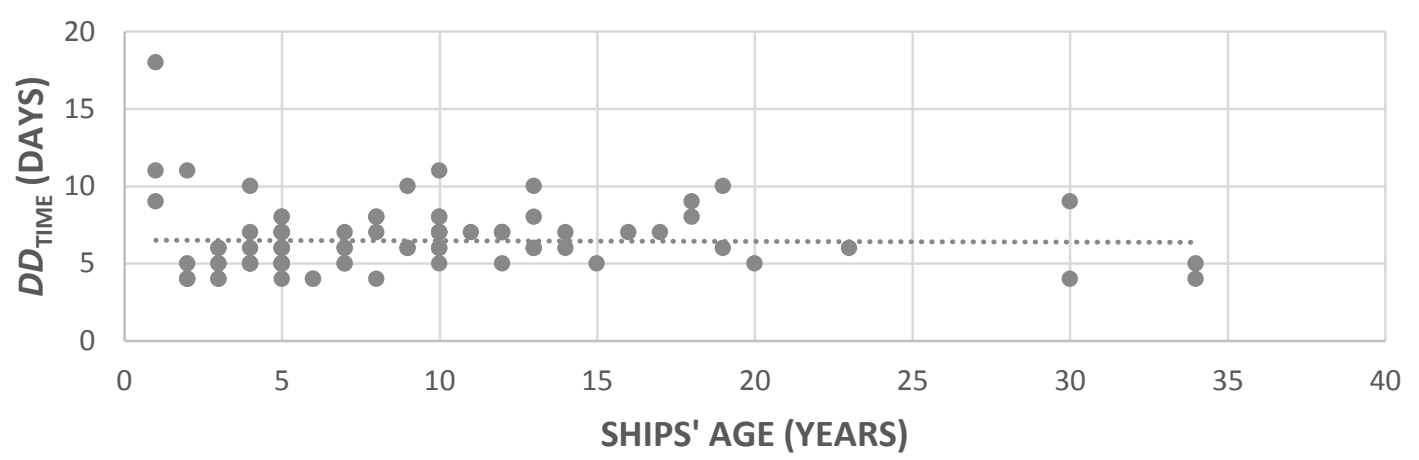

Figure.38 Dry-docking time versus ships' age for bulk carriers

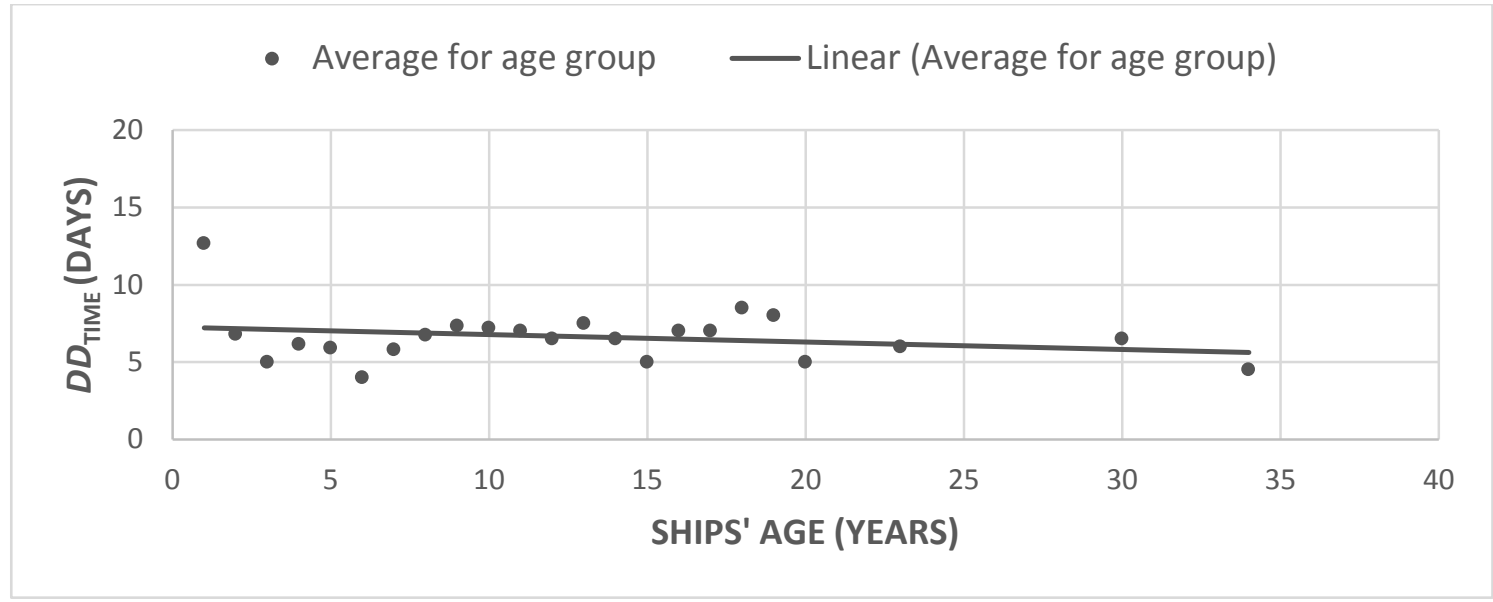

Figure.39 Average dry-docking time versus ships' age for bulk carriers

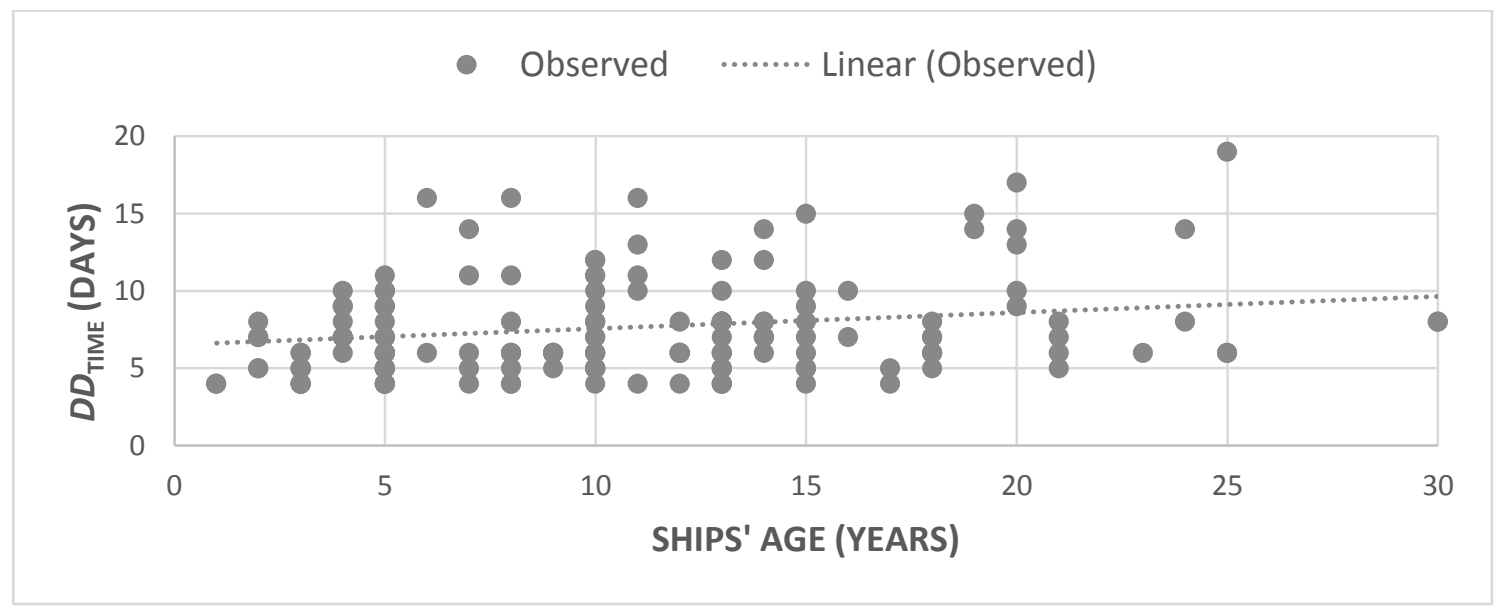

Figure.40 Dry-docking time versus ships' age for container carriers 


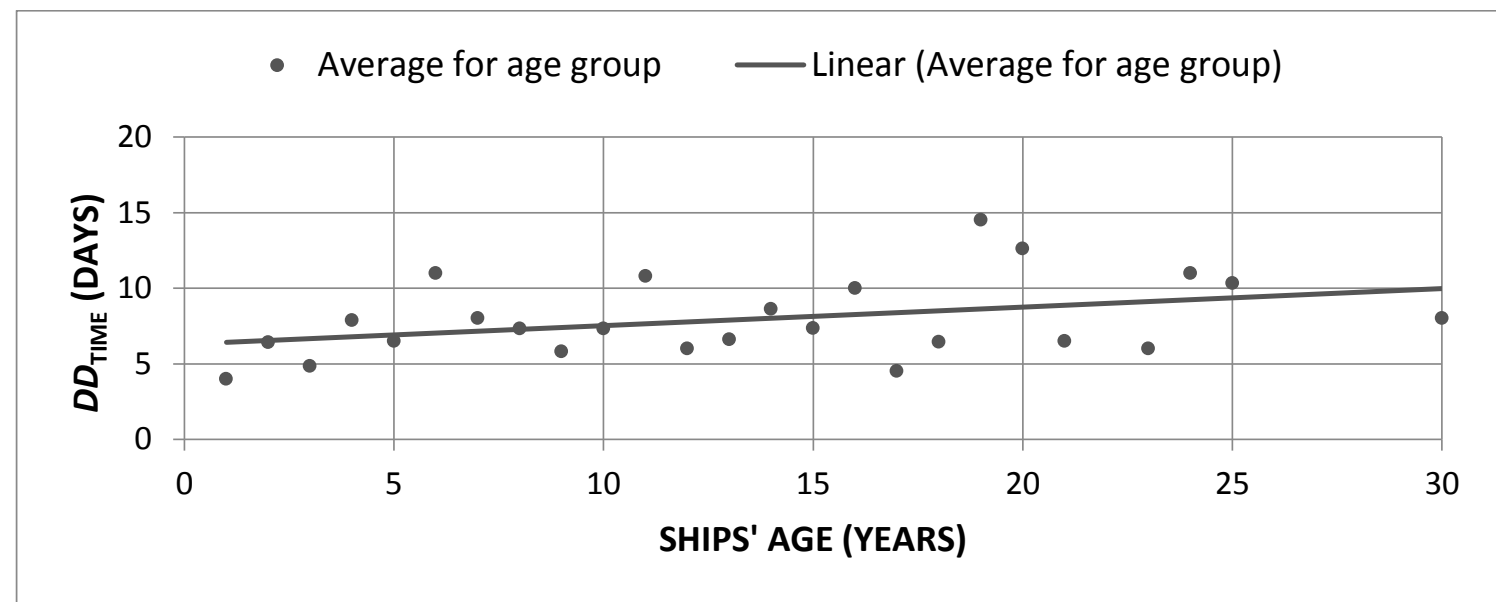

Figure.41 Average dry-docking time versus ships' age for container carriers

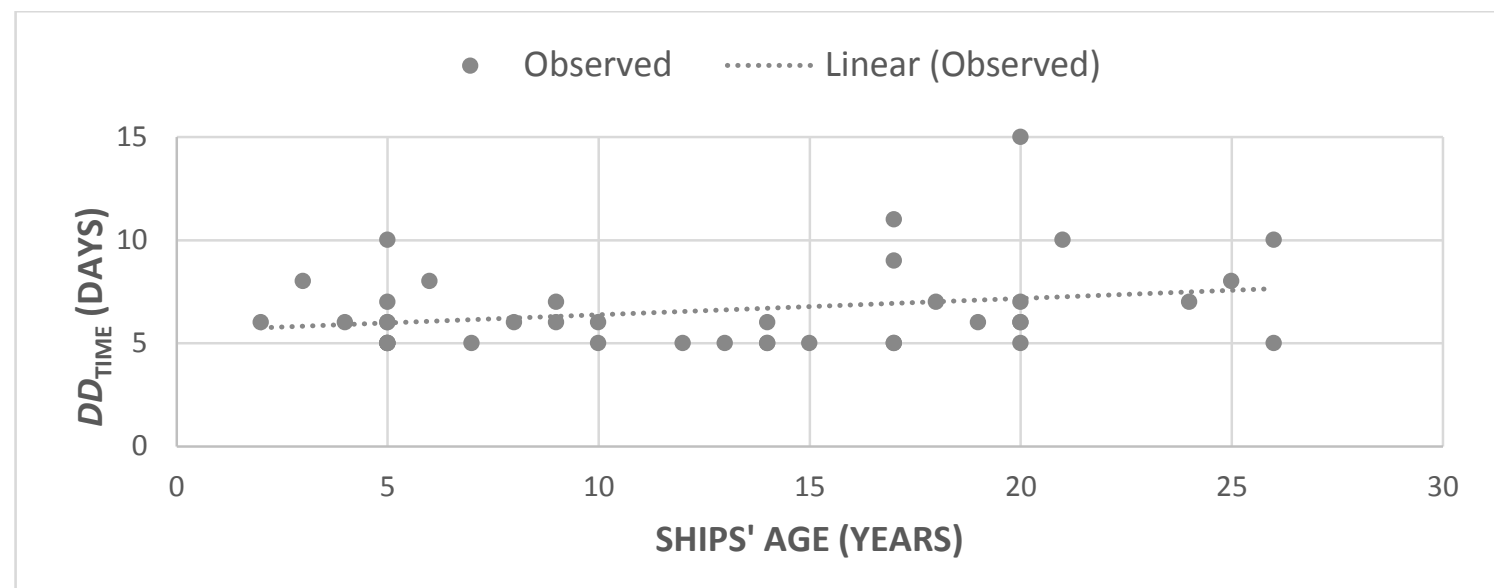

Figure.42 Dry-docking time versus ships’ age for L.P.G. carriers

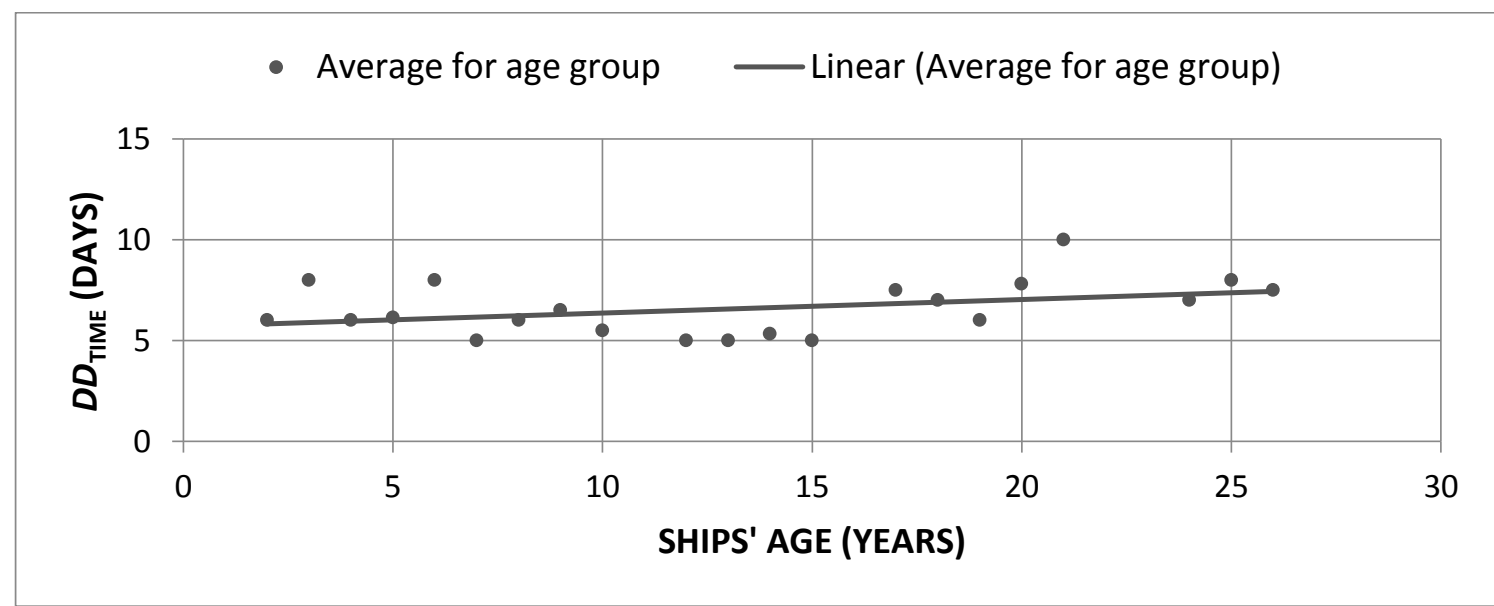

Figure.43 Average dry-docking time versus ships' age for L.P.G. carriers 


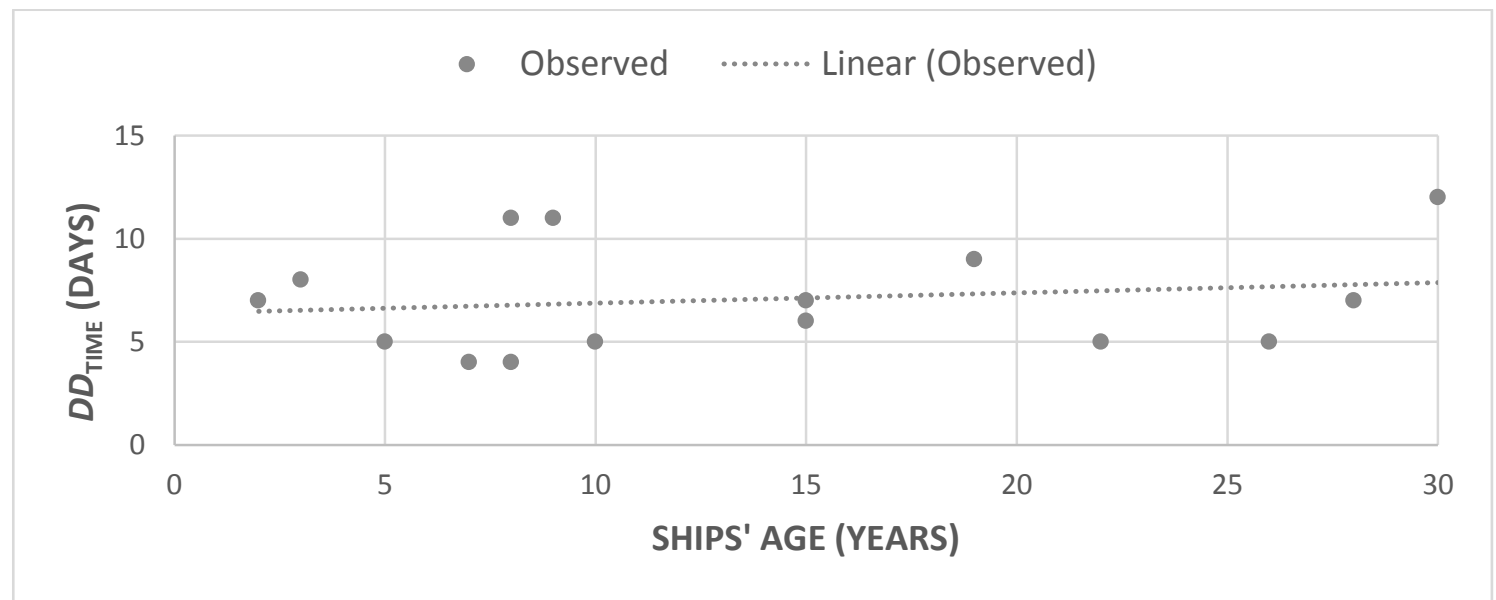

Figure.44 Dry-docking time versus ships age for car carriers

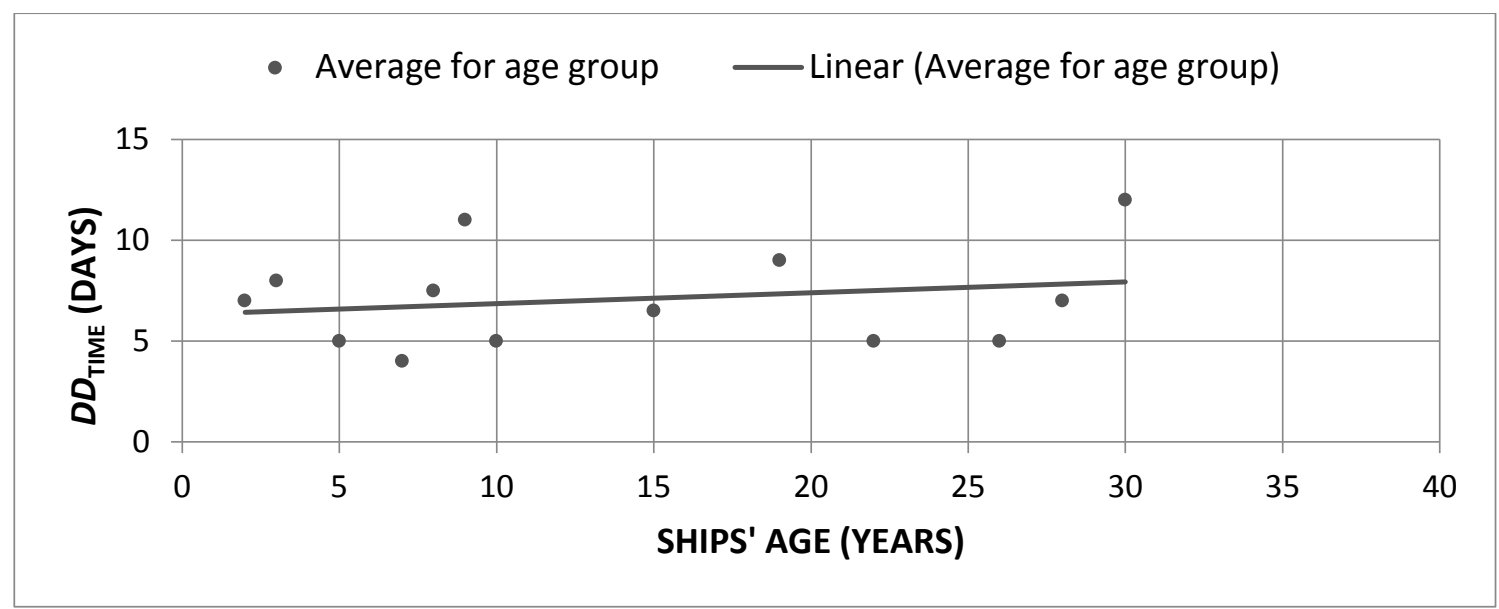

Figure.45 Average dry-docking time versus ships age for car carriers

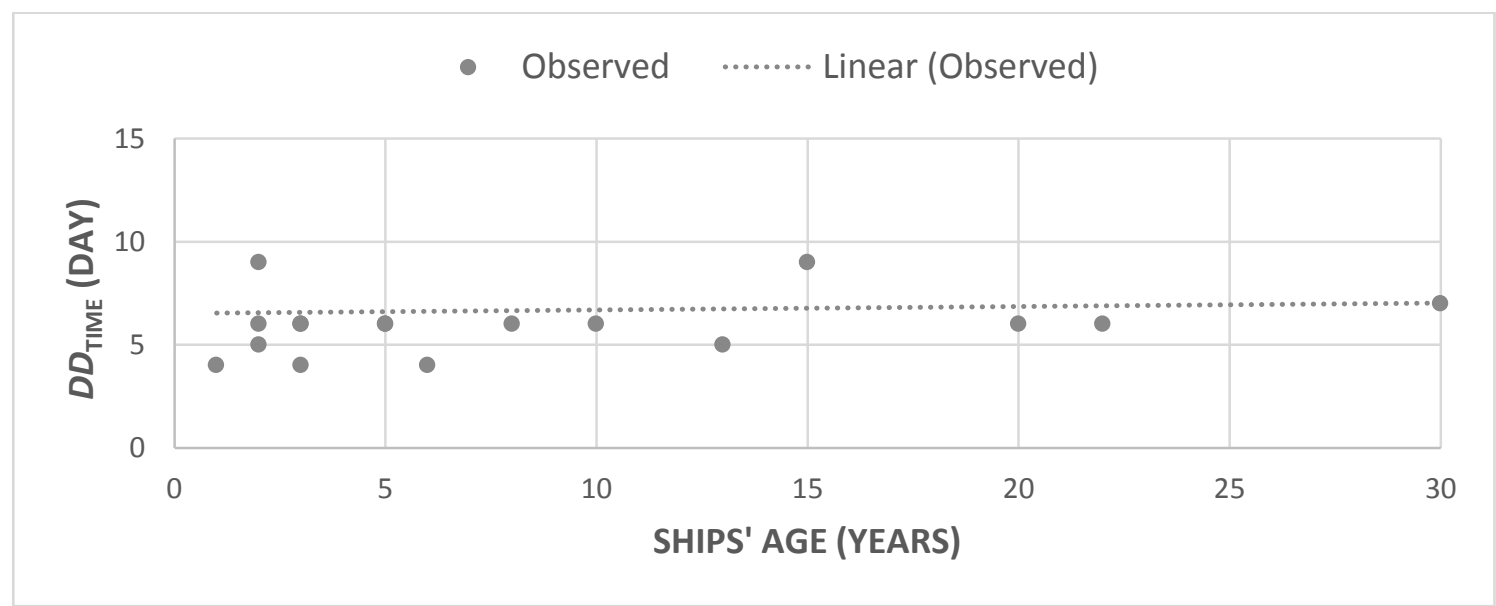

Figure.46 Dry-docking time versus ships' age for general cargo carriers 


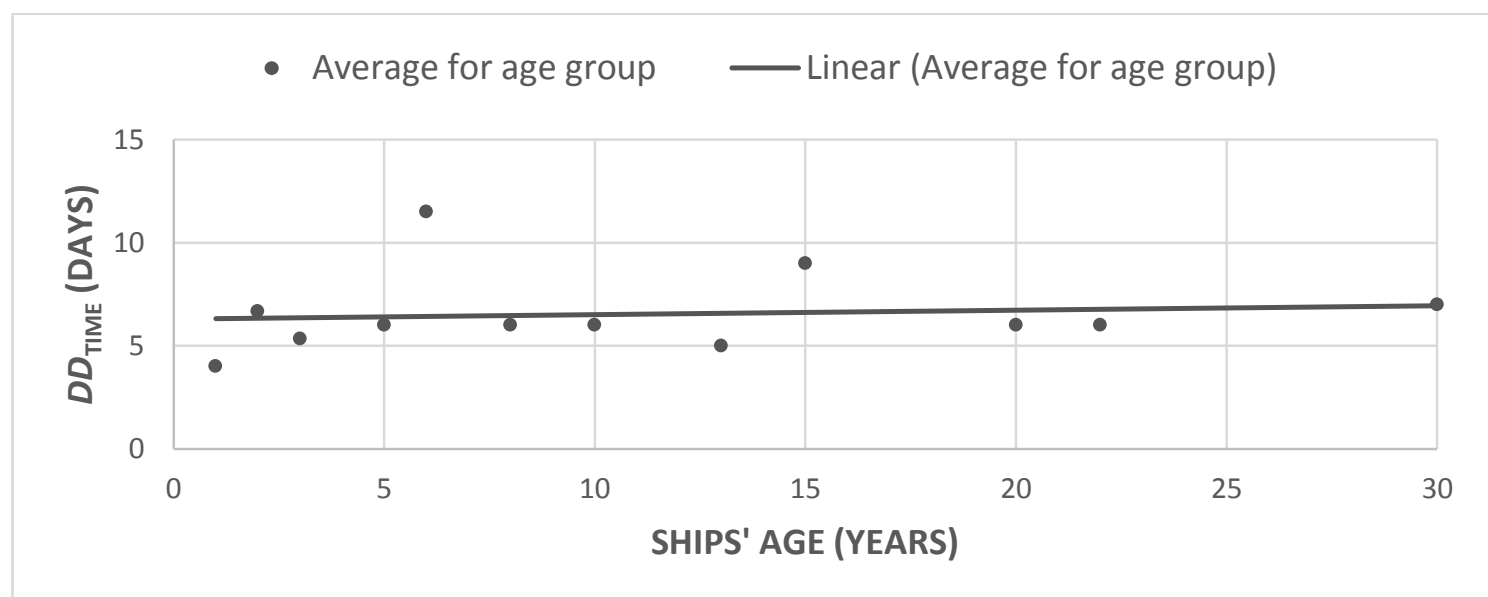

Figure.47 Average dry-docking time versus ships' age for general cargo ships

Table 7 Summary of correlation coefficients of linear and exponential relationships

\begin{tabular}{|l|l|l|l|l|}
\hline \multirow{2}{*}{$\begin{array}{l}\text { Figure } \\
\text { No. }\end{array}$} & \multirow{2}{*}{ Variables } & \multicolumn{2}{|l|}{$r^{2}$ values } & \multirow{2}{*}{ Remarks } \\
\cline { 3 - 4 } & & Linear & Exponential & \\
\hline 34 & $D D_{\text {TIME }}$ vs $S_{A}$ & 0.0896 & 0.1090 & Crude oil tanker \\
\hline 35 & $D D_{\text {TIME }}$ vs $S_{A}$ & 0.2220 & 0.2076 & Crude oil tanker \\
\hline 36 & $D D_{\text {TIME }}$ vs $S_{A}$ & 0.0754 & 0.0727 & Chemical tanker \\
\hline 37 & $D D_{\text {TIME }}$ vs $S_{A}$ & 0.1541 & 0.1555 & Chemical tanker \\
\hline 38 & $D D_{\text {TIME }}$ vs $S_{A}$ & $0.0017(-)$ & $0.0005(-)$ & Bulk carrier \\
\hline 39 & $D D_{\text {TIME }}$ vs $S_{A}$ & $0.0576(-)$ & $0.0444(-)$ & Bulk carrier \\
\hline 40 & $D D_{\text {TIME }}$ vs $S_{A}$ & 0.0799 & 0.0825 & Container carrier \\
\hline 41 & $D D_{\text {TIME }}$ vs $S_{A}$ & 0.1382 & 0.1484 & Container carrier \\
\hline 42 & $D D_{\text {TIME }}$ vs $S_{A}$ & 0.0706 & 0.0644 & L.P.G. carrier \\
\hline 43 & $D D_{\text {TIME }}$ vs $S_{A}$ & $0.0037(-)$ & NA & L.P.G. carrier \\
\hline 44 & $D D_{\text {TIME }}$ vs $S_{A}$ & 0.0303 & 0.0294 & Car carrier \\
\hline 45 & $D D_{\text {TIME }}$ vs $S_{A}$ & 0.1477 & NA & Car carrier \\
\hline 46 & $D D_{\text {TIME }}$ vs $S_{A}$ & 0.0018 & 0.0191 & General cargo carrier \\
\hline 47 & $D D_{\text {TIME }}$ vs $S_{A}$ & $0.1254(-)$ & NA & General cargo carrier \\
\hline
\end{tabular}

\section{DRY-DOCKING LABOUR ANALYSIS}

Initial investigations of pairs of variables of interests related to dry-docking labour are shown in Figures.48-67 from different viewpoints. Corresponding $r^{2}$ values assuming a linear relationship and non-linear relationship (exponential) are presented in Tables 8, 9, 10 and 11.

\subsection{DEADWEIGHT}

Dry-docking labour and corresponding deadweight of ships are analysed to determine a trend or pattern between those irrespective of age and type. The results are presented in Figures.48-51. 
Figures 48-49 show the observed dry-docking labour and average dry docking labour (average by deadweight group) respectively. Both figures suggest that with a change of deadweight, dry-docking labour does change and the regression line has a slightly negative slope. It suggests that a weak linear relationship exists between dry-docking time and deadweight. Therefore, deadweight does have an influence on dry-docking labour. It means that bigger ships unlikely need higher dry-docking labour compared to smaller ships.

Figures 50 and 51 shows the observed dry-docking labour as a fraction of ship repairing labour against deadweight and average dry-docking labour as a fraction of ship repairing labour (average by deadweight) against deadweight respectively. It suggests that with a change of deadweight, dry-docking labour as a fraction of ship repairing labour does change and the regression line has a slightly positive slope. It suggests that a linear relationship exists between dry-docking labour as a fraction of ship repairing labour and deadweight. Therefore, deadweight does have an influence on drydocking labour as a fraction of ship repairing labour. It means that bigger ships unlikely need higher dry-docking labour compared to smaller ships.

In Table 8, one can easily find that for any particular relationship (Figures.48-51), the values of $r^{2}$ for a linear relationship are higher compared to an exponential relationship.

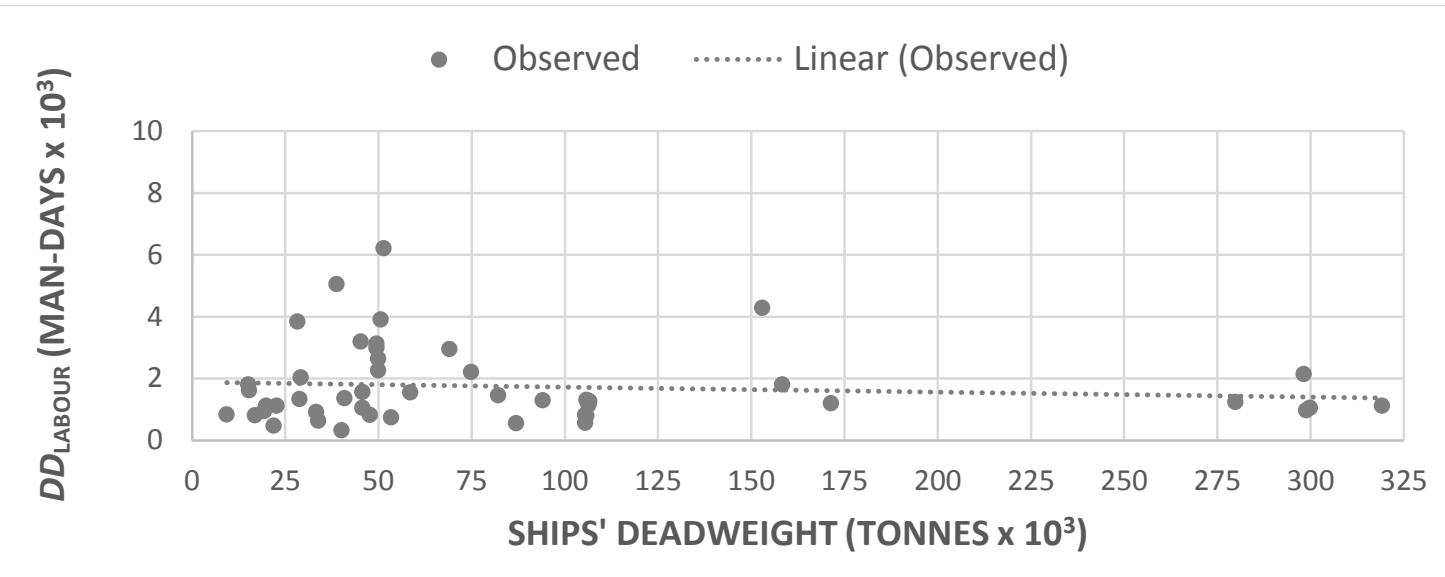

Figure.48 Dry-docking labour versus ships' deadweight of sample ships

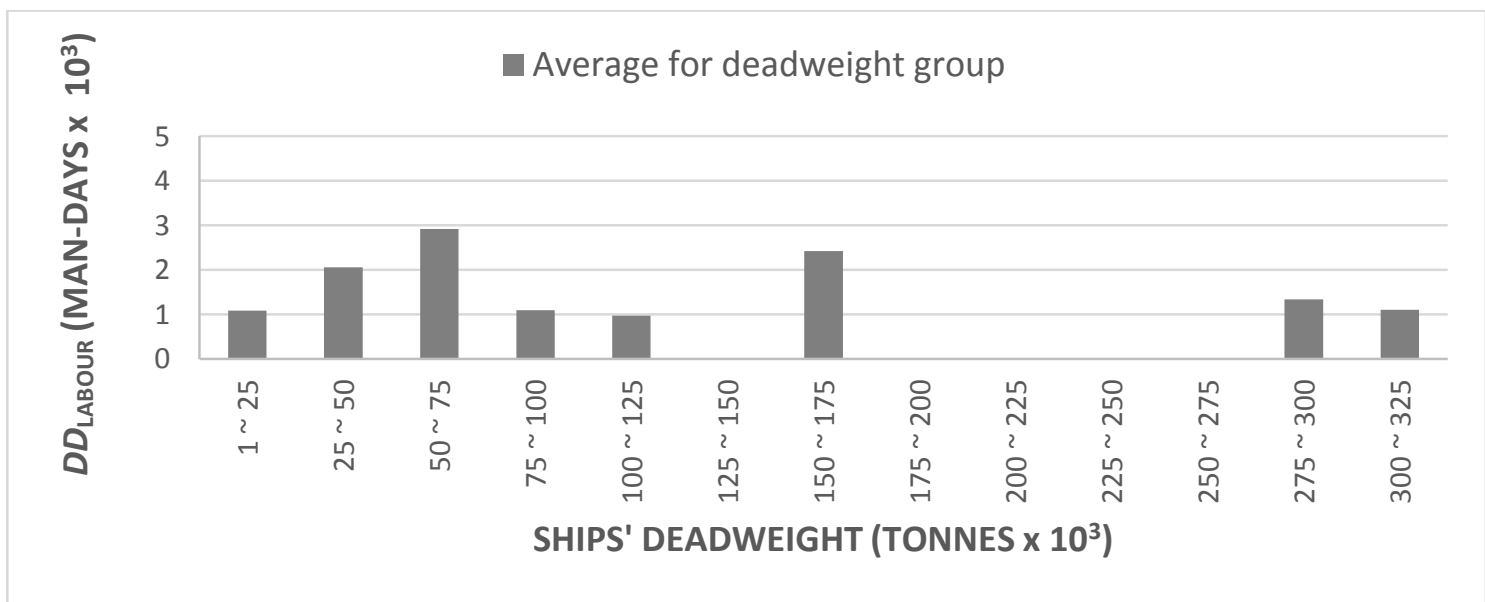

Figure.49 Average dry-docking labour versus ships' deadweight of sample ships 


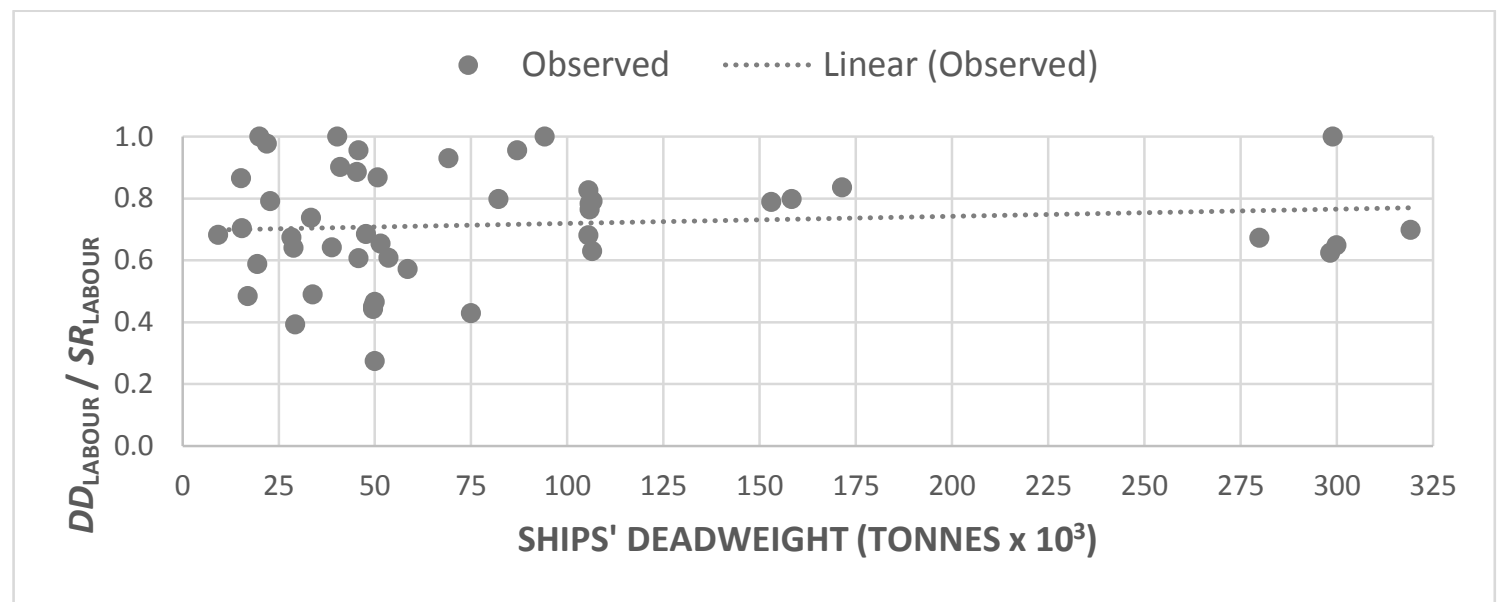

Figure.50 Dry-docking labour as fraction of $S R_{\text {LABOUR }}$ versus ships' deadweight of sample ships

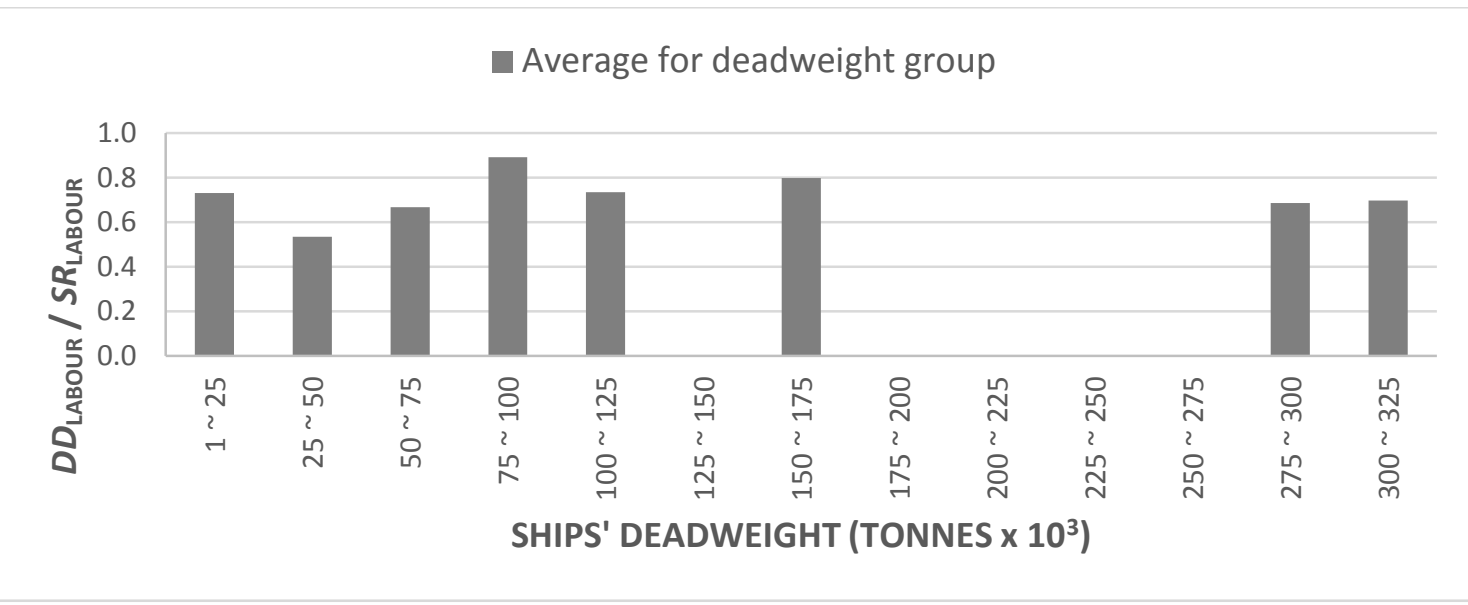

Figure.51 Average dry-docking labour as fraction of $S R_{\mathrm{LABOUR}}$ versus ships' deadweight of sample ships

Table 8 Summary of correlation coefficients of linear and exponential relationships

\begin{tabular}{|l|l|l|l|l|}
\hline \multirow{2}{*}{$\begin{array}{l}\text { Figure } \\
\text { No. }\end{array}$} & \multirow{2}{*}{ Variables } & \multicolumn{2}{|l|}{$r^{2}$ values } & \multirow{2}{*}{ Remarks } \\
\cline { 3 - 4 } & & Linear & Exponential & \\
\hline 48 & $D D_{\text {LABOUR }}$ vs $S_{\mathrm{D}}$ & $0.0116(-)$ & $0.0021(-)$ & Sample ships \\
\hline 50 & $\begin{array}{l}D D_{\text {LABOUR }} / S R_{\text {LABOUR }} \\
\text { VS } S_{\mathrm{D}}\end{array}$ & 0.0110 & 0.0173 & Sample ships \\
\hline
\end{tabular}

\subsection{AGE}

Dry-docking labour and corresponding age are analysed to determine a trend or pattern between those irrespective of their deadweight and type. The results are presented in the graphical form in Figures.52-55.

Figures 52-53 show the observed dry-docking labour and average dry docking labour (average by age group) respectively. Both figures suggest that with a change of age, dry-docking labour does change and the regression line has a sharp positive slope. It suggests that a linear relationship exists between dry-docking labour and age. Therefore, age does have a significant an influence on dry-docking labour. It means that older ships, most unlikely, need higher dry-docking labour compared to smaller ships.

Figures 54-55 show the observed dry-docking labour as a fraction of ship repairing labour against age and average dry docking labour as a fraction of ship repairing labour (average by age group) against age respectively. Both figures suggest that with a change of age, dry-docking labour does change and the regression line has a negative slope (Figure.54). Mathematically, negative slope means that contribution of dry-docking labour to ship repairing labour decreases with increase of age. It suggests that a linear relationship exists between dry-docking labour and 
age of a ship. Therefore, age of ships does have an influence on dry-docking labour. It means that older ships are expected to have higher dry-docking labour compared to smaller ships.
In Table 9, one can easily find that for any particular relationship (Figures.52-55), the values of $r^{2}$ for a linear relationship are higher compared to an exponential relationship except Figure.53.

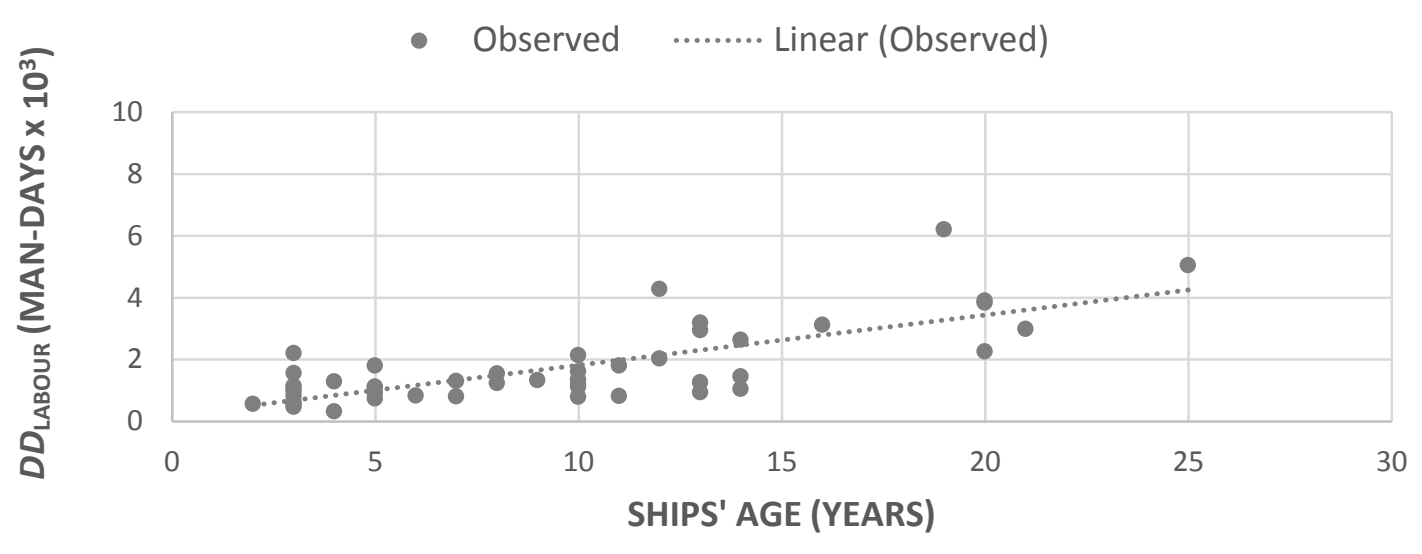

Figure.52 Dry-docking labour versus ships’ age of sample ships.

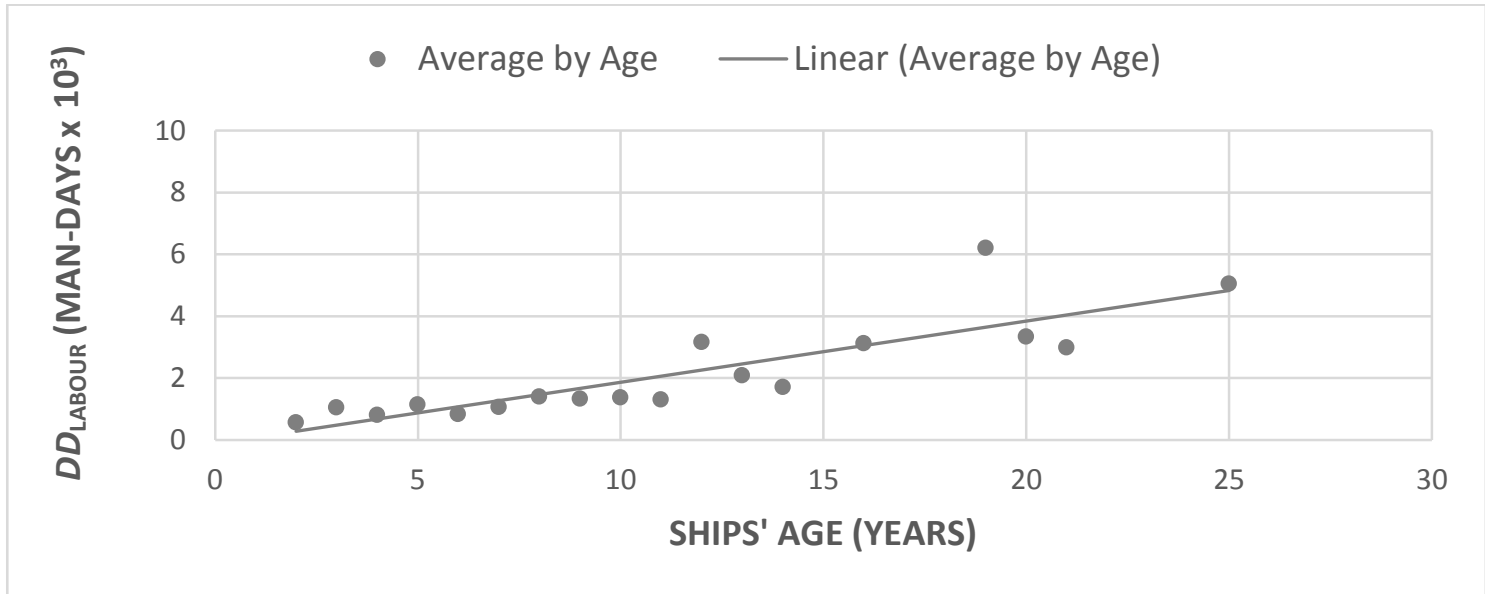

Figure.53 Average dry-docking labour versus ships’ age for sample ships

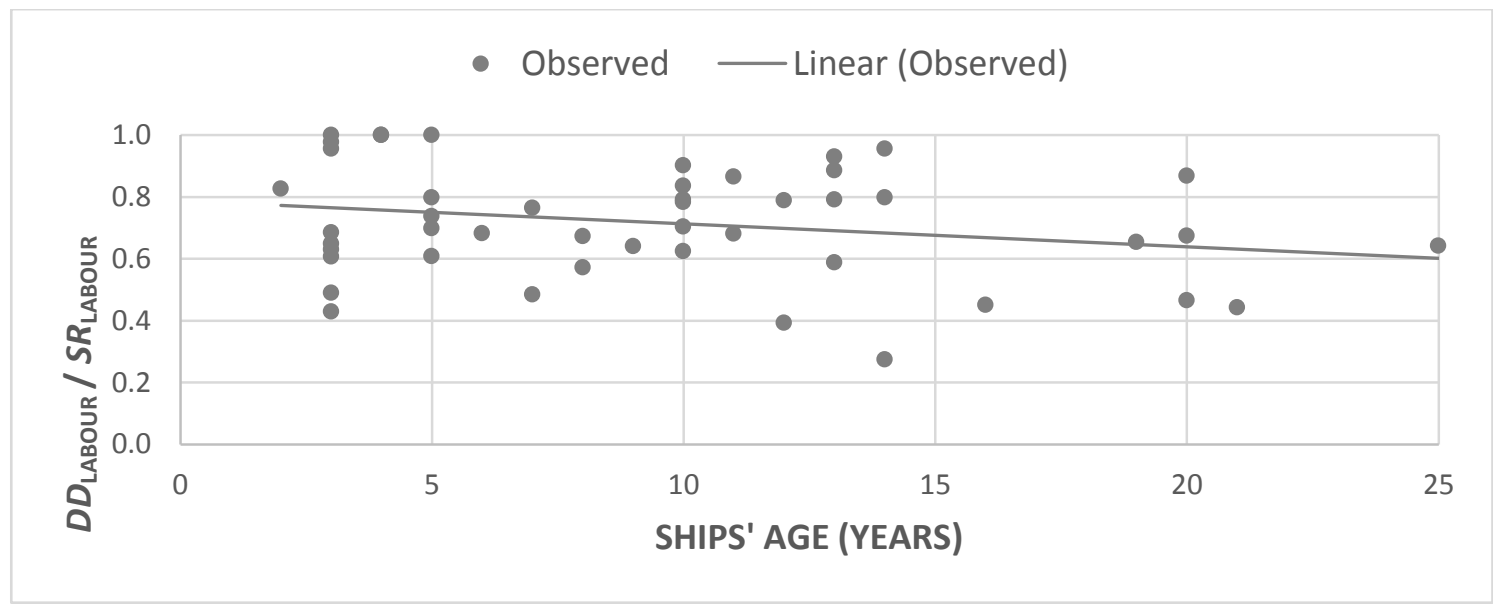

Figure.54 Dry-docking labour as fraction of $S R_{\text {LABOUR }}$ versus ships' age of sample ships 


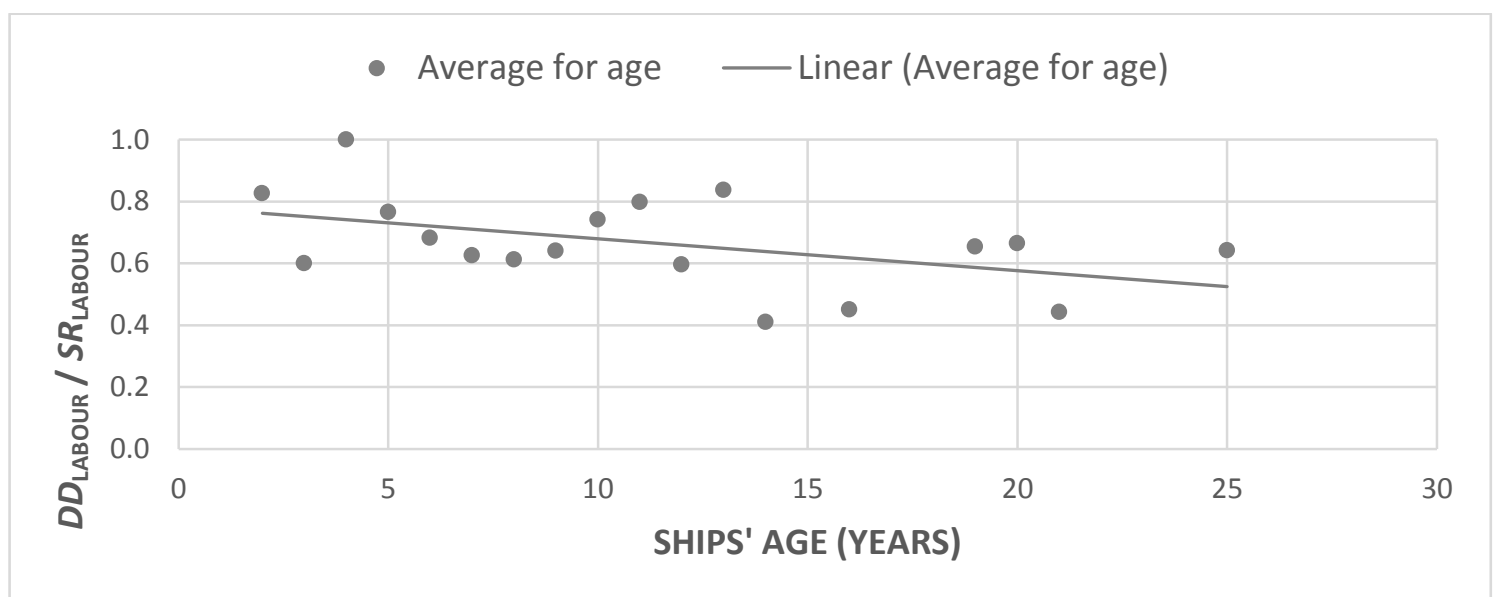

Figure.55 Average dry-docking labour as fraction of $S R_{\mathrm{LABOUR}}$ versus ships' age of sample ships

Table 9 Summary of correlation coefficients of linear and exponential relationships

\begin{tabular}{|l|l|l|l|l|}
\hline \multirow{2}{*}{$\begin{array}{l}\text { Figure } \\
\text { No. }\end{array}$} & \multirow{2}{*}{ Variables } & \multicolumn{2}{|l|}{$r^{2}$ values } & \multirow{2}{*}{ Remarks } \\
\cline { 3 - 4 } & & Linear & Exponential & \\
\hline 52 & $D D_{\text {LABOUR }}$ vs $S_{\mathrm{A}}$ & 0.5635 & 0.5556 & Sample ships \\
\hline 53 & $D D_{\text {LABOUR }}$ vs $S_{\mathrm{A}}$ & 0.7247 & 0.8406 & Sample ships \\
\hline 54 & $\begin{array}{l}D D_{\text {LABOUR }} / S R_{\text {TIME }} \text { vs } \\
S_{\mathrm{A}}\end{array}$ & 0.0576 & 0.0559 & Sample ships \\
\hline 55 & $\begin{array}{l}D D_{\text {LABOUR }} / S R_{\text {TIME }} \text { vs } \\
S_{\text {A }}\end{array}$ & $0.2158(-)$ & $0.2100(-)$ & Sample ships \\
\hline
\end{tabular}

\subsection{TYPE}

Dry-docking labour and corresponding type of ships are analysed to determine a trend or pattern between those irrespective of their deadweight and age. The result is presented in the graphical form in Figures.56-57.

Figure 56 shows the average dry-docking labour for ship type. It shows that with a change of type, dry-docking labour does change. It suggests that type does have an influence on dry-docking labour. It means that different type of ships will have different dry-docking labour even though they are of same deadweight and age.

Figure 57 shows dry-docking labour as a fraction of ship repairing labour against type. It suggests that type has some impact on dry-docking labour.

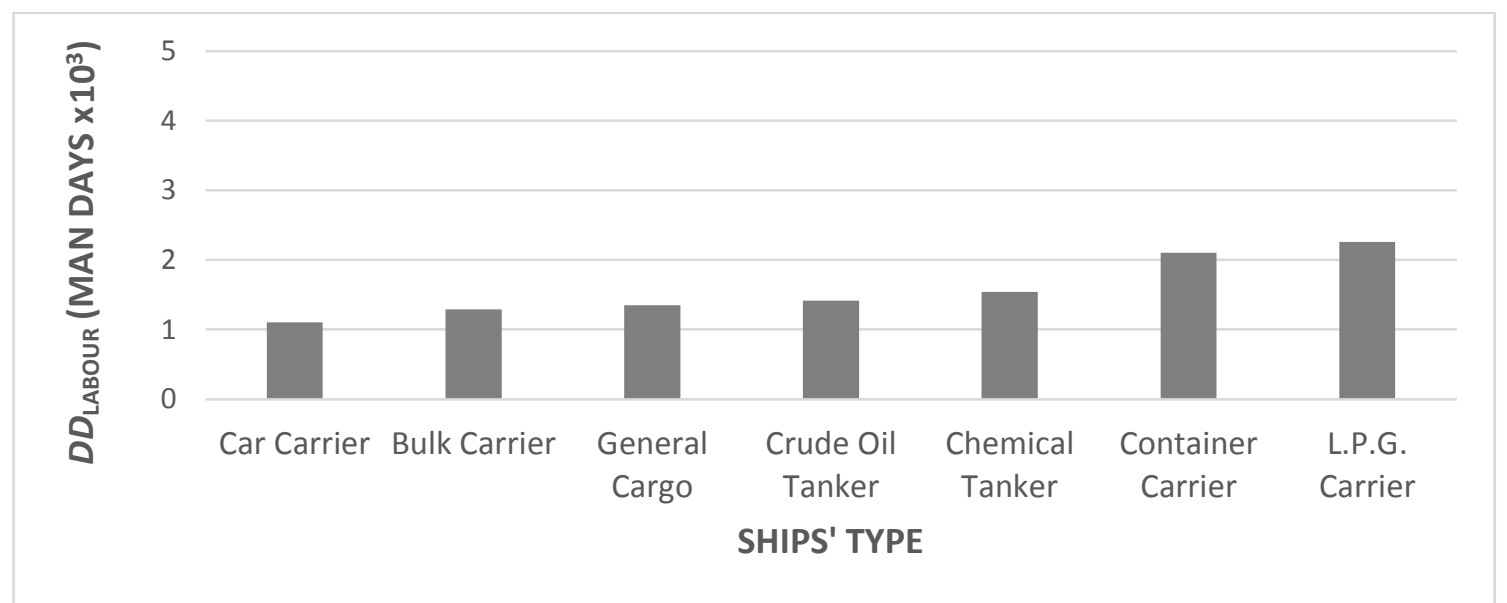

Figure.56 Average dry-docking labour versus ships' type of sample ships 


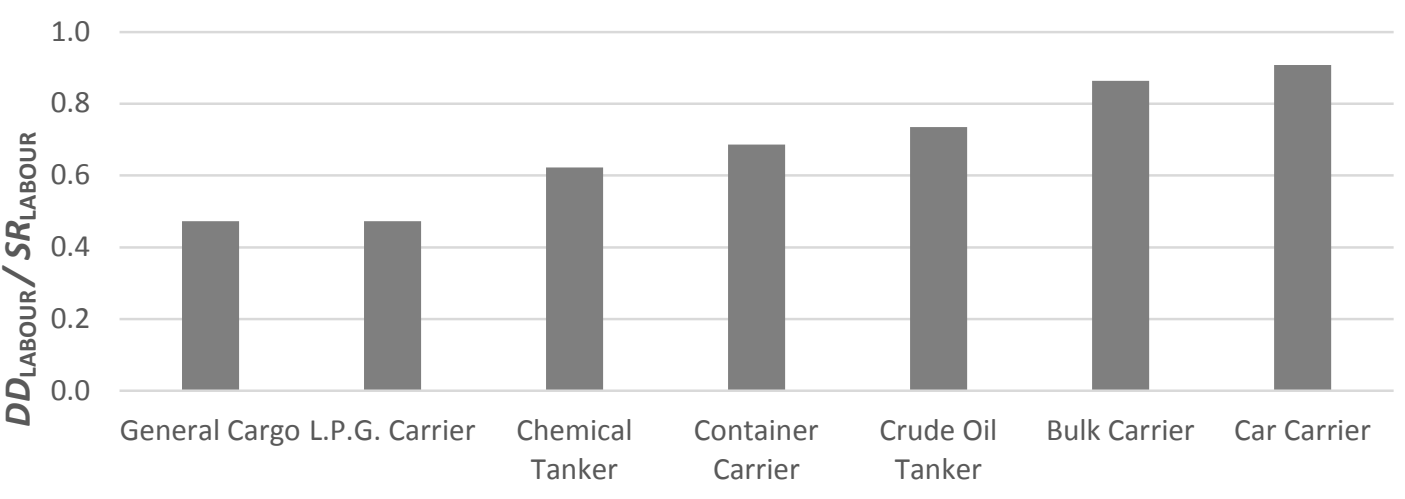

SHIPS' TYPE

Figure.57 Average dry-docking labour as fraction of $S R_{\mathrm{LABOUR}}$ versus ships' type of sample ships

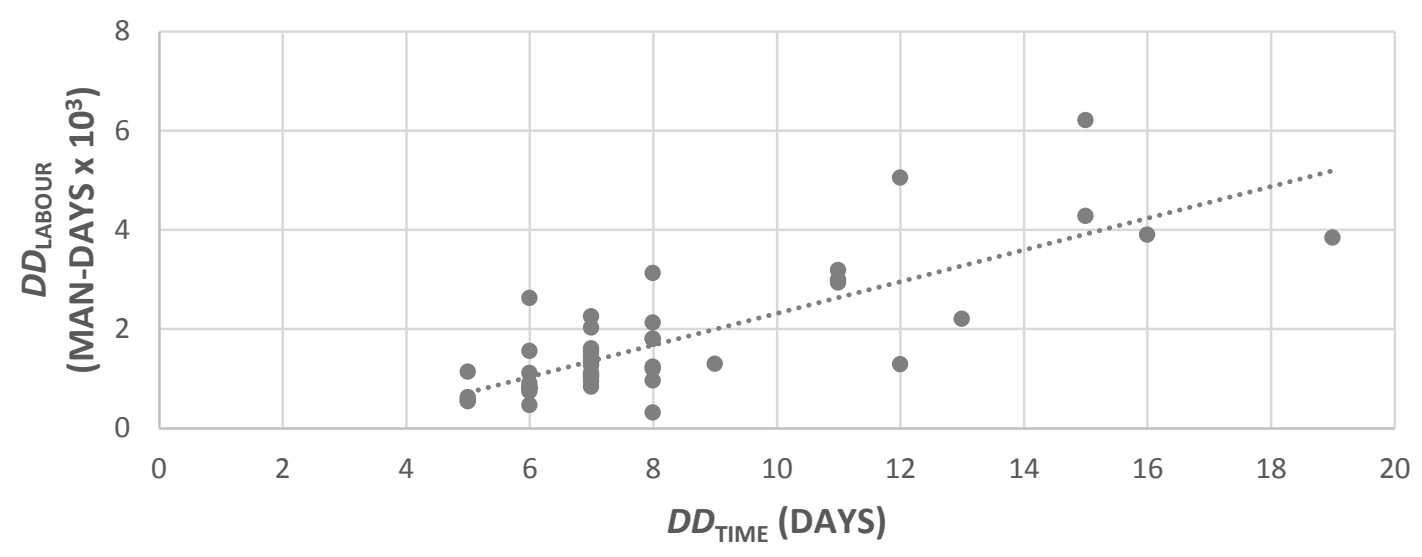

Figure.58 Dry-docking labour (man-days) versus dry-docking time (days)

\subsection{DRY-DOCKING TIME}

Dry-docking labour and corresponding dry-docking time are analysed irrespective of deadweight, age and type. The results are presented in Figure.58. It demonstrates a strong relationship and suggests that with a change of dry-docking time, dry-docking labour does change sharply and the regression line has a sharp positive slope. Therefore, drydocking time does have a strong influence on dry-docking time. It means that longer dry-docking time will consume higher dry-docking labour and it is very much expected.

\subsection{DEADWEIGHT AND TYPE}

Dry-docking labour and corresponding deadweight are analysed for various types of ships irrespective of their age. The results are presented in Figures.59-63 for crude oil tankers, chemical tankers, bulk carriers, container carriers, L.P.G. carriers respectively.

Figure 59 shows the observed dry-docking labour against deadweight for crude oil tankers. It suggests that with a change of deadweight, dry-docking labour does change and the regression line has a slight positive slope (almost horizontal). It suggests that a very weak linear relationship exists between dry-docking labour and deadweight of crude oil tankers. Therefore, deadweight of crude oil tankers does not have a significant influence on dry-docking labour. It means that bigger crude oil tankers do not necessarily need higher dry-docking labour compared to smaller ones.

Figure 60 shows the observed dry-docking labour against deadweight for chemical tankers. It suggests that with a change of deadweight, dry-docking labour does change and the regression line has a positive slope. It suggests that a linear relationship exists between dry-docking labour and deadweight of chemical tankers. Therefore, deadweight of chemical tankers does have an influence on dry-docking labour. It means that the bigger chemical tankers likely need higher dry-docking labour compared to smaller ones.

Figure 61 shows the observed dry-docking labour against deadweight for bulk carriers. It suggests that with a change of deadweight, dry-docking labour does change and the regression line has a slight negative slope (almost horizontal). It suggests that a very weak linear relationship exists between dry-docking labour and deadweight of bulk carriers. Therefore, deadweight of bulk carriers does not 
have a significant influence on dry-docking labour. It means that bigger bulk carriers unlikely need higher dry-docking labour compared to smaller ones.

Figure 62 shows the observed dry-docking labour against deadweight for container carriers. It suggests that with a change of deadweight, dry-docking labour does change and the regression line has a positive slope. It suggests that a linear relationship exists between dry-docking labour and deadweight of container carriers. Therefore, deadweight of container carriers does have an influence on dry-docking labour. It means that bigger container carriers likely need higher dry-docking labour compared to smaller ones.

Figure 63 shows the observed dry-docking labour against deadweight for L.P.G. carriers. It suggests that with a change of deadweight, dry-docking labour does change and the regression line has a sharp positive slope. It suggests that a strong linear relationship exists between dry-docking labour and deadweight of L.P.G. carriers. Therefore, deadweight of L.P.G. carriers does have an influence on dry-docking labour. It means that bigger L.P.G. carriers most likely need higher dry-docking labour compared to smaller ones.

Mathematically, the negative slope of a regression line (Figure.61) means that the rate of increase in deadweight (x-axis) is comparatively higher than the rate of increase in dry-docking labour (y-axis).

In Table 10, one can easily find that for a particular relationship (Figures.59-63), the values of $r^{2}$ for a linear and an exponential relationship, are very close, except Figures.59, 60 and 63.

Based on $r^{2}$ values, maximum relationships have fair goodness of fit to a linear relationship. Therefore, it is not biased to consider a general assumption that drydocking labour is a function of deadweight irrespective of age and type and they are linearly associated. More specifically, bigger ships are expected to have higher dry-docking labour compared to smaller ships.

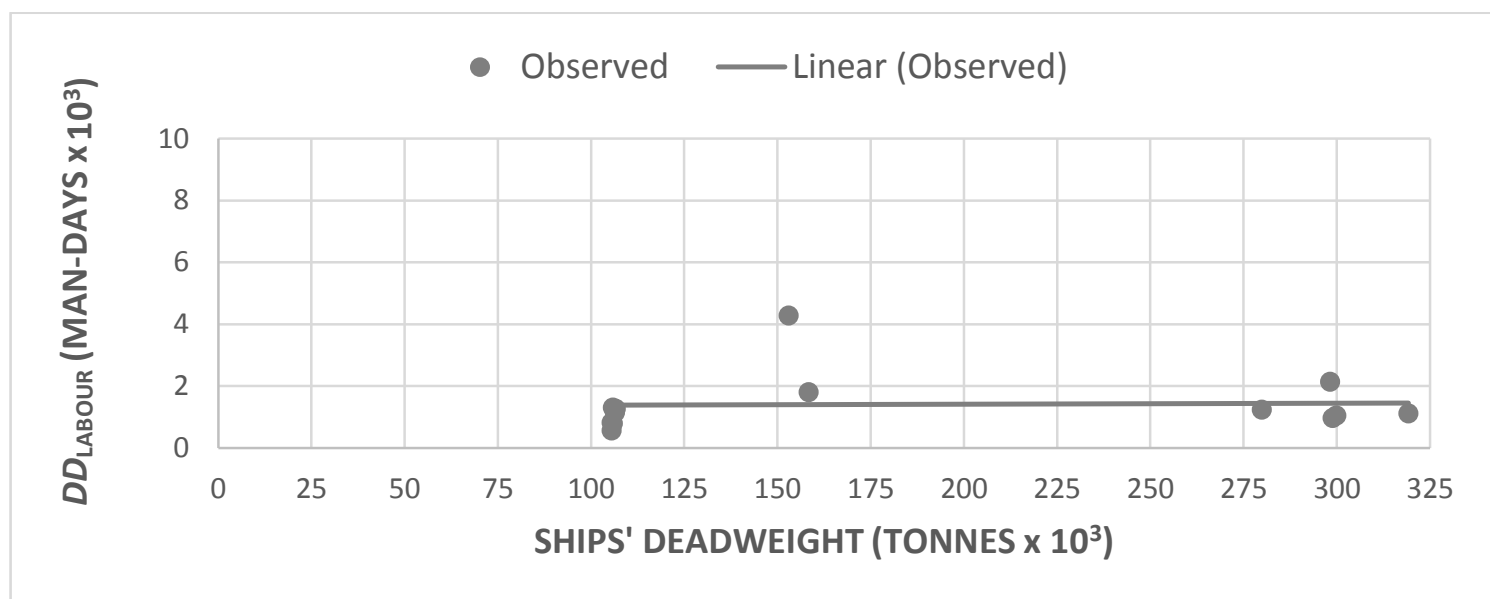

Figure.59 Dry-docking labour versus ships' deadweight for crude oil tankers

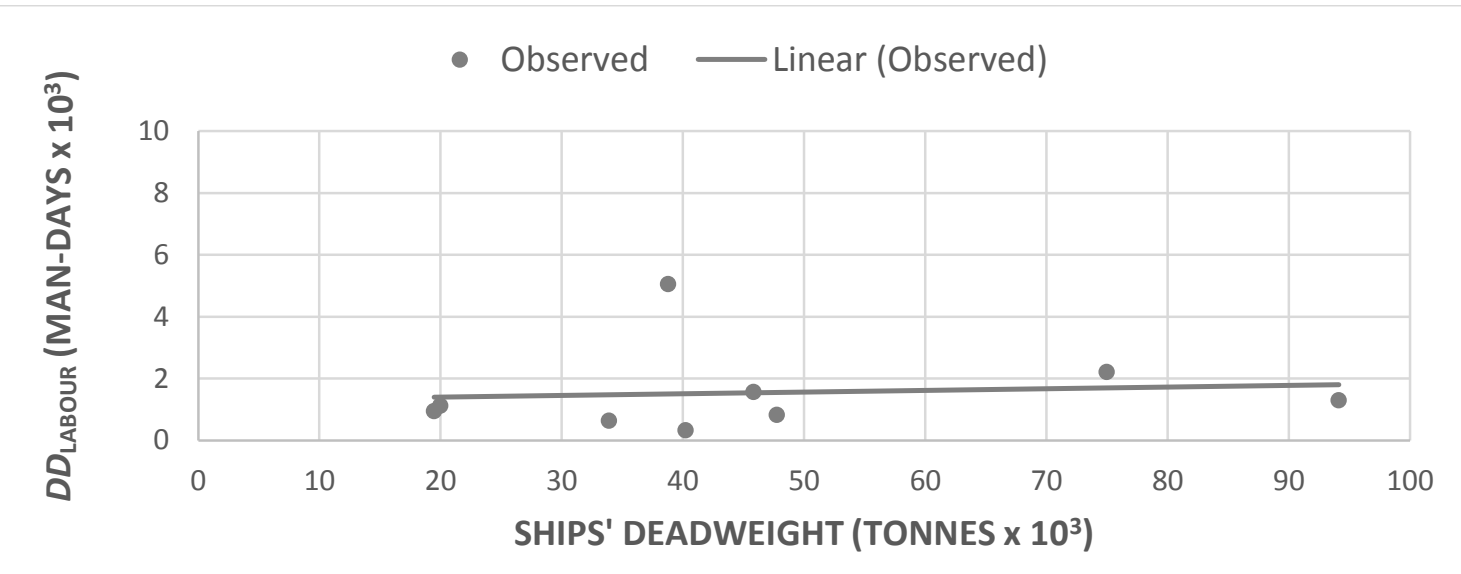

Figure.60 Dry-docking labour versus ships’ deadweight for chemical tankers 


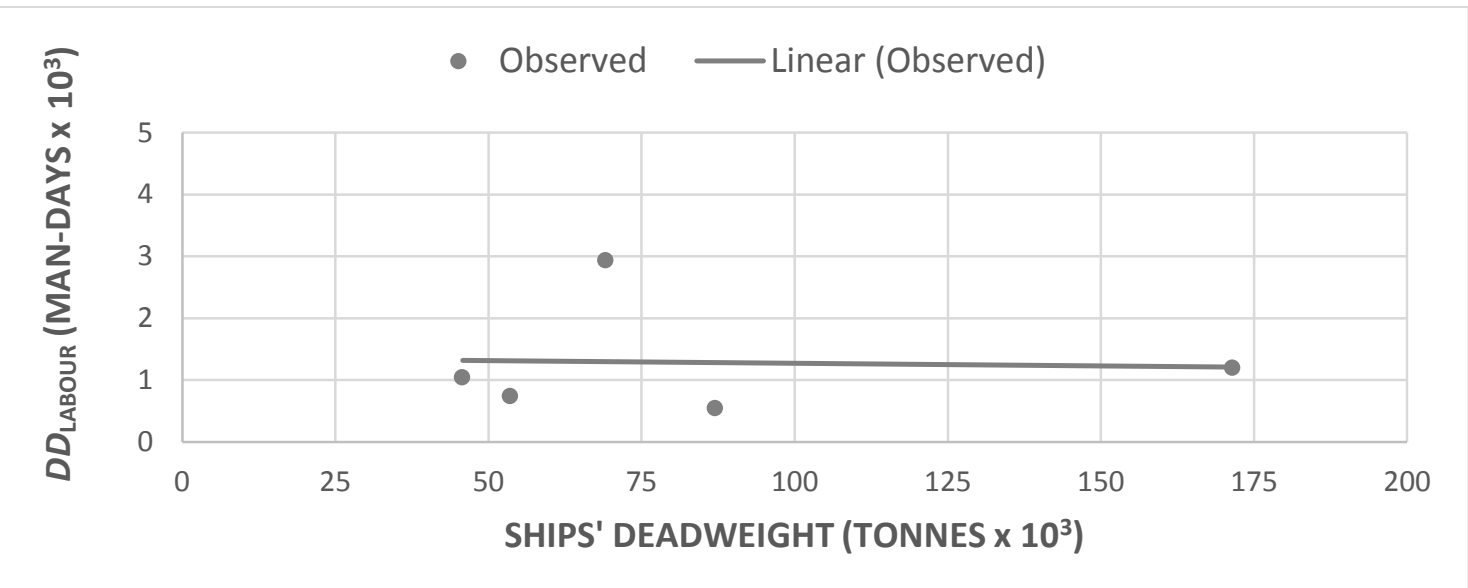

Figure.61 Dry-docking labour versus ships’ deadweight for bulk carriers

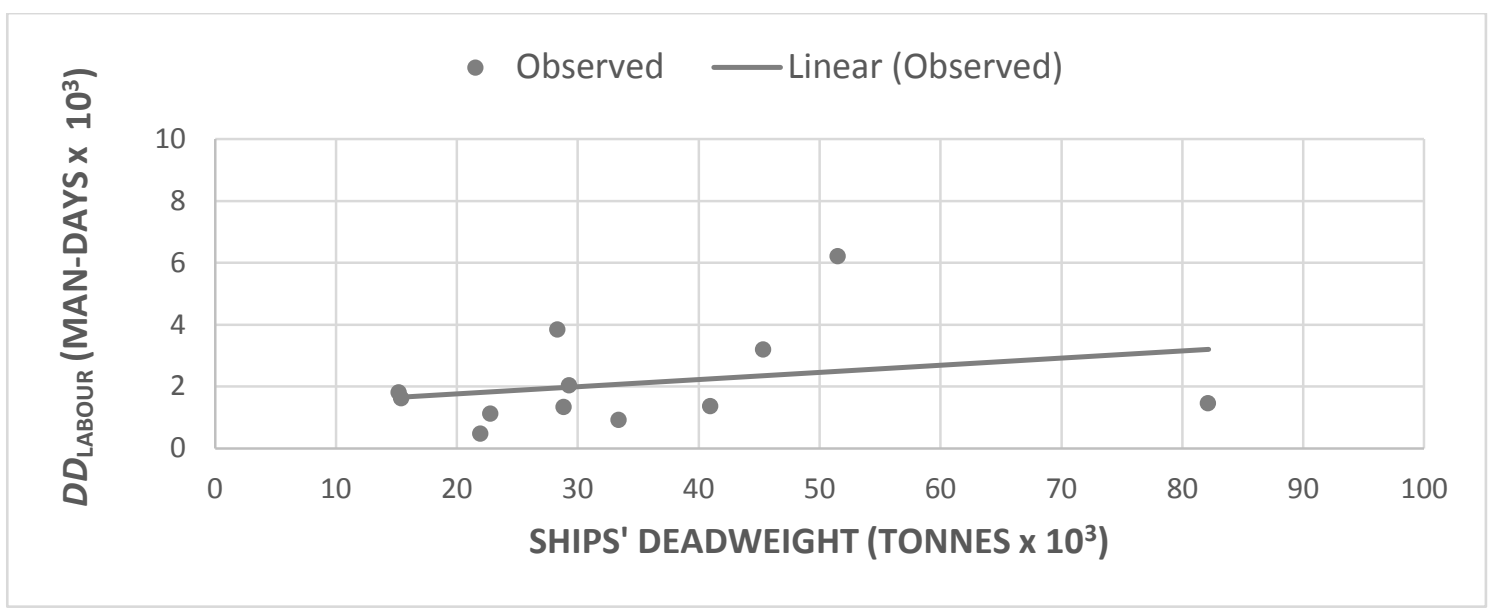

Figure.62 Dry-docking labour versus ships' deadweight for container carriers

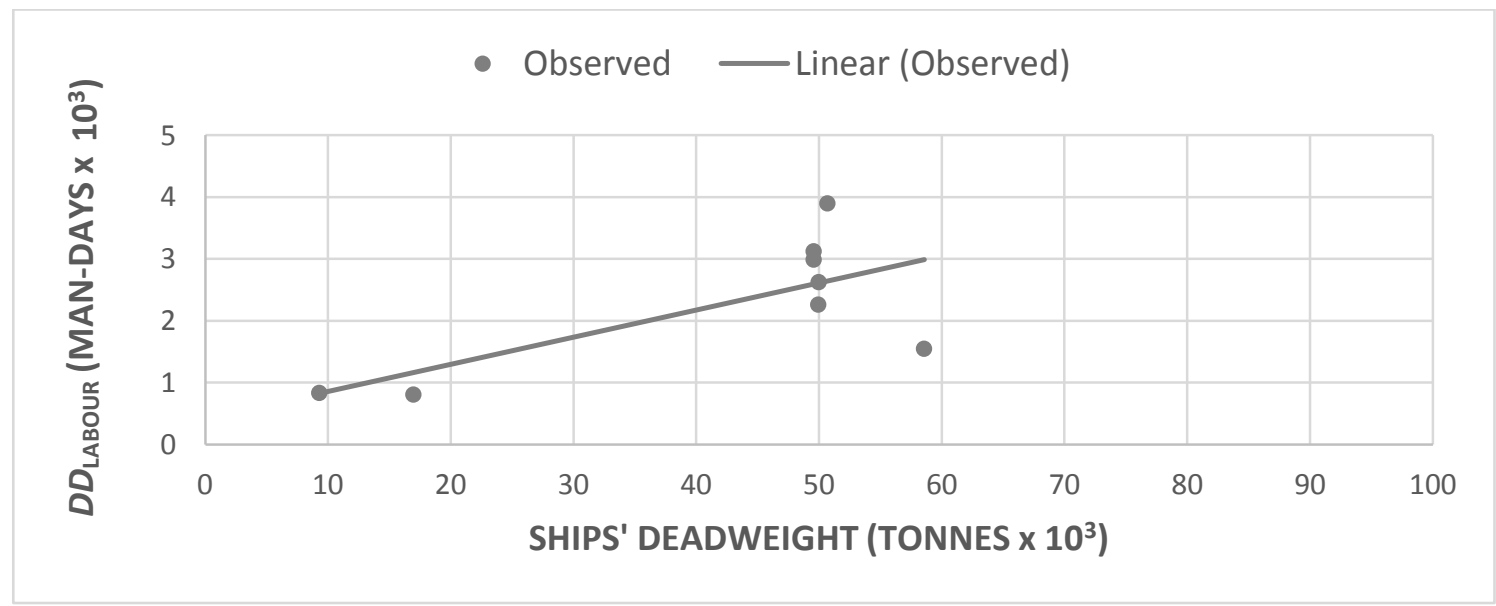

Figure.63 Dry-docking labour versus ships’ deadweight for L.P.G. carriers 
Table 10 Summary of correlation coefficients of linear and exponential relationships

\begin{tabular}{|l|l|l|l|l|}
\hline \multirow{2}{*}{ Figure No. } & \multirow{2}{*}{ Variables } & \multicolumn{2}{|l|}{$r^{2}$ values } & \multirow{2}{*}{ Remarks } \\
\cline { 3 - 4 } & & Linear & Exponential & \\
\hline 59 & $D D_{\text {LABOUR }}$ vs $S_{\mathrm{D}}$ & 0.0010 & 0.0207 & Crude oil tanker \\
\hline 60 & $D D_{\text {LABOUR }}$ vs $S_{\mathrm{D}}$ & 0.0086 & 0.0497 & Chemical tanker \\
\hline 61 & $D D_{\text {LABOUR }}$ vs $S_{\mathrm{D}}$ & $0.0020(-)$ & $0.0014(-)$ & Bulk carrier \\
\hline 62 & $D D_{\text {LABOUR }}$ vs $S_{\mathrm{D}}$ & 0.0727 & 0.0699 & Container carrier \\
\hline 63 & $D D_{\text {LABOUR }}$ vs $S_{\mathrm{D}}$ & 0.5039 & 0.6687 & L.P.G. carrier \\
\hline
\end{tabular}

Table 11 Summary of correlation coefficients of linear and exponential relationships

\begin{tabular}{|l|l|l|l|l|}
\hline \multirow{2}{*}{ Figure No. } & \multirow{2}{*}{ Variables } & \multicolumn{2}{|l|}{$r^{2}$ values } & \multirow{2}{*}{ Remarks } \\
\cline { 3 - 4 } & & Linear & Exponential & \\
\hline 64 & $D D_{\text {LABOUR }}$ vs $\mathrm{S}_{\mathrm{A}}$ & 0.1985 & 0.1965 & Crude oil tanker \\
\hline 65 & $D D_{\text {LABOUR }}$ vs $\mathrm{S}_{\mathrm{A}}$ & 0.6526 & 0.3841 & Chemical tanker \\
\hline 66 & $D D_{\text {LABOUR }}$ vs $\mathrm{S}_{\mathrm{A}}$ & 0.4148 & 0.5964 & Bulk carrier \\
\hline 67 & $D D_{\text {LABOUR }}$ vs $\mathrm{S}_{\mathrm{A}}$ & 0.7107 & 0.8462 & Container carrier \\
\hline 68 & $D D_{\text {LABOUR }}$ vs $\mathrm{S}_{\mathrm{A}}$ & 0.7537 & 0.7799 & L.P.G. carrier \\
\hline
\end{tabular}

\subsection{AGE AND TYPE}

Dry-docking labour and corresponding age are analysed for various types of ships irrespective of their deadweight. The results are presented in Figures.64-68 for crude oil tankers, chemical tankers, bulk carriers, container carriers, L.P.G. carriers respectively.

Figure 64 shows the observed dry-docking labour against age for crude oil tankers. It suggests that with a change of age, dry-docking labour does change and the regression line has a positive slope. It suggests that a linear relationship exists between dry-docking labour and age of crude oil tankers. Therefore, age of crude oil tankers does have a significant influence on the drydocking labour. It means that older crude oil tankers most likely need higher dry-docking labour compared to newer ones.

Figure 65 shows the observed dry-docking labour against age for chemical tankers. It suggest that with a change of age, dry-docking labour does change and the regression line has a sharp positive slope. It suggests that a linear relationship exists between drydocking labour and age of chemical tankers. Therefore, age of chemical tankers does have a significant influence on dry-docking labour. It means that older chemical tankers most likely need higher dry-docking labour compared to newer ones.
Figure 66 shows the observed dry-docking labour against age for bulk carriers. It suggest that with a change of age, dry-docking labour does change and the regression line has a sharp positive slope. It suggests that a linear relationship exists between dry-docking labour and age of bulk carriers. Therefore, age of bulk carriers does have an influence on dry-docking labour. It means that older bulk carriers most likely need higher dry-docking labour compared to newer ones.

Figure 67 shows the observed dry-docking labour against age for container carriers. It suggest that with a change of age, dry-docking labour does change and the regression line has a sharp positive slope. It suggests that a linear relationship exists between dry-docking labour and age of container carriers. Therefore, age of container carriers does have an influence on dry-docking labour. It means that older container carriers most likely need higher drydocking labour compared to newer ones.

Figure 68 shows the observed dry-docking labour against age for L.P.G. carriers. It suggest that with change of age, dry-docking labour does change and the regression line has a sharp positive slope. It suggests that a linear relationship exists between dry-docking labour and age of L.P.G. carriers. Therefore, age of L.P.G. carriers does have influence on dry-docking labour. It means that older L.P.G. 
carriers most likely need higher dry-docking labour compared to newer ones.

In Table 11, one can easily find that for a particular relationship (Figures.64-68), the values of $r^{2}$ for a linear and an exponential relationship, are very close and higher than an exponential relationship except Figures.65, 66 and 67.
Based on $r^{2}$ values, maximum relationships have fair goodness of fit to a linear relationship. Therefore, it is not biased to consider a general assumption that drydocking labour is a function of age irrespective of size and type and they are linearly associated. More specifically, older ships are most likely to have higher dry-docking labour compared to newer ships.

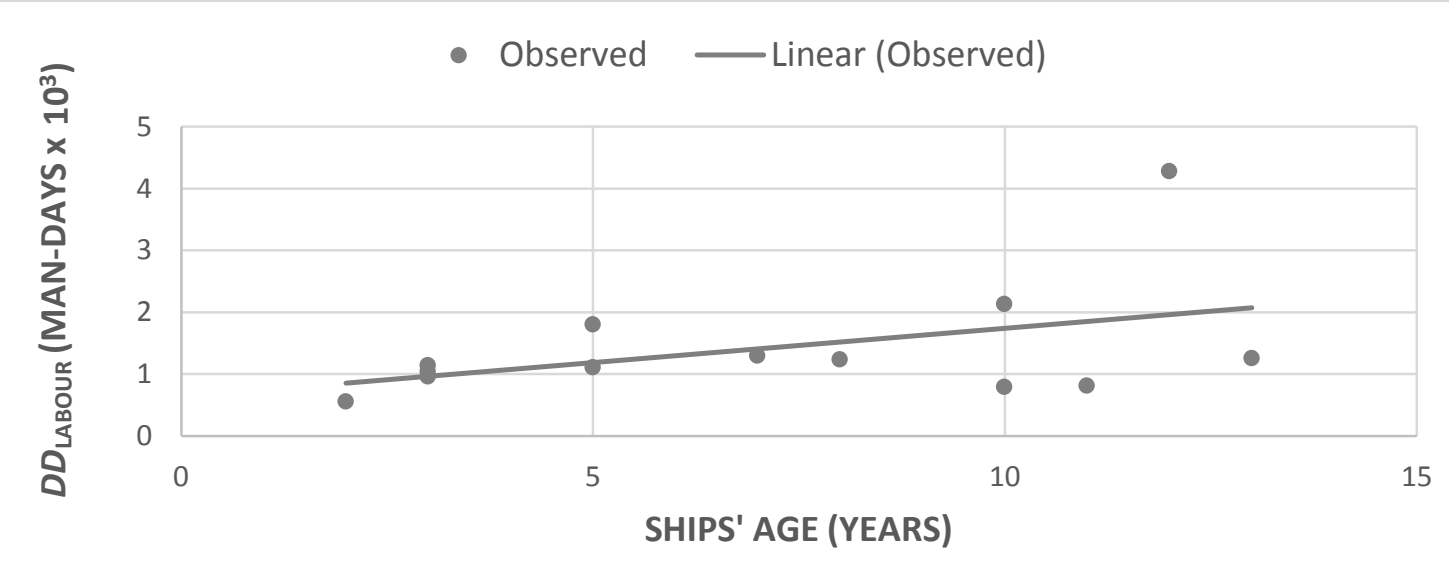

Figure.64 Dry-docking labour versus ships' age for crude oil tankers

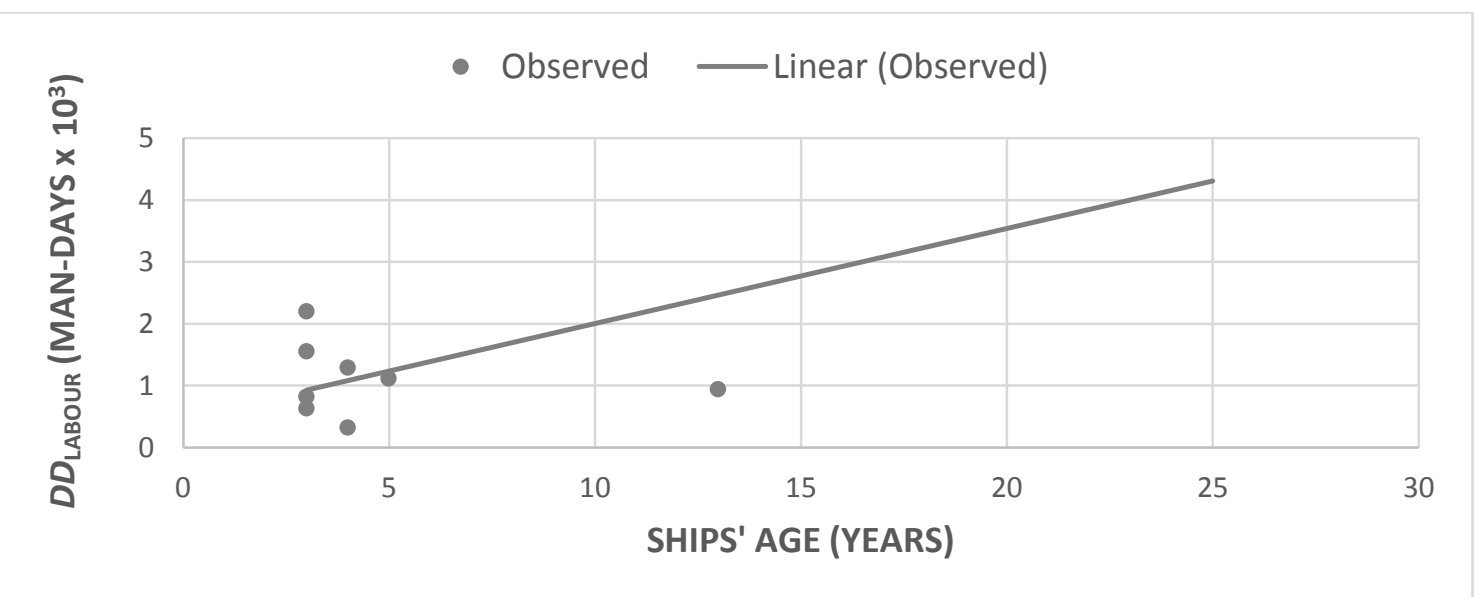

Figure.65 Dry-docking labour versus ships' age for chemical tankers

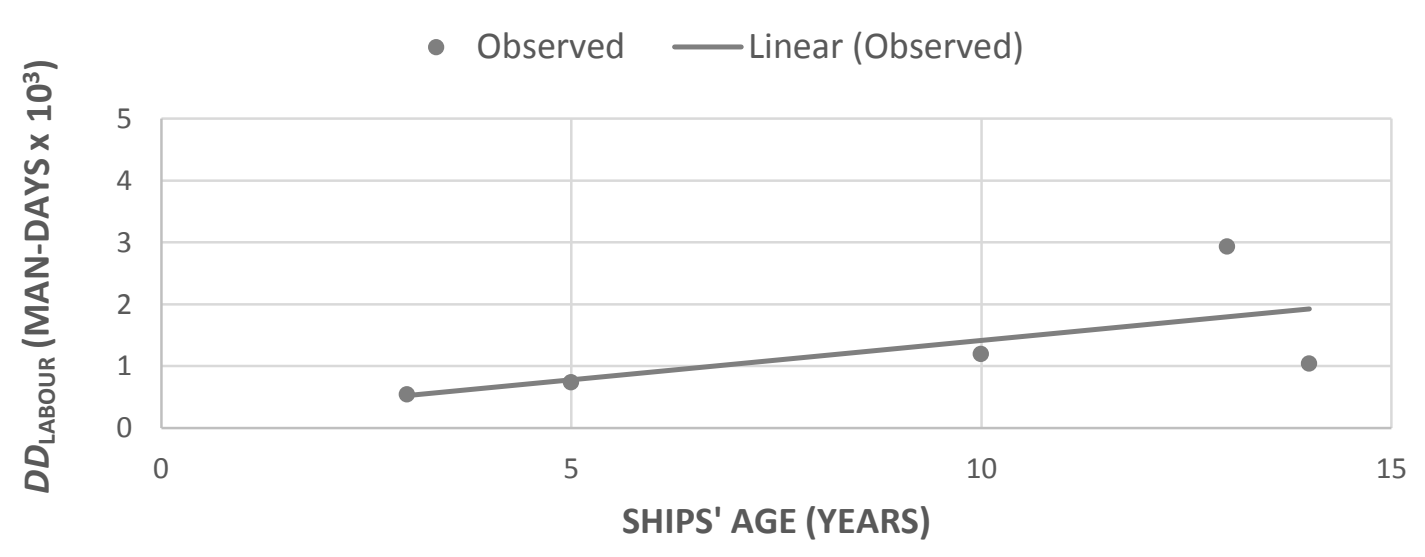

Figure.66 Dry-docking labour versus ships’ age for bulk carriers 


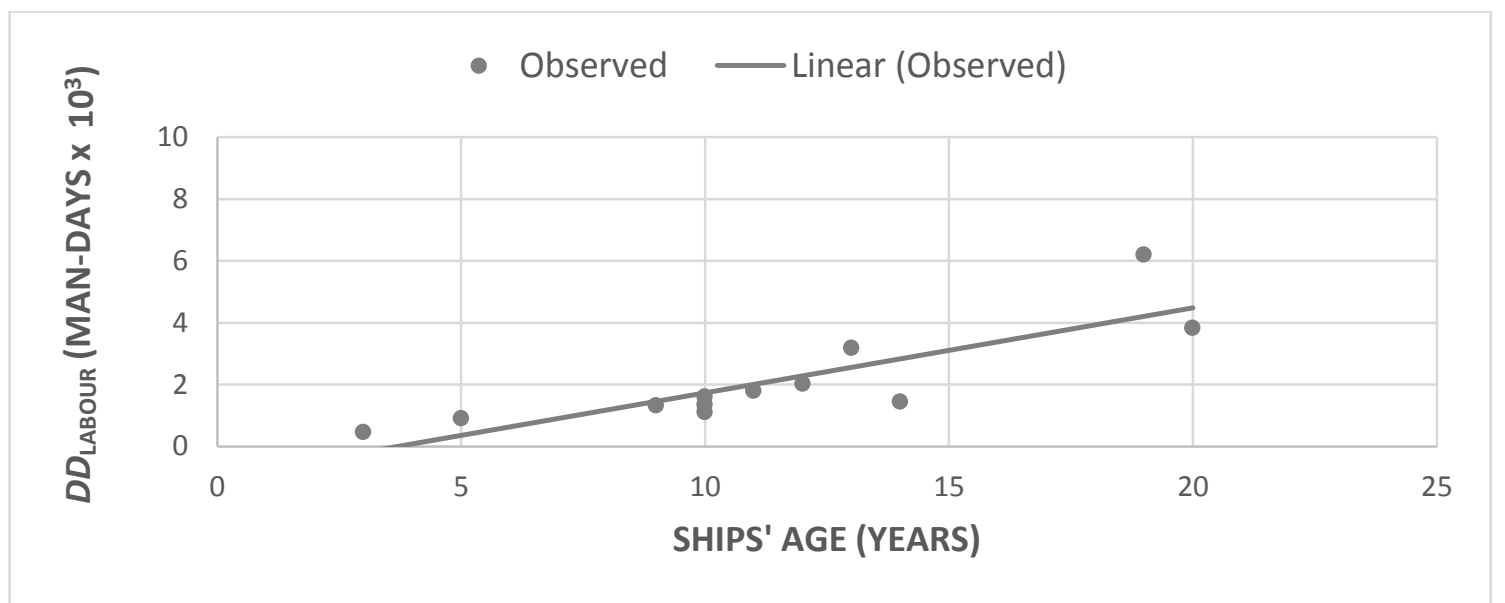

Figure.67 Dry-docking labour versus ships' age for container carriers

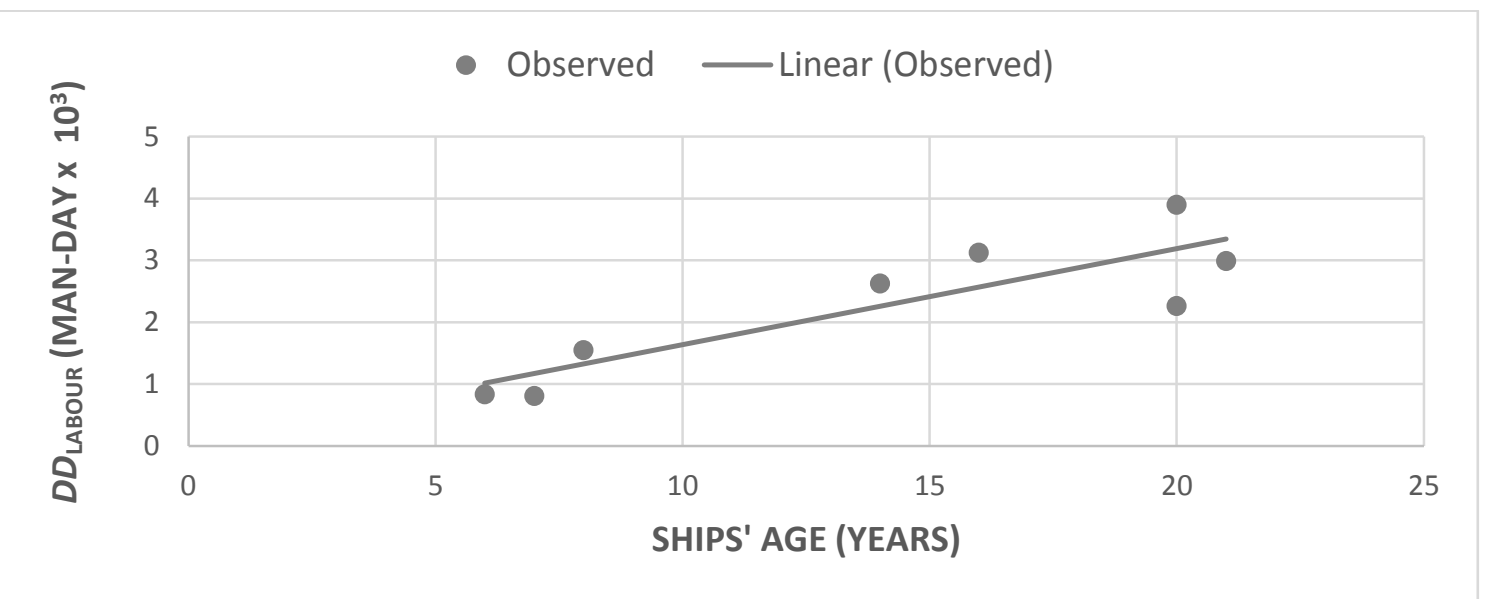

Figure.68 Dry-docking labour versus age for L.P.G. carriers

\section{DISCUSSION}

\subsection{GENERAL}

The research reveals some fundamental facts regarding dry-docking time (days) and labour (mandays) for various types of ships irrespective of their deadweight and age. The longest average dry-docking time was found to be 11.40 days for dredgers, followed by 8.00 days for L.N.G. carriers, 7.57 days for crude oil tankers, 7.29 days for container carriers, 7.07 days for car carriers, 6.67 days for general cargo carriers, 6.63 days for L.P.G. carriers and so on, irrespective of deadweight and age (Table 2, and Figure.18). Likewise, the highest dry-docking labour was found to be 2,258 man-days for L.P.G. carriers, followed by 2,104 man-days for container carriers, 1,543 man-days for chemical tankers and so on, irrespective of size and age (Table 3 and Figure.56).

The contribution of dry-docking time and labour to ship repairing time and labour (\%) respectively for various types of ship is presented in Table 12 and in Figure.69 using Table 2 and 3. One can easily identify in Table 12 that dry-docking time varies from $30 \%$ for L.P.G. carriers to $60 \%$ for container carriers, of their ship repairing time irrespective of deadweight and age. Whereas, dry-docking labour varies from $48 \%$ for L.P.G. carriers to $86 \%$ for bulk carriers, of their ship repairing labour irrespective of deadweight and age. This 
behaviour re-confirms the fact that labour consumption rate (man/day) during dry-docking is higher than that of alongside with a novel objective of reducing dry-docking duration. This basic information may serve as a useful guideline for both owner and yard.

Table 12 Summary of dry-docking time and labour as \% of ship repairing time and labour for different types of ship

\begin{tabular}{|l|l|l|}
\hline Types & $\begin{array}{l}D D_{\text {TIME }} \text { as a fraction } \\
\text { of } S R_{T I M E}(\%)\end{array}$ & $\begin{array}{l}D D_{\text {LABOUR }} \text { as a fraction of } S R_{\text {LABOUR }} \\
(\%)\end{array}$ \\
\hline Livestock Carrier & 24.05 & NA \\
\hline LPG Carrier & 31.42 & 47.31 \\
\hline LNG Carrier & 34.41 & 51.32 \\
\hline Crude Oil Tanker & 36.80 & 73.45 \\
\hline Ore Carrier & 45.16 & NA \\
\hline Bulk Carrier & 46.16 & 86.43 \\
\hline Chemical Tanker & 46.37 & 62.19 \\
\hline Wood Carrier & 50.00 & NA \\
\hline General Cargo Carrier & 53.62 & 47.22 \\
\hline Car Carrier & 56.70 & 90.79 \\
\hline Container Carrier & 58.52 & 68.65 \\
\hline Dredger & 58.76 & NA \\
\hline
\end{tabular}

* NA: Not Available

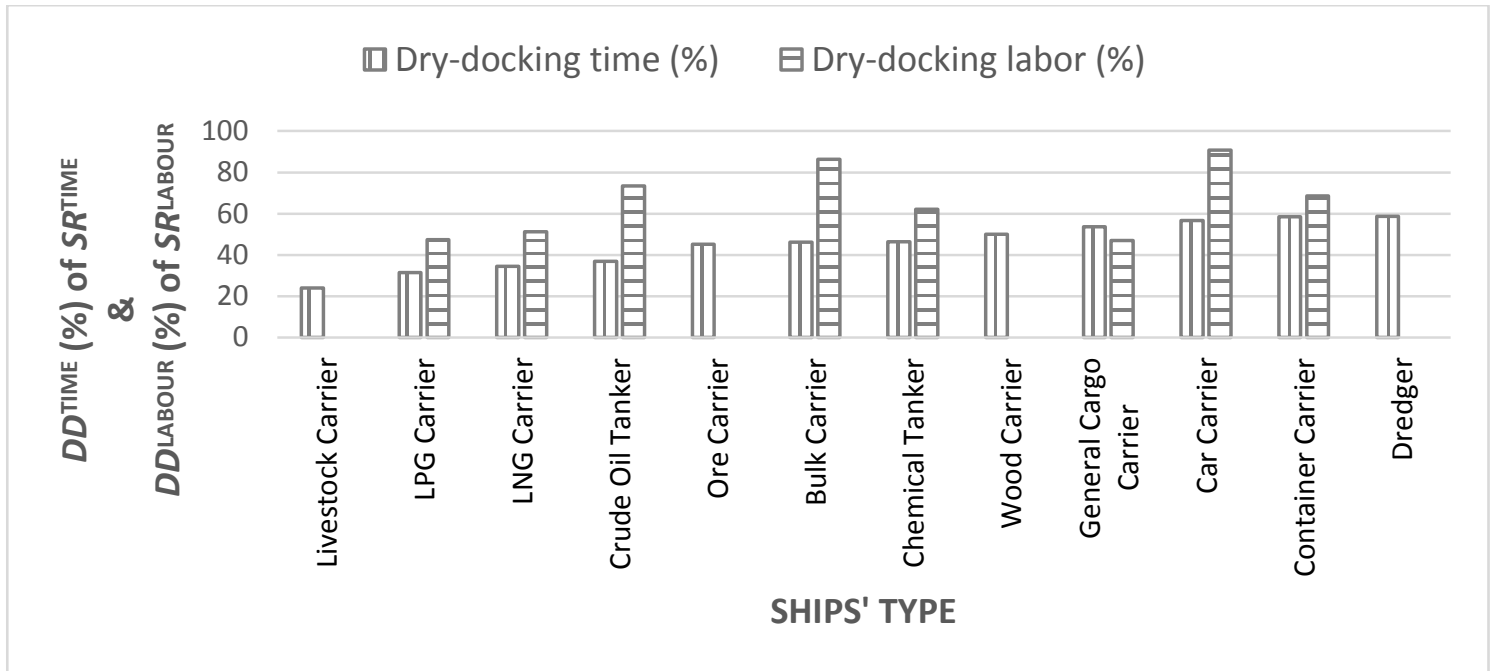

Figure.69 Average dry-docking time and labour as \% of ship repairing time and labour versus ships' type of sample ships

\subsection{DRY-DOCKING TIME}

The influence of assumed independent variables that control dry-docking time, such as, deadweight, age and type, is demonstrated in Figures.10-47. Figures 10-19 describe the relationship of dry-docking time on deadweight, age and type. A detail explanation of figures is given in sections 5.1, 5.2 and 5.3 respectively. Figures 20-33 describe the relationship of dry-docking time on deadweight for various types of ships. A detail explanation of figures is given in sections 5.4. Figures 34-47 describe the relationship of dry-docking time on age for various types of ships. A detail explanation of figures is given in section 5.5. All these figures suggest that the aforementioned independent variables have a positive influence on dry-docking time but within the close range with a different response level from variable to variable.

Data analyses of dry-docking time against deadweight suggest that dry-docking time does change widely and inconsistently with change in deadweight (Figure.10). It means that deadweight does have an impact on its drydocking time. It is also observed that the average drydocking time against various deadweight intervals varies between 6 and 8 days with a mean of 7 days (Figure.11). 
Data analyses of dry-docking time against age suggest that dry-docking time does change widely and inconsistently with change of age (Figure.14). It means that age does have an impact on its dry-docking time. It also appears that average dry-docking time against various age varies between 6 and 8 days with a mean of 7 days (Figure.15).

Data analyses of dry-docking time against type irrespective of deadweight and age suggest that drydocking time does change widely with a change of type of ship (Figure.18). It means that different types of ships will need different dry-docking time and it varies from 6 days to 8 days.

Same phenomena of dry-docking time against deadweight and age are observed in various types (Figures.20 through 47). It also appears that the average dry-docking time against various types of ships irrespective of deadweight and age, varies between 6 days (for general cargo ships and chemical tankers) and 8 days (for L.N.G carriers) with a mean of 7 days (Figure.18).

Figures 13 and 17 demonstrate the average contribution of dry- docking time to ship repairing time (\%) against deadweight group and age group respectively. Both figures display a tendency of decrease in the contribution of dry-docking time with an increase in deadweight and age. This behavior is very much expected and explained in the next paragraph.

It is shown in (Dev, A.Kr and Saha, M 2015) that the ship repairing time and dry-docking time, independently, is a function of age and those are linearly associated. Both increase with an increase of age but at a different rate. Ship repairing time increases at a higher rate than that of dry-docking time. It is why the contribution of ships' dry-docking time to ship repairing time $\left(D D_{\mathrm{TIME}} /\right.$ $S R_{\mathrm{TIME}}$ ), decreases and the contribution of quay-side time increases with an increase of age to satisfy the below relationship (Equation 8). Figure 70 demonstrates the above-mentioned behaviour.

$\frac{D D_{T I M E}}{S R_{T I M E}}+\frac{Q S_{T I M E}}{S R_{T I M E}}=1$
It is also observed that after a certain age, the contribution of dry-docking time is almost constant. This phenomenon is equally true for deadweight.

\subsection{DRY-DOCKING LABOUR}

The influence of independent variables that control drydocking labour, such as, deadweight, age and type, is demonstrated in Figures.48-67. Figures 48-57 describe the relationship of dry-docking labour on deadweight, age and type. A detail explanation of figures is given in sections 6.1, 6.2 and 6.3 respectively. Figure 58 describes the relationship of dry-docking labour on dry-docking time. A detail explanation is given in section 6.4. Figures 59-63 describe the relationship of dry-docking labour on deadweight for various type. A detail explanation of figures is given in sections 6.5. Figures 64-68 describe the relationship of dry-docking labour on age for various types of ships. Detail explanation of figures are given in sections 6.6. All these figures suggest that the aforementioned independent variables have a positive influence on the dry-docking labour but within the close range with a different response from variable to variable.

Data analyses of dry-docking labour against deadweight suggest that dry-docking labour does change widely with a change in deadweight (Figure.48). It means that deadweight of a ship does have an impact on its drydocking labour. It also observed that the average drydocking labour against various deadweight intervals varies between 1,000 and 3,000 man-days with a mean of 1,763 man-days (Figure.49).

Data analyses of dry-docking labour against age suggest that dry-docking labour does change widely with a change of age (Figure.52). It means that age of ship does have an impact on its dry-docking labour. It also appears that the average dry-docking labour against various age varies between 555 man-days for 2 years old and 6,204 man-days for 19 years old with a mean of 1,745 mandays (Figure.53).

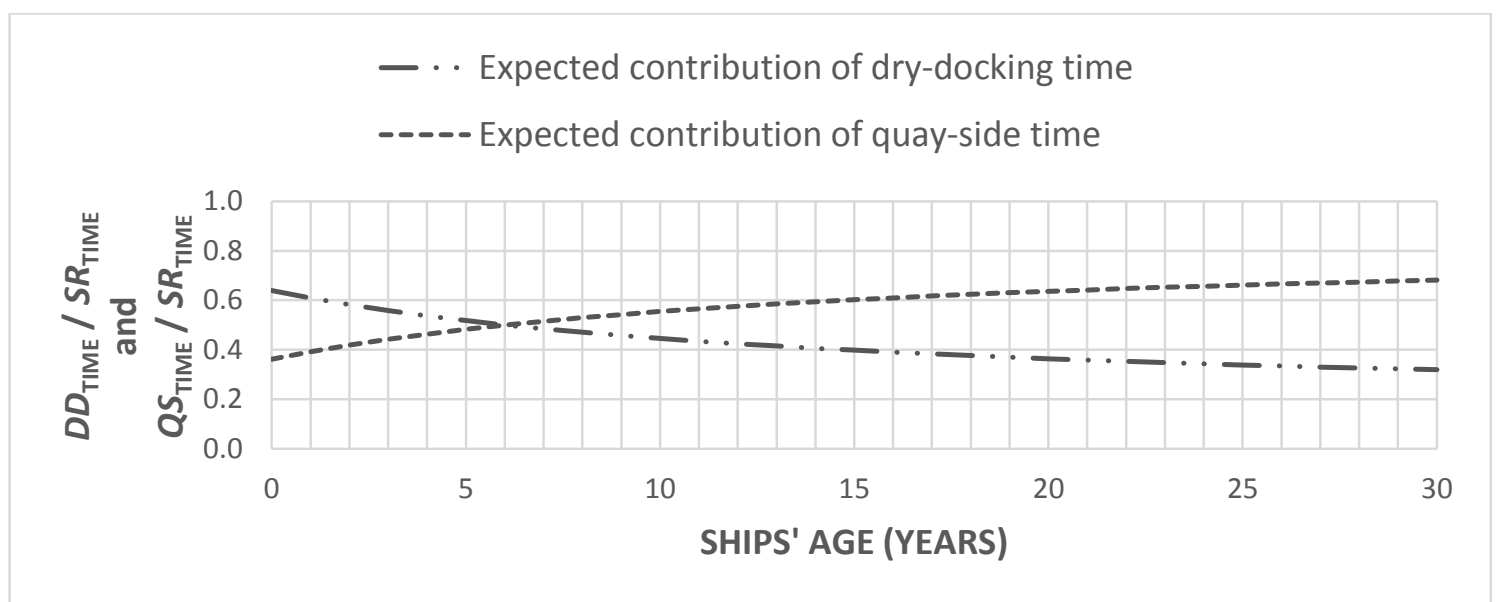

Figure.70 Contribution of dry-docking time and quay-side time to ship repairing time versus age of sample ships 


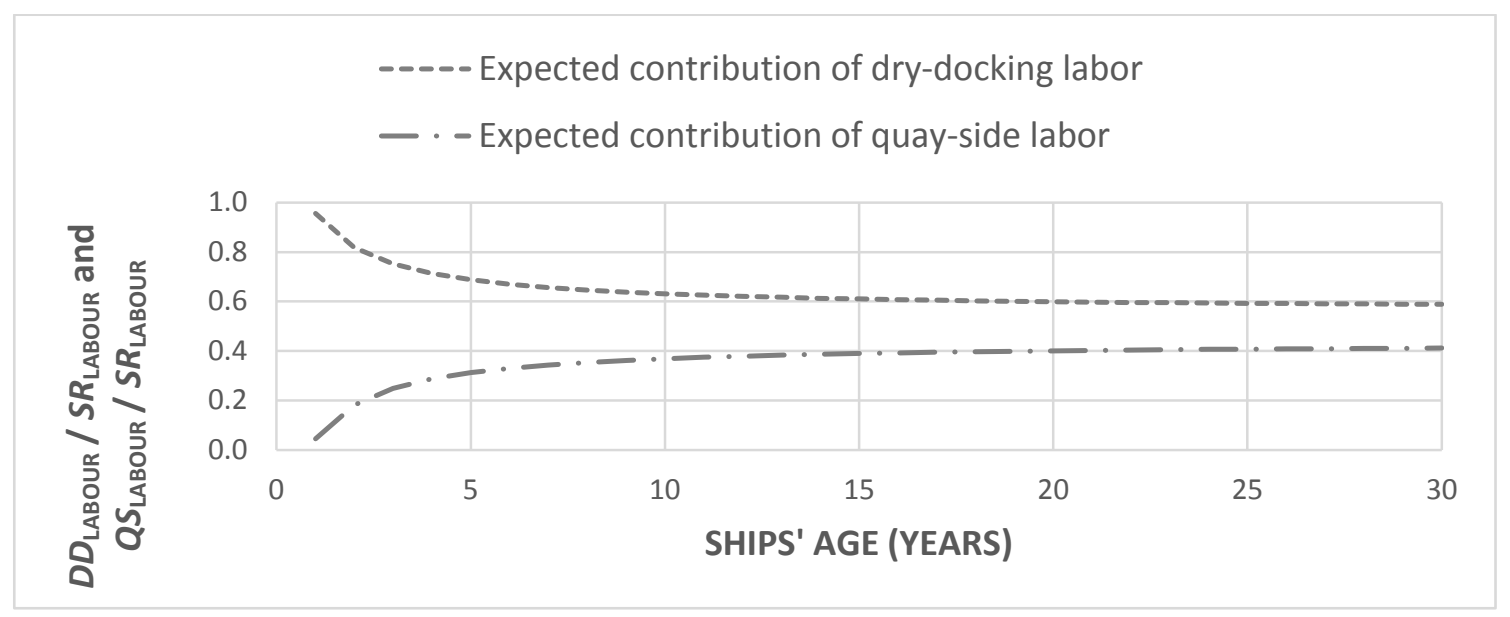

Figure.71 Contributions of dry-docking labour and quay-side labour to ship repairing labour versus age

Data analyses of dry-docking labour against type irrespective of deadweight and age suggest that drydocking labour does change widely with change in type (Figure.56). It means that different types of ship most likely need different dry-docking labour and it varies from 1,287 man-days to 2,258 man-days.

Same phenomena of dry-docking labour against deadweight and age are observed in various types (Figures.59-68). It also appears that average dry-docking labour against various types of ships, irrespective of deadweight and age, varies between 1,287 man-days (for bulk carriers) and 2,258 man-days (for L.P.G carriers).

Figures 51 and 55 demonstrate the contribution of drydocking labour to ship repairing labour (\%) against deadweight group and age group respectively. Both figures display a tendency of decrease in the contribution of ships' dry-docking labour to ship repairing labour with the increase of ships' deadweight and age. This behaviour is very much expected and explained in the next paragraph.

It is shown in (Dev, A.Kr and Saha, M 2016) that the ship repairing labour and dry-docking labour, independently, is a function of ships' age and those are linearly associated. Both increase with the increase of age but at a different rate. Ship repairing labour increases at a higher rate than that of dry-docking labour. This is why the contribution of dry-docking labour to ship repairing labour $\left(D D_{\text {LABOUR }} / S R_{\text {LABOUR }}\right)$, decreases and the contribution of quay-side labour increases with the increase of age to satisfy the below relationship (Equation 9). Figure 71 demonstrates the abovementioned behaviour.

$\frac{D D_{L A B O R}}{S R_{L A B O R}}+\frac{Q S_{L A B O R}}{S R_{L A B O R}}=1$
It is also observed that after certain age, contribution of ships' dry-docking labour is almost constant. This phenomenon is equally true for ships' deadweight.

The comparison of $r^{2}$ values of various relationships under linear and exponential relationships (Table 4-11) is highlighted for reference only for better understanding of trend of dependent variables on the independent variable. No attempt is made to develop and propose any mathematical model to estimate dry-docking time and labour regarding deadweight, age and type of a ship.

Finally, focusing on the various findings, it is unbiased to conclude that the dry-docking time and labour do depend on deadweight, age and type of a ship. Hence, bigger ships and older ships of any type likely need longer drydocking time, and labour for routine maintenance works.

\subsection{APPLICATION OF FINDINGS}

Figure 72 is constructed using Figure.10. It demonstrates the expected trend of dry-docking time against deadweight irrespective of age and type.

Figure 73 is constructed using Figure.15. It demonstrates the expected trend of dry-docking time against age irrespective of deadweight and type.

Figures 74A and 74B are constructed using Figures.34, 36, 42 and Figures.40, 44 respectively. These demonstrate the expected trend of dry-docking time against age for crude oil tankers, chemical tankers L.P.G. carriers and container carriers, car carriers respectively irrespective of deadweight.

Figure 75 is constructed using Figure.52. It demonstrates the expected trend of dry-docking labour against age irrespective of deadweight and type. 


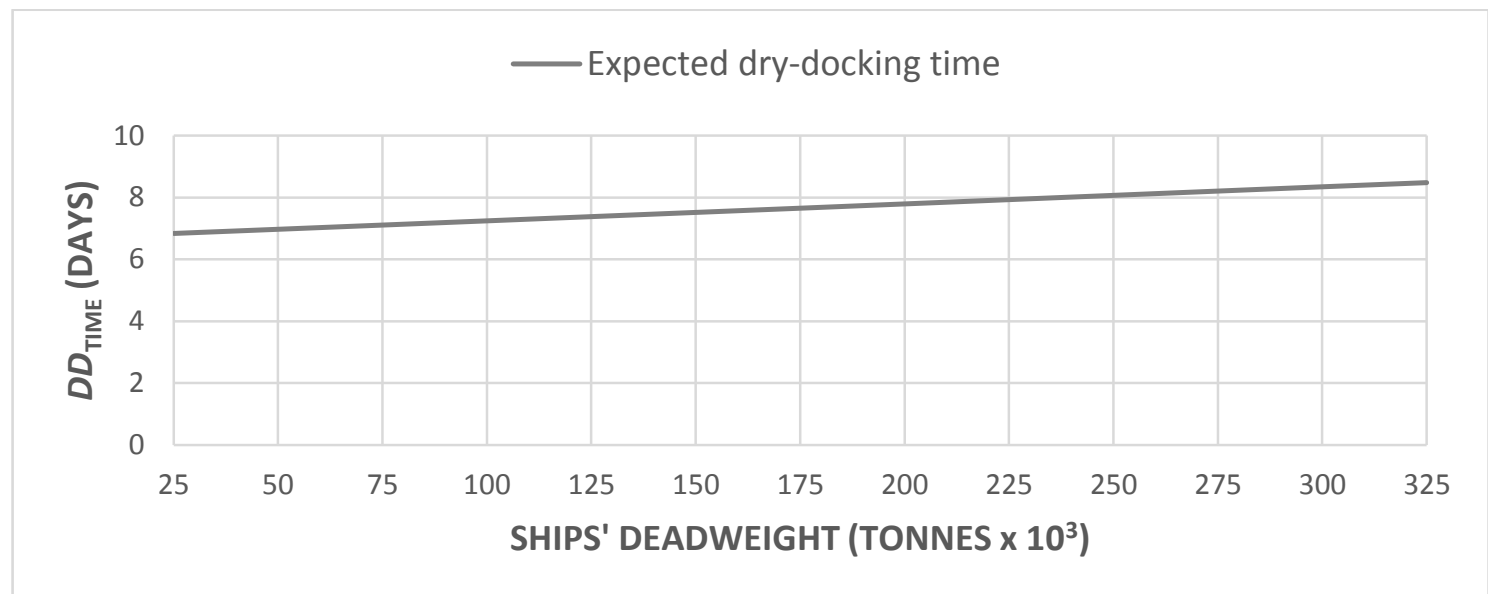

Figure. 72 Expected dry-docking time versus deadweight

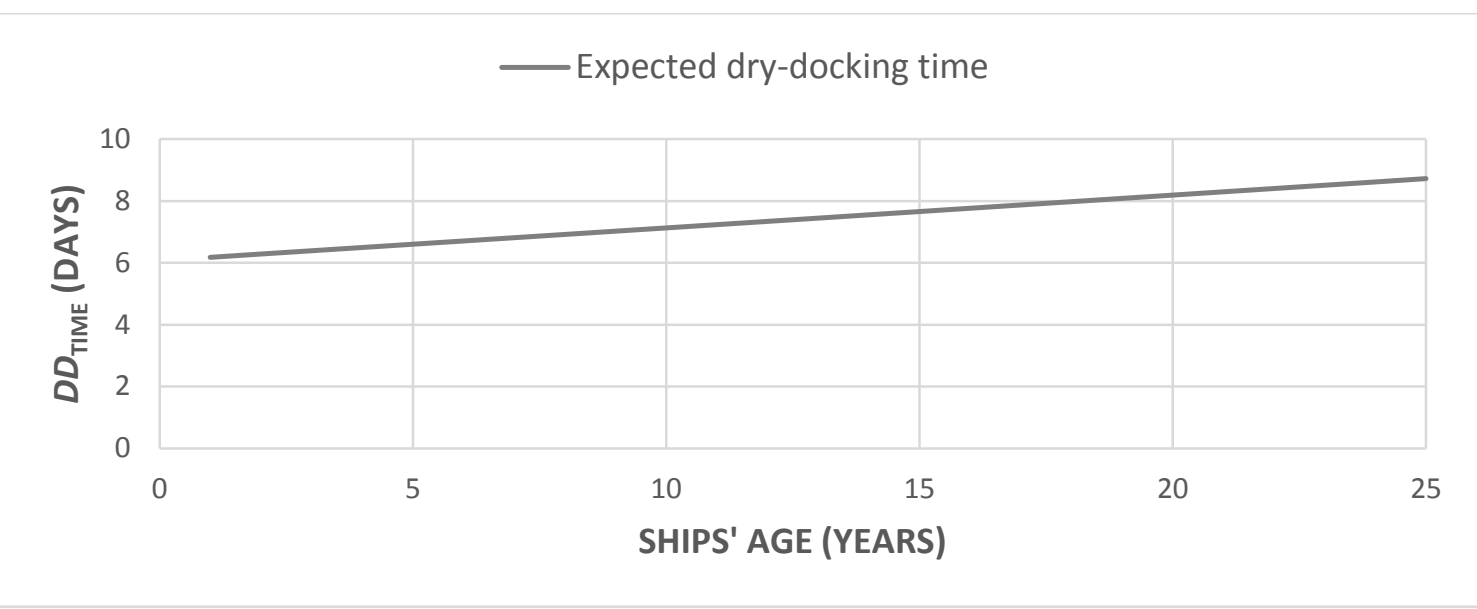

Figure. 73 Expected dry-docking time versus age

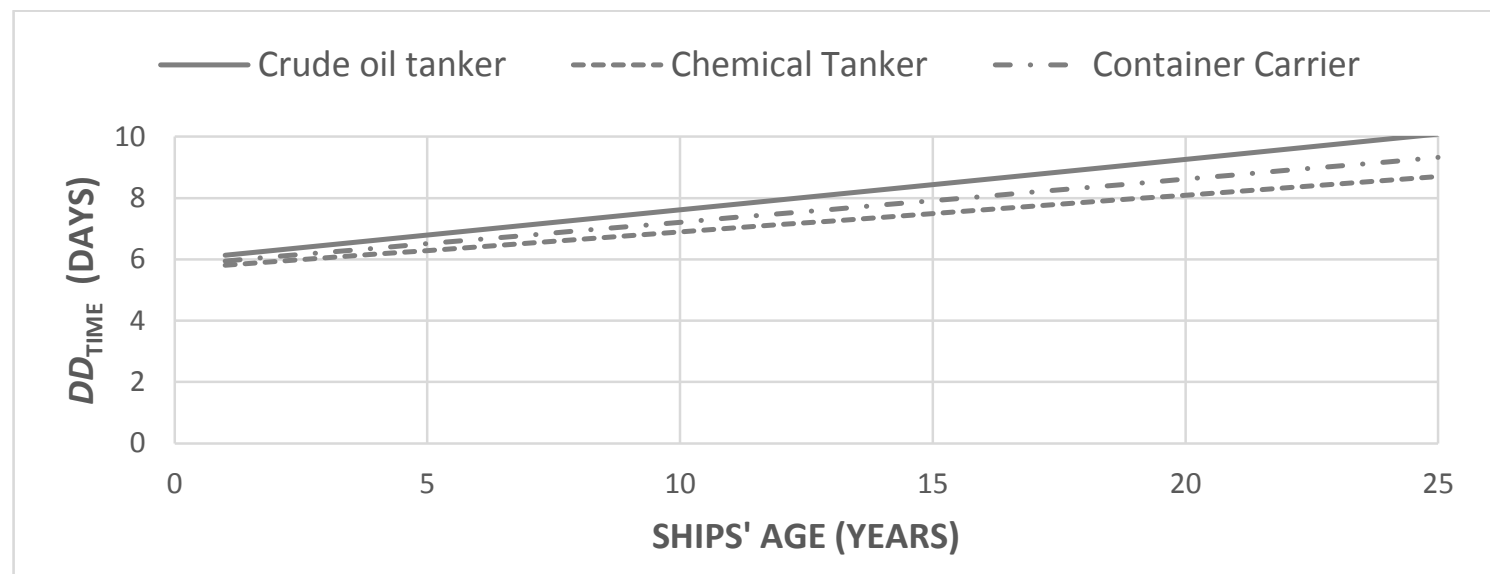

Figure. 74A Expected dry-docking time versus age for types (crude oil tankers, chemical tankers and L.P.G. carriers) 


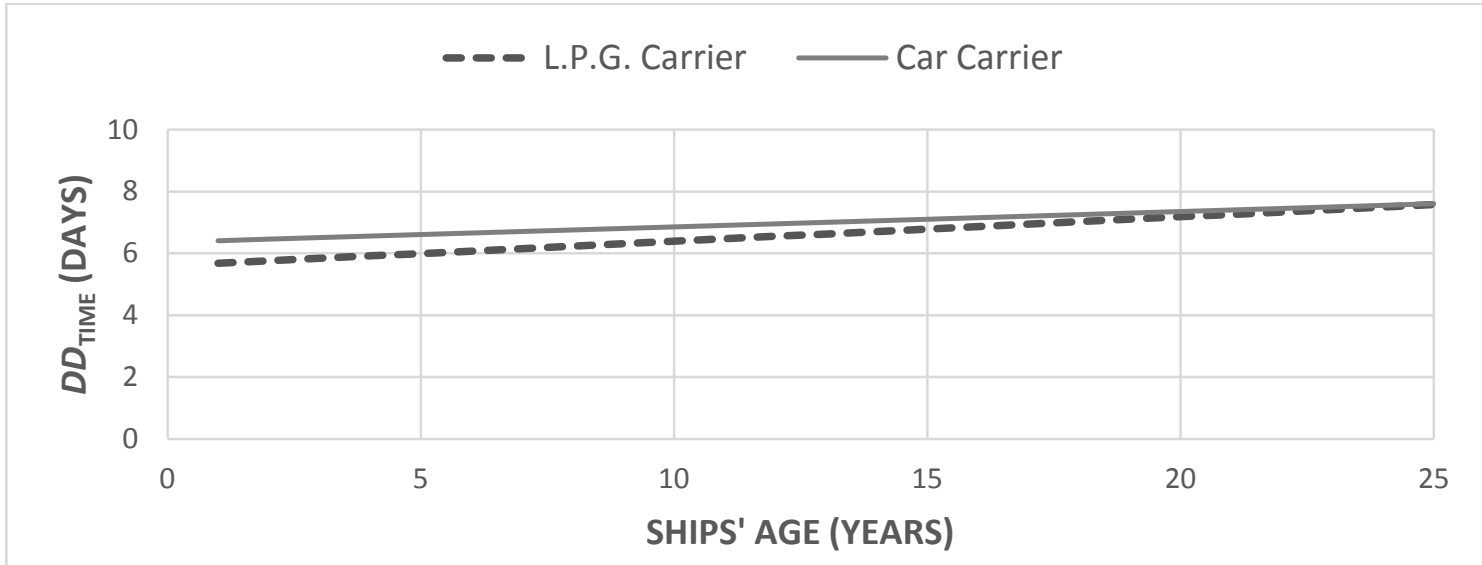

Figure. 74B Expected dry-docking time versus age for types (L.P.G. carriers and car carriers)

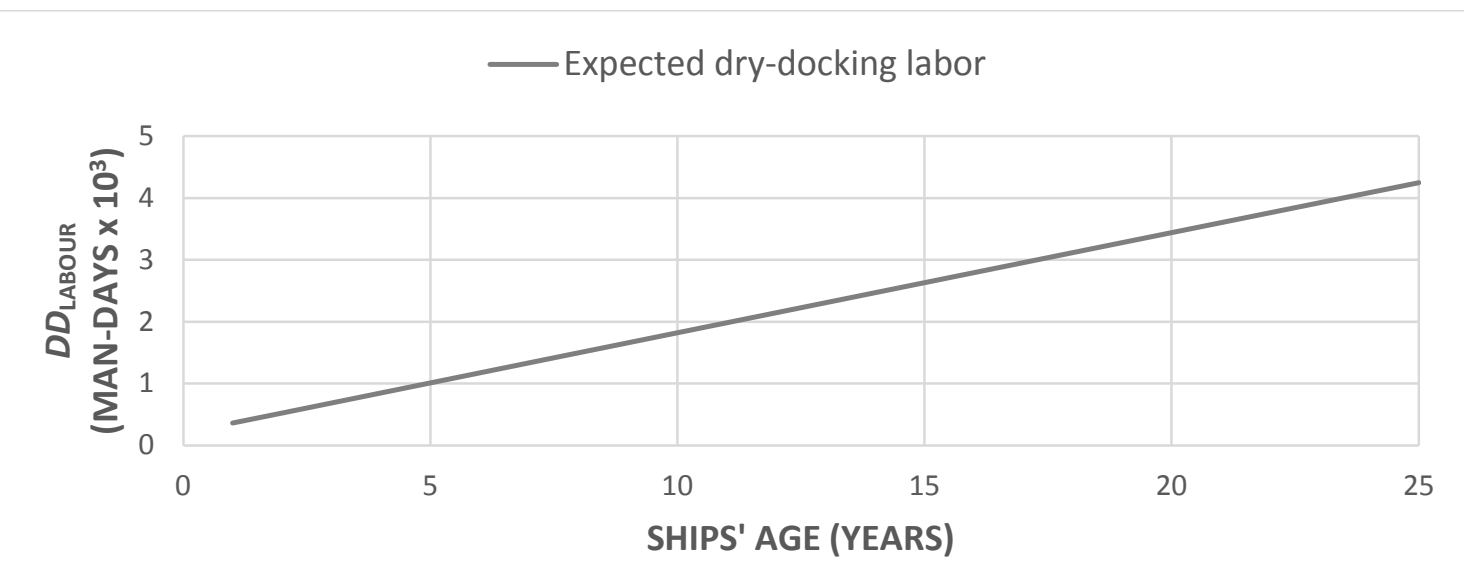

Figure.75 Expected dry-docking labour versus age

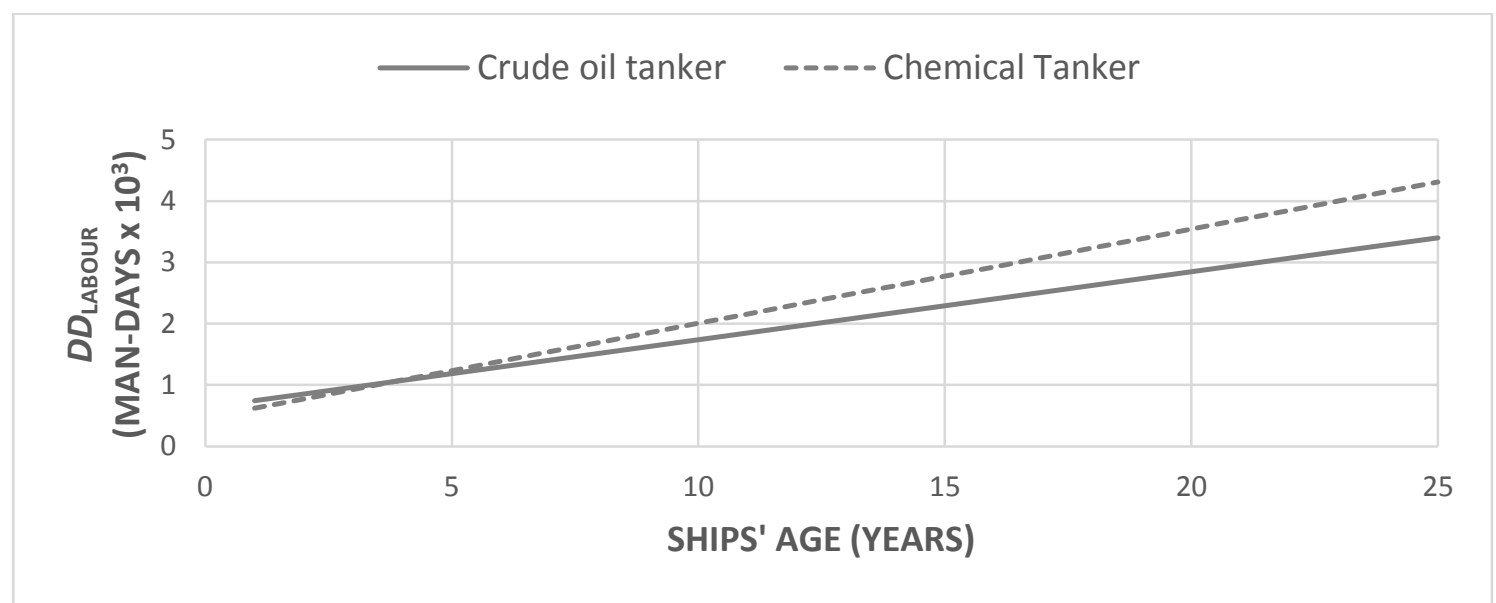

Figure. 76A Expected dry-docking labour versus age for types (crude oil tankers and chemical tankers) 


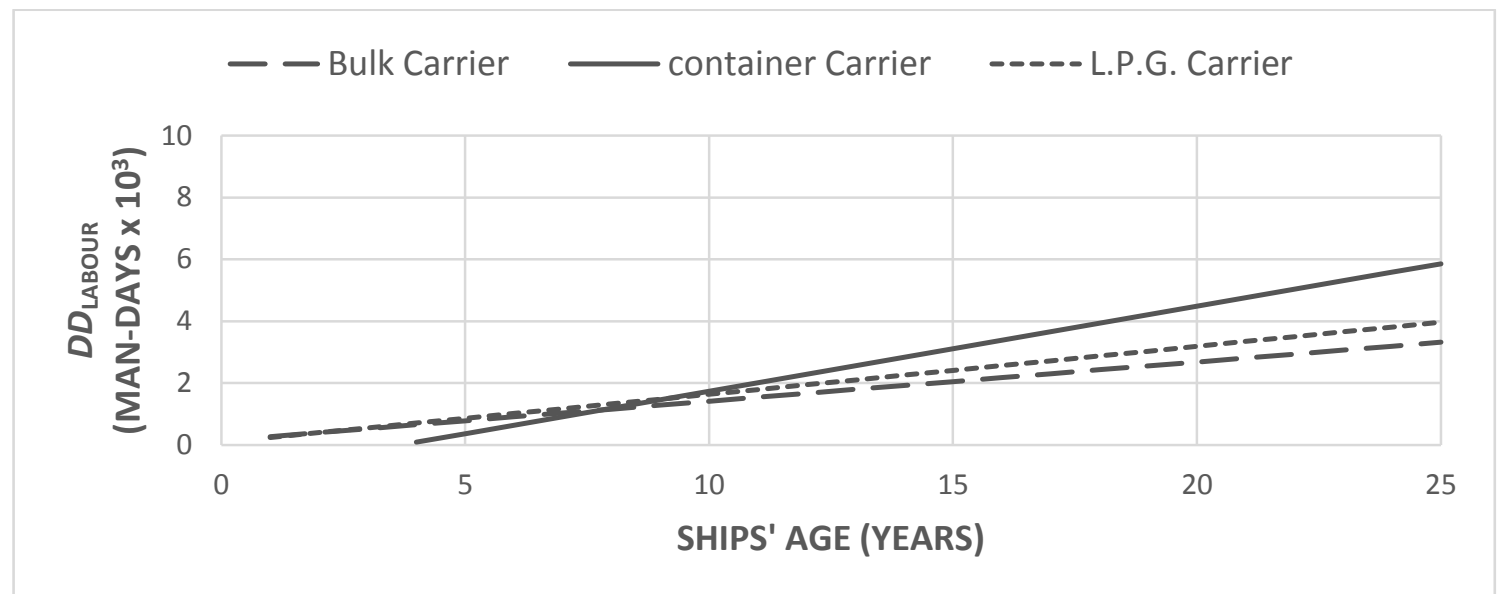

Figure. 76B Expected dry-docking labour versus age for types (bulk carriers, container carriers and L.P.G. carriers)

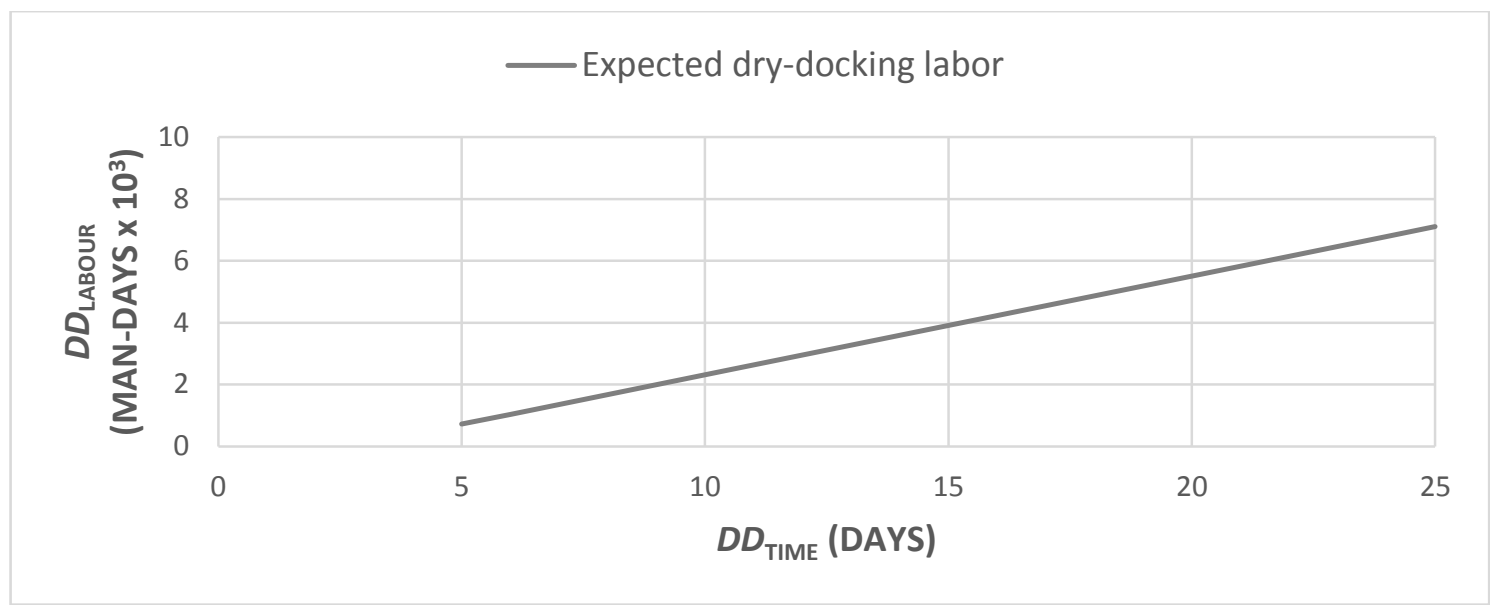

Figure. 77 Expected dry-docking labour versus dry-docking time

Figures 76A and 76B are constructed using Figures.64, 65 and Figures.66, 67, 68 respectively. These demonstrate the expected trend of dry-docking labour against age for crude oil tankers, chemical tankers and bulk carriers, container carriers, L.P.G. carriers respectively irrespective of deadweight.

Figure 77 is constructed using Figure.58. It demonstrates the expected trend of dry-docking labour against drydocking time irrespective of deadweight, age and type.

Based on various findings of this research works, the following procedures are proposed to estimate drydocking time and labour for budget and schedule preparation. Due to weak relationships of dry-docking time and labour against deadweight of various types, estimation of dry-docking time and labour for various types using deadweight may result in an error, and as such, it is avoided.

\section{Dry-docking time (Days)}

Option - I

Use deadweight and estimate the expected dry-docking time irrespective of age and type (Figure.72).
Option - II

Use age and estimate the expected dry-docking time irrespective of deadweight and type (Figure.73).

Option - III

Use age and type and estimate the expected dry-docking time for corresponding type, irrespective of deadweight (Figures.74A, 74B).

\section{Dry-docking labour (Man-days)}

Option - I

Use age and estimate the expected dry-docking labour irrespective of deadweight and type (Figure.75).

\section{Option - II}

Use age and type and estimate the expected dry-docking labour irrespective of deadweight (Figure.76A, 76B).

Option - III

Use dry-docking time (days) and estimate the expected dry-docking labour irrespective of age, deadweight and type (Figure.77). 
However, with all the above findings and limitations of the research concerning sample size, it is logical and unbiased to conclude that all these independent variables have a collective and significant impact on the drydocking time and labour and those are apparently linearly associated.

\section{CONCLUSIONS}

This article attempts to demonstrate the trends of drydocking time and labour concerning ships' deadweight, age and type of ships. The analyses suggest that drydocking time and labour are functions of deadweight, age and type of a ship but at different degrees of responses. It also reveals some fundamental basis for the estimation of average dry-docking time and labour for various deadweight, age and type. All independent variables are mostly linearly associated with the dependent variable. Hence, it can be concluded that deadweight, age and type have an impact on the dry-docking time and labour and these are mostly linearly associated, although their range is very close. No attempt was made to formulate and develop any mathematical model that adequately fits the behavior of the dependent variables, the dry-docking time and labour, concerning independent variables, deadweight, age and type of ship. It could be the future scope of a research work.

Table 12 may be useful for owner and yard for estimating dry-docking time and labour prior to docking and prepare the necessary schedule and budget.

It is interesting to note that for a ship, irrespective of size, age and type, dry-docking labour (as \% of ship repairing labour) is always higher than dry-docking time (as \% of ship repairing time). It translates the fact that during drydocking period labour consumption rate (man-days) is higher than other time, which is in agreement of the reallife situation. In practice too, there is always an attempt to reduce dry-docking time. Therefore, one may choose to estimate dry-docking time and labour using Table 12 based on the type of the subject ship.

Despite the limitations of sample size, the various findings of this research can be useful to owners and yards. Using these as guidelines, owners and yards may be able to estimate the expected dry-docking time and labour of a ship to be handled and also a proper drydocking schedule and budget.

This article should be considered as a first step to knowing the relationship that exists between the possible variables in dry-docking time and labour. These works can further be fine-tuned with larger sample size. A multiple linear regression model may then be considered to develop a mathematical model (Dev, A.K and Saha, $2015,2016)$ that will be able to predict the expected drydocking time and labour concerning size, age, type and other potential variables if any.

\section{REFERENCES}

1. DEV, A.K. and SAHA, M. 2015 Modeling and Analysis of Ship Repairing Time, Journal of Ship Production and Design, Vol.31, No.2, May 2015, pp. 129-136.

2. DEV, A.K., and SAHA, M. 2016 Modeling and Analysis of Ship Repairing Labour, Journal of Ship Production and Design, Vol 32, No.4, November 2016, pp. 258-271.

3. JOSE, R.S.C. 2009 A goal programming model for vessel drydocking, Journal of Ship Production, Vol 25, No.2, May 2009, pp. 95-98.

4. NAFFISAH, M. S., SURJANDARI, I., RACHMAN, A. and PALUPI, R. 2014 Estimation of Dry Docking Maintenance Duration using Artificial Neural Network, International Journal of Computing, Communications \& Instrumentation Engineering (IJCCIE), Vol.1, Issue.1, pp. 113115.

5. SURJANDARI, I. and NOVITA, R. 2013 Estimation Model of Dry Docking Duration Using Data Mining, World Academy of Science, Engineering and Technology, Vol.7, No.7, pp 1718-1721. 